\title{
AN ASSESSMENT OF THE LIGHT AND NUTRIENT REGIMES CONSTRAINING PHYTOPLANKTON DYNAMICS IN MISSOURI RESERVOIRS
}

\author{
A thesis \\ presented to the University of Missouri \\ in partial fulfillment \\ of the requirements for the degree of \\ Master of Science \\ Prepared By: \\ Erin Louise Petty \\ Thesis Advisor: \\ Dr. Rebecca L. North ${ }^{1}$ \\ Committee Members: \\ Dr. Alba Argerich ${ }^{1}$ \\ Dr. Michael Urban ${ }^{2}$ \\ ${ }^{1}$ School of Natural Resources, University of Missouri \\ ${ }^{2}$ Department of Geography, University of Missouri
}

July 2021

Natural Resources · Water Resources Emphasis Area

School of Natural Resources, University of Missouri · Columbia, Missouri, USA 
The undersigned, appointed by the dean of the Graduate School, have examined the thesis entitled

\section{AN ASSESSMENT OF THE LIGHT AND NUTRIENT REGIMES CONSTRAINING PHYTOPLANKTON DYNAMICS IN MISSOURI RESERVOIRS}

presented by Erin L. Petty,

a candidate for the degree of Master of Science in Natural Resources, and hereby certify that, in their opinion, it is worthy of acceptance.

Dr. Rebecca North, School of Natural Resources

Dr. Alba Argerich, School of Natural Resources

Dr. Michael Urban, Department of Geography 


\section{This work is dedicated to}

\section{Mom and Dad}

for instilling in me a love of nature, a thirst for knowledge, and a hope for a better tomorrow.

Without your endless love and support, I would not be the person I am today.

Thank you for always believing in me. 


\section{Acknowledgements}

This thesis is the culmination of my water resources graduate work at the University of Missouri (MU), which included two field seasons, two international conferences, eight regional, state, or local conferences, and one published manuscript. I would like to first acknowledge my thesis advisor, co-author, and mentor, Dr. Rebecca North, who facilitated these efforts, and without whom, none of this work would have been possible. I thank her for her guidance and expertise, as well as her scientific drive, enthusiastic nature, and critical eye. Under Dr. North's leadership, I acquired knowledge and skills needed for both academic and professional success. The experience I gained by working with her and the MU Limnology Lab ultimately contributed to the start of my professional career with the Missouri Department of Natural Resources. For that, I will always be grateful to her and this program.

I would also like to thank my undergraduate advisor and mentor, Dr. Keith Goyne, for encouraging me to pursue a master's degree and for nudging me in the direction of MU's Water Resources Program; and professor emeritus, Dr. Jack Jones, for introducing me to water quality as an undergraduate student and for inspiring me through his captivating lectures and talents as a scientist and as a storyteller. I would like to thank Dr. Michael Urban for serving as a committee member, and for extending to me his kindness, thoughtful advice, and unwavering support. I would also like to thank Dr. Alba Argerich for serving as a committee member and mentor, and for always being supportive, thoughtful, and genuinely interested in my work. I am also incredibly thankful to Dr. Argerich for inviting me to participate in a collaborative workshop between MU and the China Agricultural University held in Beijing, China. The once in a lifetime trip, which was my first abroad, was truly unforgettable. 
I would like to thank the numerous MU Limnology Laboratory employees, past and present, who have contributed their time and efforts to sample collection, preparation, and analysis. Specifically, thank you to Thomas Swenson, my undergraduate research assistant; Carol Pollard, Clare Vanderwerken, and Jaylen Bragg, laboratory technicians; Cody Kimbell and Matthew Sauer, 2017 field rovers; Madalyn Stoeker and Emily Phaup, 2018 field rovers; and Kyra Florea, undergraduate researcher. Additional special thanks to Carol Pollard for her delightful demeanor, her friendship, and for truly being a pleasure to work with in the lab. Thank you to my mentor, co-author, and allaround handyman, Dan Obrecht, for coordinating field and lab efforts; for always being constructive, approachable, and willing to troubleshoot problems with me; and for delivering an abundance of laughs and solid advice throughout my graduate career. Thank you to the always entertaining, Tony Thorpe, for keeping me on my toes with his quintessential wit, humor, and creativity; and for teaching me all the important stuff and things. I would also like to acknowledge my fellow Water Resources graduate students, Jacob Cianci-Gaskill, Emily Kinzinger, Garrett Frandson, and Jessi Wilson, whose friendship, support, and camaraderie have been very much appreciated over the years; my dearest friends at the Missouri Department of Conservation and the Missouri Department of Natural Resources for their positivity and continual encouragement; and my devoted parents, Jim and Eva Petty, for a lifetime of endless love and support.

I would like to extend my thanks to Dr. Greg Silsbe for his insight regarding the 'phytotools' R-package; Dr. Christine Spinka for providing statistical consultation; Drs. Chung-ho Lin and Jacob Westhoff for generously sharing environmental chamber space for my experiments; and Dr. Patrick Neale for providing expert testimonial for 
development of ideas for Chapter 2. I would also like to acknowledge Dr. Joy Matthews and the University of California, Davis' Stable Isotope Facility for their professional and timely analytical services; and Matthew Marciniak and the MU College of Engineering Machine Shop for their technical services in creating a customized filter packing tool. This research was funded in part by grants from the Environmental Protection Agency and the Missouri Department of Natural Resources in support of the Missouri Statewide Lake Assessment Program. A portion of analytical costs were covered by a Grant-in-Aid-of-Research awarded by Sigma-Xi, the Scientific Research Honor Society. Over the course of my program, I received financial support for personal expenses and conference travel through various scholarships, including the Carl Marrow Scholarship in Soil and Water Conservation awarded by the Missouri Conservation Federation, the Douglas D. Randall Young Scientists Development Fund, the MU School of Natural Resources Graduate Travel Scholarship, the Global Lake Ecological Observatory Network All Hands' Meeting Travel Award provided by the Cary Institute of Ecosystem Studies, and the Conference Presentation Travel Award granted by the MU Graduate Professional Council. This research and my professional development have also greatly benefitted from the start-up funds provided to Dr. North from the University of Missouri. 


\section{Table of Contents}

Acknowledgements ......................................................................................................................... ii

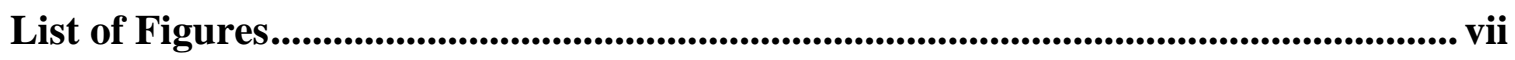

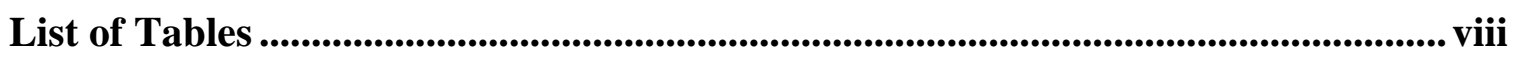

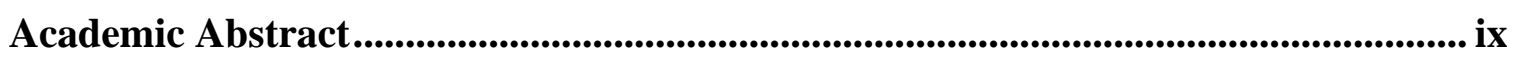

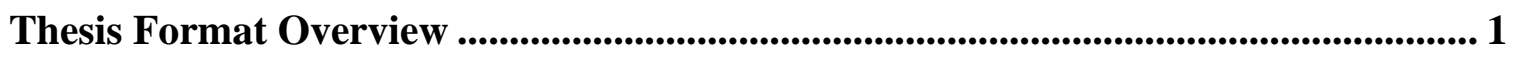

Chapter 1: General Introduction and Background ............................................................ 2

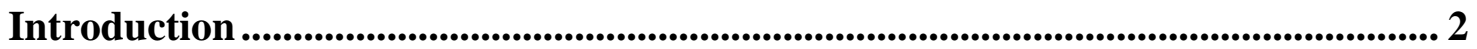

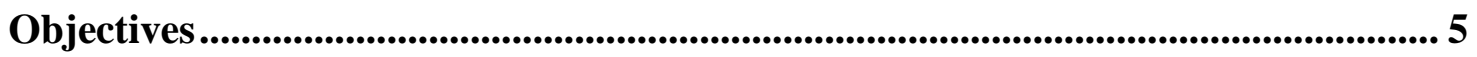

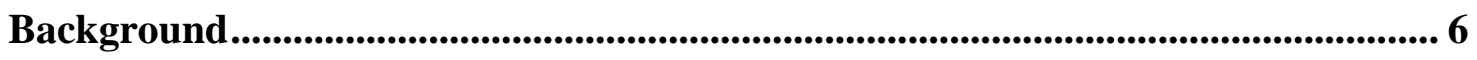

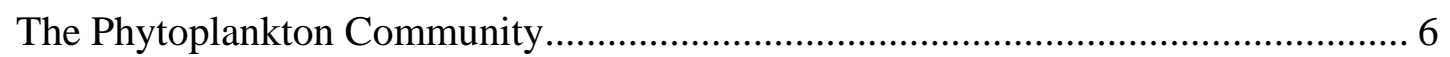

Eutrophication and Cyanobacterial Harmful Algal Blooms...................................... 9

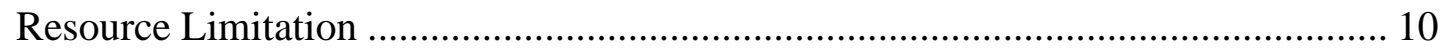

Top-Down Predation: Grazing and the Zebra Mussel Effect ................................. 23

The Study Area: Missouri Regions and Reservoirs.......................................... 25

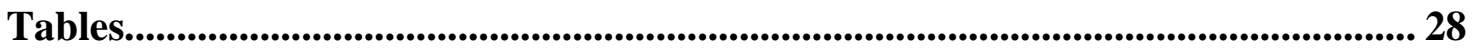

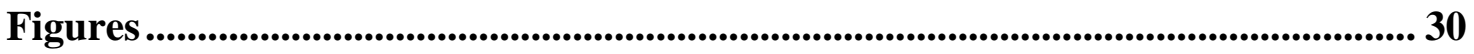

Chapter 2: The Proximate Light and Nutrient Status of Phytoplankton

Communities in Missouri Reservoirs ........................................................................ 32

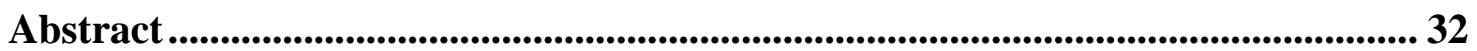

Introduction .......................................................................................................... 33

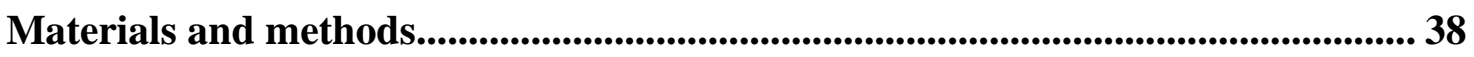

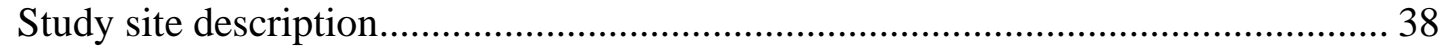

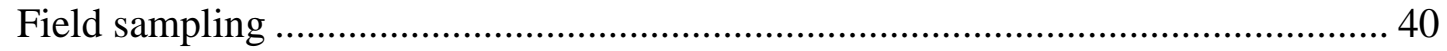

Laboratory analyses and data processing ..................................................... 40

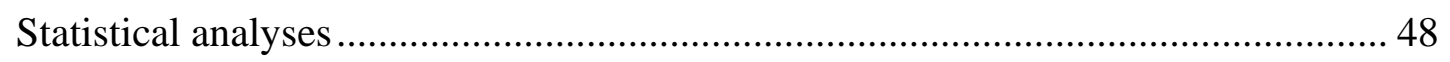

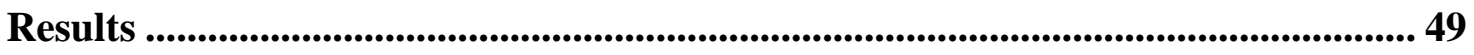

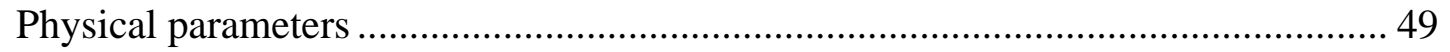

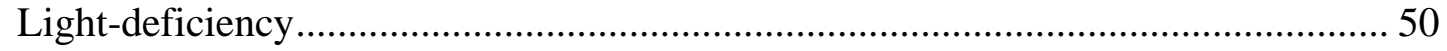

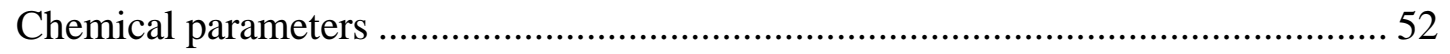

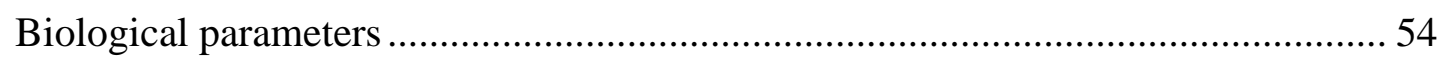

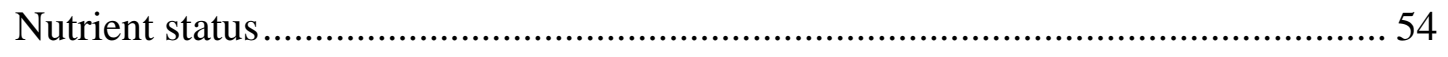

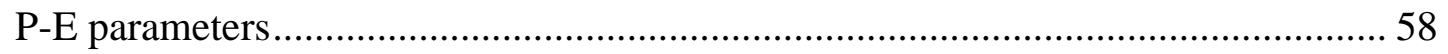




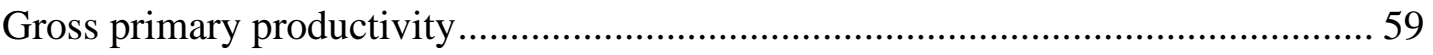

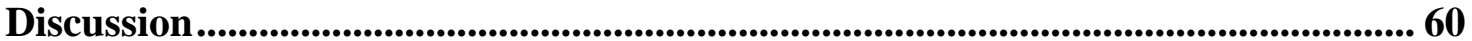

The physical light environment as a constraint on phytoplankton biomass .............. 60

Nutrient constraint on phytoplankton biomass in an agricultural state .................... 63

How photosynthetic response informs light and nutrient status ............................. 66

The disconnect between phytoplankton biomass and primary productivity ............. 68

Light and nutrients constraining phytoplankton dynamics in a changing world....... 72

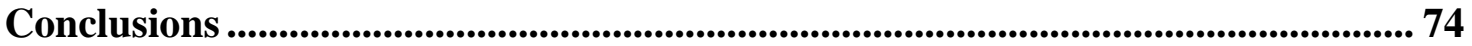

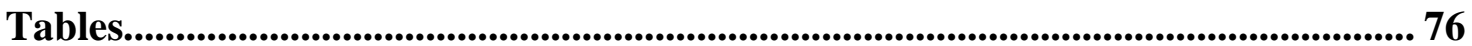

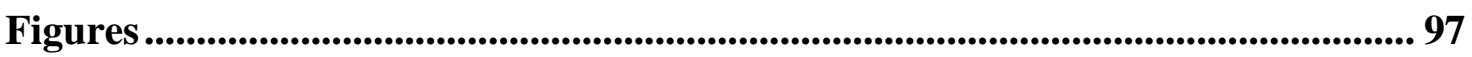

Chapter 3: Overall Conclusions and Projected Outcomes .................................... 103

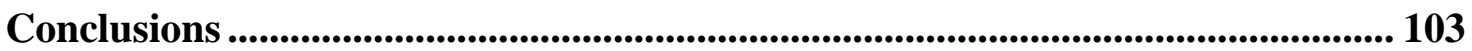

Chapter 2 summary and significance ............................................................................. 104

Projected outcomes (meaningful application of research) ...................................... 106

Future considerations for further research ................................................................. 109

Lessons learned ........................................................................................................... 111

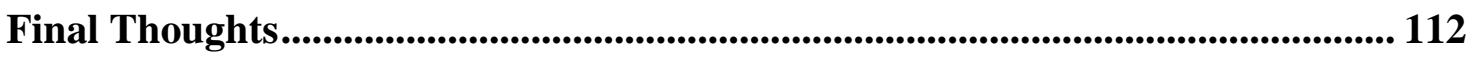

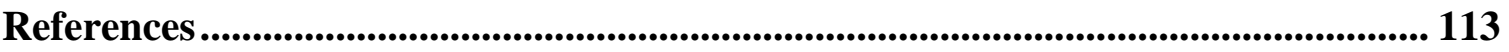




\section{List of Figures}

Figure

Figure 1.1. (From Brauer et al., 2012) Competition for light, nitrogen, and phosphorus between algae and cyanobacteria, as predicted by resource competition theory under various nutrient loading scenarios..

Figure 1.2. Photographs of a blooming phytoplankton community as seen with the naked eye and as seen under a compound microscope.

Figure 1.3. (From Kalff, 2002) The photosynthetic-irradiance (P-E) curve, which describes a rectangular hyperbola that plots intensity of light against rate of primary production per unit of biomass (chlorophyll-a). ..... 31

Figure 1.4. Conceptual diagram illustrating how thermal stratification and mixing influence light availability for the phytoplankton

Figure 2.1. Map of the 32 study reservoirs located across Missouri, USA.

Figure 2.2. Mean daily mixed layer irradiance $\left(\overline{\mathrm{E}}_{24}\right)$ across the trophic gradient during the 2017 and 2018 sampling seasons.

Figure 2.3. Chlorophyll-a, light utilization efficiency $\left(\alpha^{\mathrm{B}}\right)$ per unit of chlorophyll-a, and gross primary production $\left(\mathrm{GPP}^{\mathrm{B}}\right)$ rates normalized to chlorophyll-a across the trophic gradient in 2018

Figure 2.4. Patterns of phosphorus $(\mathrm{P})$ status across the trophic gradient, and, if applicable, the two-year sample period, based on P-deficiency indicators: particulate nitrogen to particulate phosphorus (PN:PP) ratios, particulate organic carbon to particulate phosphorus (POC:PP) ratios, phosphorus debts $\left(\mathrm{P}\right.$ debt), and percent change in $\phi_{\mathrm{PSII}}$ relative to the control treatment following P-additions.

Figure 2.5. Patterns of nitrogen $(\mathrm{N})$ status across the trophic gradient, and, if applicable, the two-year sample period, based on N-deficiency indicators: particulate organic carbon to particulate nitrogen (POC:PN) ratios, ammonium debts $\left(\mathrm{NH}_{4}{ }^{+}-\mathrm{N}\right.$ debt), percent change in $\phi_{P S I I}$ relative to the control treatment after $\mathrm{NH}_{4}{ }^{+}$-additions, nitrate debts $\left(\mathrm{NO}_{3}{ }^{-}-\mathrm{N}\right.$ debt $)$, and percent change in $\varphi$ PSII relative to the control treatment after $\mathrm{NO}_{3}{ }^{-}$-additions

Figure 2.6. Summary of nutrient-deficiency across the trophic gradient in 2018 according to the phosphorus (P) and ammonium-nitrogen $\left(\mathrm{NH}_{4}{ }^{+}-\mathrm{N}\right)$ debt experiments. 


\section{List of Tables}

$\underline{\text { Table }}$

$\underline{\text { Page }}$

Table 1.1. Trophic status as determined by the seasonal and two-year combined averages of Secchi depth (Secchi), total chlorophyll (TChl), total phosphorus (TP), and total nitrogen (TN), and the Jones et al., 2008 trophic status classification thresholds

Table 1.2. Summary of trophic status, geographic location, designated use, morphology and watershed land-use for the 32 study reservoirs.

Table 2.1. List of parameter definitions, abbreviations, and units. 76

Table 2.2. Summary of morphology and watershed land-use (generalized by trophic status) for the 32 study reservoirs.

Table 2.3. Summary of limnological parameters and epilimnetic nutrient chemistry (generalized by trophic status) for the 32 study reservoirs.

Table 2.4. The light and nutrient status indicator thresholds applied to assess deficiency among the reservoir phytoplankton communities....

Table 2.5. Linear mixed effect (LME) model, ANOVA, and Tukey post-hoc results, which tested for the effects of year, sampling event, trophic status, and watershed land-use, grouped by physical, chemical, biological, nutrient status, and photosynthesis-irradiance $(\mathrm{P}-\mathrm{E})$ parameters.

Table 2.6. Kruskal Wallis ANOVA and Dunn's post-hoc results for the 2018 nutrient debts ( $\mathrm{P}$ debt, $\mathrm{NH}_{4}{ }^{+}-\mathrm{N}$ debt, $\mathrm{NO}_{3}{ }^{-}-\mathrm{N}$ debt), which tested for the effects of sampling event, trophic status, and watershed land-use.

Table 2.7. One-way ANOVA and Dunnett post-hoc results, which compared maximum quantum yields ( $\phi$ PSII) of the phytoplankton in response to nutrient additions $\left(+\mathrm{P},+\mathrm{NH}_{4}{ }^{+},+\mathrm{NO}_{3}{ }^{-},+\mathrm{P}+\mathrm{NH}_{4}{ }^{+}\right)$as a part of the photosynthetic efficiency experiments.

Table 2.8. Pearson correlation results for physical, chemical, biological, and physiological light (P-E) parameters that tested significant against daily gross primary productivity rates normalized to chlorophyll-a $\left(\mathrm{GPP}^{\mathrm{B}}\right)$.

Table 2.9. Epilimnetic and hypolimnetic dissolved nutrient chemistry (generalized by trophic status) from the 27 reservoirs sampled in 2018 .

Table 2.10. Percentages of nutrient deficient samples during the 2018 season based on individual nutrient status indicators. 92

Table 2.11. Nutrient status indicator agreement for the 2018 sampling season. 93

Table 2.12. A brief literature survey of gross primary productivity (GPP) rates from relevant lake and reservoir studies.. 


\title{
An assessment of the light and nutrient regimes constraining phytoplankton dynamics in Missouri reservoirs
}

\author{
Erin L. Petty
}

Dr. Rebecca North, Thesis Advisor

\begin{abstract}
Academic Abstract
Worldwide, nutrient pollution, or eutrophication, is one of the most pervasive environmental issues threatening water quality. Anthropogenic influences, primarily urbanization and agriculture, have drastically increased inputs of bioavailable nutrients to surface water resources, such as lakes and reservoirs. Excessive phosphorus (P) and nitrogen $(\mathrm{N})$ in these waters amplify the growth of suspended algae, or phytoplankton, resulting in unsightly, sometimes odorous, cyanobacterial harmful algal blooms (CyanoHABs) that further degrade water quality and potentially endanger human and animal health. As global climate change increases surface water temperatures, promotes water column stability, and drives down bottom-water oxygen concentrations, environmental conditions are also becoming more favorable for CyanoHABs. With eutrophication prevailing and CyanoHABs increasing in frequency, intensity, and distribution around the globe, I seek to further understand the role of light and nutrients as limiting agents for phytoplankton biomass and primary productivity across Midwestern reservoirs. I utilize numerous lines of evidence to create a robust assessment exploring the influences of climate, eutrophication, and land-use on the proximate light and nutrient status of phytoplankton in 32 Missouri reservoirs. Through observation and experimentation, deficiencies of light, $\mathrm{P}$, and $\mathrm{N}$ are evaluated using general indicators of water quality and physiological stress, including mixed layer irradiance, nutrient stoichiometry/debts, photosynthetic efficiency, and the photosynthetic-irradiance (P-E)
\end{abstract}


parameters. Ultimately, I determine if phytoplankton biomass and productivity are constrained by light, $\mathrm{P}, \mathrm{N}$, or a combination thereof, across gradients of trophic status and land-use within the context of two contrasting wet and dry summers. As expected, higher proportions of agricultural land-use correspond with higher total in-reservoir nutrient concentrations. Despite agricultural prevalence, however, bioavailable N concentrations in the mixed layer are, overall, relatively low. Yet, P-deficiency is more prominent than either N- or light-deficiency. For the 2018 season, I estimate nearly half of all samples to be P-deficient, with fewer than $20 \%$ suggesting alternative deficiency or co-deficiency combinations, and approximately one-third indicating sufficiency in both light and nutrients. Primary productivity demonstrates negative relationships with nutrients, biomass, and turbidity, and positive relationships with light. Thus, productivity is highest in clear, low-nutrient reservoirs where light utilization efficiency is also highest. Overall, in Missouri reservoirs, phytoplankton biomass and primary productivity are constrained by $\mathrm{P}$ and light, respectively. If current conditions in Missouri reservoirs are at all indicative of those to come as surface waters are further affected by climate change and eutrophication, both $\mathrm{P}$ and light will be important regulators of phytoplankton dynamics and subsequent water quality. Contributing to the ongoing P vs NP nutrient management debate, these results both support and challenge aspects of the traditional P-paradigm of limitation on phytoplankton dynamics. It underscores the importance of P control in reservoirs, while offering support for additional consideration of light and N. Having critical implications for watershed management throughout the region, these results are particularly useful within watersheds experiencing high agricultural nutrient loading. Results inform resource managers seeking to employ more effective strategies to control 
phytoplankton biomass, avoiding harmful regime shifts and CyanoHAB development. Additionally, results may inform lawmakers and regulators developing policies and standards to mitigate nutrient pollution and its effects on water quality at the local, regional, and, potentially, global scales. 


\section{Thesis Format Overview}

The research presented in this thesis follows a three-chapter format:

- Chapter 1 provides a general introduction to the overarching themes and research objectives while also providing relevant background information on topics to be covered in greater detail in the following data-chapter.

- Chapter 2 is an ambitious and comprehensive data-chapter which reveals how algal communities in Missouri reservoirs are proximately influenced by in situ levels of light and the macronutrients, phosphorus and nitrogen. This data-chapter was originally written as an independent manuscript for publication in a peer-reviewed scientific journal. In July 2020, an adaptation of Chapter 2 was published in Frontiers in Environmental Science as a part of a special issue in Freshwater Science. ${ }^{1}$ As a result, content may be repeated between Chapter 2 and the published manuscript.

- Chapter 3 serves as a final synthesis of meaningful findings, conclusions, and applications of the research as they relate to the overarching thesis themes.

This thesis also utilizes a comprehensive reference list that combines citations for all three chapters, listing them together at the end of the thesis document rather than at the end of each individual chapter.

\footnotetext{
${ }^{1}$ Manuscript citation: Petty, E. L., Obrecht, D. V., and North, R. L. (2020). Filling in the Flyover Zone: high phosphorus in Midwestern (USA) reservoirs results in high phytoplankton biomass but not high primary productivity. Frontiers in Environmental Science. 8, 1-24. doi:10.3389/fenvs.2020.00111
} 


\section{Chapter 1: \\ General Introduction and Background}

\section{Introduction}

Increased nutrients inputted to aquatic ecosystems is one of the most widespread pollution problems threatening the quality of global surface waters, including lakes and reservoirs (Paerl et al., 2016). Although nutrient enrichment, or eutrophication, can occur naturally (Kalff, 2002), widespread anthropogenic influences on the landscape- primarily urbanization and agriculture- have dramatically altered nutrient loading, accelerating the development of overly enriched surface waters. Excessive inputs of the macronutrients, phosphorus $(\mathrm{P})$ and nitrogen $(\mathrm{N})$, amplify the growth of suspended algae, or phytoplankton, resulting in problematic algal blooms (Anderson et al., 2002), particularly in water bodies valued for their consumptive, recreational, irrigational, and industrial purposes (Kalff, 2002).

With global water temperatures rising as a result of climate change and a surplus of nutrients being supplied from the landscape, anthropogenically induced cyanobacterial harmful algal blooms (CyanoHABs) are increasing in frequency, intensity, and distribution around the globe (Morales-Williams et al., 2017; Su et al., 2017). These undesirable blooms can form unsightly, dense, mucilaginous scums on surface waters while also degrading the quality of the waters below. Phytoplankton growth and decomposition increase water column turbidity and deplete the subsurface of oxygen which, among other things, can cause fish and shellfish mortality. Green blooming surface waters have the potential to produce a variety of hazardous toxins and frequently exhibit taste and odor issues. As climate change promotes environmental conditions favoring CyanoHABs, blooming water bodies are also expected to pose increasingly 
greater health risks to humans, pets, livestock, and wildlife (Downing et al., 2001; Paerl et al., 2001; Anderson et al., 2002).

Phytoplankton productivity and community structure are often shaped by the influences of processes from the top-down (i.e., predation) and bottom-up (i.e., light and nutrients). According to the bottom-up control theory, phytoplankton abundance is largely driven by availability of resources (e.g., light and nutrient supply; Kalff, 2002). Although it has long been established that these photosynthetic organisms require light to carry out nutrient uptake and assimilation, the exact role of nutrients as limiting agents have been less straight-forward due to the complex and often variable nature of aquatic ecosystems (Anderson et al., 2002; Kalff, 2002; Conley et al., 2009; Schindler, 2012). Historically, P was thought to be the primary limiting nutrient in freshwater ecosystems, whereas $\mathrm{N}$ was thought to be limiting in ocean, estuarine, and coastal ecosystems (Wetzel, 2001). As a result, nutrient management in freshwater lakes and reservoirs has largely focused on controlling P inputs (Schindler et al., 2008). Numerous studies, however, have since suggested that $\mathrm{N}$ may also have an important role to play in these ecosystems (Elser et al., 1990; Maberly et al., 2002).

Within the last fifteen years, renewed advocacy for $\mathrm{N}$-control has resulted in consideration of combined N- and P- control to mitigate eutrophication in systems such as Lake Winnipeg and the Baltic Sea (Schindler et al., 2008). In 2017, the hypoxic "dead" zone in the Gulf of Mexico was the largest ever recorded at 22,720 $\mathrm{km}^{2}$-which is roughly the size of New Jersey (Faust et al., 2018). High nutrient loading from the Mississippi River Basin largely contributes to the net surface primary productivity that drives bottom water oxygen deficiency in what is currently the largest hypoxic zone in 
the western hemisphere (Mitsch et al., 2001). Although $\mathrm{N}$ is believed to be the primary nutrient responsible for the major effects of eutrophication in the Gulf, there is evidence that primary production may switch seasonally between $\mathrm{N}$ and $\mathrm{P}$ limitation (Rabalais et al., 2002; Howarth and Marino, 2006). In fact, as N levels in the Mississippi River have continued to rise, ratios of $\mathrm{N}$ to $\mathrm{P}$ and silica have increased to the point where both seasonal limitation or co-limitation are certainly possible (Mitsch et al., 2001; Rabalais et al., 2002). This suggests that $\mathrm{P}$, too, may play a larger role than previously thought (Alexander et al., 2008). As a result, some are advocating for a more holistic view regarding $\mathrm{P}-$ only/N-only vs $\mathrm{N}$ and $\mathrm{P}$ control for both coastal ecosystems, such as the Gulf of Mexico, and inland ecosystems, such as the Mississippi River and the streams and reservoirs within its drainage basin (Mitsch et al., 2001; Howarth and Marino, 2006; Alexander et al., 2008; Paerl et al., 2016).

Centrally located in the Mississippi River Basin, the Missouri landscape demonstrates a wide range in geology, which in turn influences land cover, nutrient loading, and subsequently, the characteristics of its reservoirs (Jones et al., 2008a). Previous research suggests that constraint by light, as well as both $\mathrm{P}$ and $\mathrm{N}$, are likely to occur in Missouri reservoirs (Jones and Knowlton, 1993), but little is known about the extent to which that might happen. In lakes and reservoirs, phytoplankton light and nutrient status can be measured by assessing the organisms' physiological responses to various controlled stimuli. These responses can be indicative of the resources controlling phytoplankton growth and productivity (Guildford et al., 2000), as well as the potential for CyanoHAB development. Since cyanobacteria are well-adapted to low light and limited $\mathrm{N}$ concentrations, they tend to dominate phytoplankton communities under such 
conditions (Figure 1.1; Brauer et al., 2012). Given that some Missouri reservoirs are also frequently dominated by cyanobacteria (Graham et al., 2004), the state offers an ideal platform for studying the light and nutrient regimes influencing phytoplankton communities under various natural and anthropogenically-shaped environmental conditions (Jones et al., 2008a).

\section{Objectives}

As anthropogenic eutrophication continues to be of concern throughout much of the world, I seek to assess the light and nutrient regimes that drive phytoplankton dynamics in the American Midwest, a region where inland surface waters are subject to a variety of land-use influences including intensive row-crop agriculture. The overarching purpose of this research is to assess how the interactions between light and nutrients influence phytoplankton biomass and primary productivity across multiple freshwater reservoir environments, particularly as they relate to regional nutrient loading and climate change. Within the context of two climatically contrasting summers (wet versus dry), I aim to draw connections between watershed land-use, light and nutrient availability, and water quality across a gradient of mid-latitude, temperate reservoirs. To appropriately represent the variability in environmental conditions and to account for spatial differences in lake trophic status and dominant watershed land-use, a total of 32 manmade Missouri reservoirs are featured in this work. I hypothesized that watershed landuse would influence reservoir trophic-status, nutrient bioavailability, and light attenuation. Therefore, it would also influence chlorophyll-a $(\operatorname{chl} a)$, a proxy for phytoplankton biomass, and primary productivity across the demonstrated gradient of reservoir environments. 


\section{Background}

\section{The Phytoplankton Community}

This thesis focuses on a community of aquatic plant-like organisms known as phytoplankton (Figure 1.2). Within the context of this research, I define phytoplankton as the collective group of photosynthetic, unicellular microorganisms living suspended in the open waters of lakes and reservoirs (Kalff, 2002; Reynolds, 2006). I describe the phytoplankton community generally as a diverse assemblage of taxonomic groups, which include several groups of algae and one major group of photosynthetic bacteria, cyanobacteria (Wetzel, 2001; Kalff, 2002). Although not true algae, photosynthetic cyanobacteria function similarly and are thereby discussed as members of the phytoplankton community (Kalff, 2002).

Consisting of photoautotrophic organisms, the phytoplankton community plays a fundamental role in many lake and reservoir ecosystems. As one of the central primary producers in the aquatic food web, phytoplankton are active participants in the global carbon cycle via photosynthetic carbon fixation and oxygen production (Reynolds, 2006). The light dependent process of photosynthesis is commonly simplified and described as:

$$
6 \mathrm{CO}_{2}+12 \mathrm{H}_{2} \mathrm{O} \stackrel{\text { light }}{\longrightarrow} \mathrm{C}_{6} \mathrm{H}_{12} \mathrm{O}_{6}+6 \mathrm{H}_{2} \mathrm{O}+6 \mathrm{O}_{2}
$$

where the carbon from carbon dioxide is fixed, or taken up by autotrophic cells, to form organic substances, such as simple carbohydrates, and oxygen as a by-product. The rate at which carbon energy is stored into organic forms for eventual nutrient uptake and assimilation is defined as primary production. Working in the opposite direction of photosynthesis is the process of respiration. The dynamic flux between photosynthesis and respiration defines ecosystem metabolism. Additional terms, gross (GPP) and net 
(NPP) primary productivity, specify rates of carbon fixation unadjusted and adjusted, respectively, to account for respiration $(\mathrm{R})$ where NPP $=$ GPP $-\mathrm{R}$ (Kalff, 2002).

The rate of carbon fixation, or oxygen production, via photosynthesis can be quantified at varying light levels using a photosynthetic-irradiance curve (P-E curve, formerly P-I curve; Figure 1.3; Kirk, 2011). The P-E curve, which is typically illustrated as a rectangular hyperbola, describes the relationship between primary production rates per unit of biomass and increasing irradiance, or intensity of light (Kalff, 2002). When phytoplankton are light-limited, the specific photosynthetic rate of an algal cell increases linearly with increasing irradiance. The slope of the P-E curve $(\alpha)$, which is dependent on the light, nutrient, and temperature history of the phytoplankton, as well as speciesspecific attributes, indicates an algal cell's efficiency to harvest light when it is limited (Kirk, 2011). At the onset of light-saturation $\left(\mathrm{E}_{\mathrm{k}}\right)$, light absorbance and carbon fixation are in equilibrium (Arrigo et al., 2010), and continued photosynthesis is dependent on the phytoplanktons' ability to photoacclimate (Kalff, 2002). At light-saturation, algal cells reach photosynthetic capacity and primary production is sustained at the maximum photosynthetic rate of the phytoplankton $\left(\mathrm{P}_{\max }\right.$; Kirk, 2011). At supersaturated irradiances, phytoplankton exhibit photoinhibition with declines in growth and primary production rates. If supersaturation is prolonged, phytoplankton can succumb to photodamage (Kalff, 2002).

To sustain long-term growth and development, phytoplankton require adequate amounts of both light and nutrients (Guildford et al., 2000). Individual species of phytoplankton have different physiological requirements and respond differently to physical and chemical stimuli, such as light, temperature, and nutrient supply (Wetzel, 
2001). These factors, in addition to top-down predation by fish, zooplankton, or mussels, and species adaptability will determine the success of a phytoplankton population (Hecky and Kilham, 1988).

Competition among phytoplankton, as well as between heterotrophic bacteria, can have a large impact on who thrives and who dies in the phytoplankton community (Brauer et al., 2012). Phytoplankton ordinarily serve as an essential source of organic matter for largely dependent heterotrophic bacteria, which typically allows the two to coexist with limited direct competition for resources. When supplies of organic matter are high relative to $\mathrm{P}$, however, heterotrophic bacteria can easily outcompete the phytoplankton for the nutrient (Grover, 2000; Kalff, 2002). Alternatively, when competition occurs among phytoplankton, some phytoplankton have developed physical adaptations that offer them a competitive advantage over other phytoplankton (Reynolds, 2006). For example, when light or nutrients are in short supply, flagellated algae and cyanobacteria can swim or utilize gas-vacuoles, respectively, to adjust their buoyancy and maximize access to any available resources in their environment (Kalff, 2002).

Similarly, under low $\mathrm{N}$ conditions, some cyanobacteria have also adapted to exploit the abundant pool of $\mathrm{N}$ gas in the atmosphere (Reynolds, 2006). This biological process of capturing atmospheric $\mathrm{N}$, which is most commonly associated with filamentous cyanobacteria although it occurs in some unicellular forms as well (Wetzel, 2001), requires relatively warm water temperatures, generous light conditions, and an abundant iron supply (Howarth et al., 1988). When these conditions are met but the system is deficient in $\mathrm{N}$, filamentous cyanobacteria can develop specialized, thick-walled cells called heterocysts. $\mathrm{N}$ fixation is confined to these heterocystic cells, where the 
anaerobic conditions required for fixation are maintained (Wetzel, 2001). Because heterocysts are not permanent features (Reynolds, 2006), their presence, as well as their size and abundance, are indicative of fixation activities (Higgins et al., 2018). Although less conspicuous, $\mathrm{N}$-fixation can also occur in non-heterocystous cyanobacteria. In these cases, rather than structurally separating sites of $\mathrm{N}$-fixation into anaerobic heterocysts, $\mathrm{N}$ fixation is often temporally separated from oxygen production, with photosynthesis occurring during the day and N-fixation occurring at night (Wetzel, 2001).

Having been one of the first organisms to develop on Earth, cyanobacteria are well-adapted for survival (Wetzel, 2001). Particular adaptive capabilities, such as buoyancy regulation and $\mathrm{N}$ fixation, enable cyanobacteria to thrive in systems facing constraint by light or $\mathrm{N}$ (Reynolds, 2006). With warmer surface water temperatures expected from a warming climate (O' Reilly et al., 2015) and a steady supply of nutrients from an increasingly anthropogenic landscape, there are concerns that global eutrophication of surface waters could lead to widespread cyanobacteria dominated phytoplankton communities (Paerl et al., 2001).

\section{Eutrophication and Cyanobacterial Harmful Algal Blooms}

Eutrophication of surface freshwater resources is one of the most ubiquitous and troubling environmental issues threating global water quality today (Higgins et al., 2018). Classically defined as nutrient enrichment and most often characterized by the formation of algal blooms, eutrophication accelerates primary productivity and organic biomass accrual while inhibiting the abilities of many organisms to adapt to the imposed shift in nutrient dynamics. This leads to the simplification of biotic communities and creates instability within the aquatic ecosystem (Wetzel, 2001). 
Algal blooms associated with anthropogenic eutrophication typically consist of a monoculture of opportunistic species (Levine and Schindler, 1999). Unfortunately, this means eutrophication tends to favor well-adapted species, such as cyanobacteria (Paerl et al., 2001). Algal blooms dominated by cyanobacteria often form dense, green scums on surface waters that are unaesthetically pleasing and promote taste and odor issues. Some species of cyanobacteria can produce harmful algal toxins that compromise drinking water and threaten the health of humans and animals, alike (Anderson et al., 2002), while others lack much nutritional value to upper level aquatic organisms (Higgins et al., 2018).

Phytoplankton are essential for supporting the aquatic food web in lentic ecosystems. Therefore, algal bloom management should address not only the abundance of phytoplankton but also the types of phytoplankton present within the community (Hecky and Kilham, 1988). During the summer, excessive phytoplankton growth is

fueled by warm temperatures, ample light, and excessive anthropogenic inputs of $\mathrm{N}$ and $\mathrm{P}$ (Higgins et al., 2018). With an improved understanding of how these resources limit primary production, the undesirable effects of eutrophication, such as cyanobacteria dominated blooms, may be mitigated.

\section{Resource Limitation}

The basis of this work originates from the assumptions described by Liebig's Law of the Minimum, which is frequently applied to biological population dynamics. According to the Law of the Minimum, the yield of an organism or a population is dictated not by the total resources available in the system, but by the abundance of the single most limiting resource, or the resource in shortest supply relative to demand (Von Liebig, 1840). Therefore, in theory, the yield of a phytoplankton population should cease 
when the source of its limiting agent, whether that be light or nutrients, is depleted in the environment (Lewis et al., 2011).

From Liebig's Law of the Minimum came an alternative concept of limitation known as Blackman Limitation, or rate limitation. This concept, which is very similar to the Law of the Minimum, describes how the growth rate rather than the yield of an organism or population is limited by the resource in shortest supply (Blackman, 1905). Although the two concepts can be interrelated (Saito et al., 2008), the nutrient status work described here is more closely aligned with the Blackman definition of limitation. Therefore, within the context of this work, resource limitation refers to the condition(s) by which rates of phytoplankton growth, productivity, and photosynthetic responses are constrained or controlled by resource availability (Blackman, 1905).

Liebig's Law of the Minimum and Blackman Limitation originally described control by a single limiting resource. However, contemporary science has shifted and frequently invokes the term co-limitation to expand these concepts to include multiple limiting agents (Arrigo, 2005; Saito et al., 2008). Generally defined, co-limitation describes a simultaneous constraint of growth by more than one resource (Saito et al., 2008), whether that be by both light and a nutrient or by multiple nutrients (Healey, 1985). More specifically, recent literature has identified three distinct types of colimitation. Of these three types, independent nutrient co-limitation is the most relevant to this work as it describes scenarios in which two mutually exclusive biochemical factors are potentially limiting when present in low concentrations (e.g., N and P; Saito et al., 2008). When growth is co-limited by a physical factor, such as light or temperature, and a nutrient, phytoplankton can increase the supply of one factor to compensate for the 
decreased supply of the other. This has been shown to be particularly more applicable in instances of constraint by $\mathrm{N}$ rather than $\mathrm{P}$ (Healey, 1985).

This work describes limitation and co-limitation in terms of proximate deficiency, which considers the phytoplankton communities' local or instantaneous responses to constraining resources, such as light or nutrients (Tyrrell, 1999). For example, when inadequate light levels do not meet the phytoplanktons' physiological needs for being able to photosynthesize, the population is described as deficient in light; therefore, their growth and productivity could be light-limited. Light and nutrient status is the collective term used to describe the state of light and nutrient deficiency or limitation for the phytoplankton community.

To understand how to effectively control excessive phytoplankton growth within a system, it is essential to identify the phytoplankton community's limiting element or elements with appropriate consideration given to temporal and spatial scales (Lewis et al., 2011). Given that light and nutrient status are influenced by dynamic interactions between physical, chemical, and biological processes, limiting resources can often vary across systems as well as within systems both temporally (e.g., from season to season, year to year) and spatially (e.g., from shallow littoral zones to deep pelagic zones). Such variability can be attributed to differences in climate (i.e., precipitation and temperature), lake morphology, nutrient supply, and biological interactions (Kalff, 2002).

The reservoir continuum concept delineates reservoirs into three spatial regions (i.e., riverine, transition, and lacustrine), and hypothesizes that light and nutrients will vary across the length of a reservoir (Kimmel and Groeger, 1984). This thesis only focuses on the lake, or lacustrine, portion of the reservoir continuum concept and does 
not test this hypothesis. However, the reservoir continuum concept addresses withinsystem spatial variation, predicting that nutrients decrease and light availability increases with distance from the riverine inflow (Kimmel and Groeger, 1984).

Nutrient status is commonly assessed through nutrient enrichment bioassay experiments, which can be conducted across a range of volumetric and temporal scales. A typical nutrient enrichment experiment involves dosing a volume of sample water with a known nutrient concentration and monitoring the phytoplankton response over a certain duration of time (Hecky and Kilham, 1988). For decades, this approach has been applied to small-scale bottle experiments, spanning hours to days, to indefinitely long wholeecosystem scale experiments (Kolzau et al., 2014), but not without criticism and controversy (Hecky and Kilham, 1988; Carpenter, 1996; Schindler, 2012).

Unfortunately, nutrient status results originating from nutrient enrichment bioassays are likely to depend on the experimental test system (Hecky and Kilham, 1988). Whole lake experiments reflect natural conditions and account for complex interactions between chemical, physical, and biological variables (Schindler, 1998). They are, however, often expensive to conduct and lack experimental control or replication (Spivak et al., 2011). Conclusions from whole lake experiments tend to be systemspecific, and because of their ecological impact, cannot typically be used to determine limiting nutrients. Alternatively, small-scale bioassay experiments lack the naturalness that include the dynamic processes influencing real systems, but allow for ample control of experimental conditions, such as light intensity or temperature, with larger sample sizes and repeatability at lower operational costs. Although increasing sample volumes 
and incubation durations can improve the realism of nutrient bioassays, ultimately, they cannot fully replicate the conditions of a natural system (Kolzau et al., 2014).

When inferences for whole lakes are drawn exclusively from small-scale bioassay experiments, the validity of the identified limiting nutrient and the severity of the limitation may be criticized (Spivak et al., 2011; Schindler, 2012). Such inferences can be given more power, however, when supported by additional measurements of ambient water chemistry or phytoplankton physiology (Hecky and Kilham, 1988) and/or coupled with modeling or long-term observational studies (Huston et al., 1999); ergo, this work's small-scale bioassay experiments have been accompanied by measurements of ambient light and nutrient chemistry, as well as phytoplankton physiology. Although experimental data does suggest that lake response to nutrients can be reasonably predicted from smallscale experimentation (Huston et al., 1999; Spivak et al., 2011; Kolzau et al., 2014), caution should still be exercised when applying results of small-scale experiments to larger, complex systems, and consideration should always be given to the scale at which the research was conducted.

\section{Light Limitation}

Solar radiation plays a significant role in aquatic ecosystem dynamics (Wetzel, 2001). While providing the light that enables sight in aquatic environments, sunlight also drives photosynthesis (Kalff, 2002) and determines the depth of the euphotic zone as well as the strength of thermal stratification (Rose et al., 2014). For the purposes of this work, light will be defined as part of the radiant energy of the electromagnetic spectrum (Wetzel, 2001) composed of particles known as photons and characterized by wavelength. Approximately half of the sunlight that reaches surface waters is within the 
photosynthetic range of 380 to 700 nanometers (Kalff, 2002). In aquatic environments, light availability is measured within this wavelength and described as photosynthetically active radiation (PAR; Rose et al., 2014). The euphotic zone describes the uppermost portion of the water column wherein phytoplankton photosynthesize, and PAR is greater than or equal to one percent of that entering at the surface (Kalff, 2002).

As light passes vertically through the water column, its intensity and spectral quality decreases due to selective absorption and particle scattering. The vertical light attenuation coefficient $\left(\mathrm{K}_{\mathrm{d}}\right)$ quantifies the rate at which light decreases with depth (Kalff, 2002). Large $K_{d}$ values indicate greater absorption of light (Kirk, 2003). Therefore, turbid waters are expected to have larger $K_{d}$ values than clear, oligotrophic waters (Knowlton and Jones, 1996). Previous studies have found $\mathrm{K}_{\mathrm{d}}$ values in Missouri reservoirs to typically range from 0.24 to 7.46 per meter (Watanabe et al., 2009).

In addition to providing the light that drives photosynthesis, solar radiation facilitates thermal stratification and lake mixing, which establishes the vertical distribution of the phytoplankton community and contributes, in part, to light availability and nutrient supply (Toseland et al., 2013). Permitting depth and climate, lakes and reservoirs can thermally stratify, or form distinct thermal layers, when prolonged heat from the sun increases surface water temperatures, creating stark thermal density differences between top and bottom waters. During stratification, cold, dense water sinks to the bottom where it forms the hypolimnion and receives no further influence from the surface. Less dense, warmer water remains at the surface where it is mixed by wind and turbulence, forming the surface mixed layer or the epilimnion. Between the hypolimnion 
and epilimnion is the metalimnion, which is the transitionary zone where the temperature gradient, or the thermocline, is most pronounced (Kalff, 2002).

Thermocline formation imposes restrictions on nutrient and gas circulation, as well as on phytoplankton distribution in the water column. During the summer, an estimated $95 \%$ of Missouri reservoirs thermally stratify and remain stably stratified throughout the season. Consequently, most also have anoxic, or poorly oxygenated, hypolimnions (Jones et al., 2011). Because the thermal density gradient at the thermocline is often too strong for phytoplankton to overcome, they are physically confined to the surface mixed layer of a stratified lake. When a lake is not stratified, or is isothermal (i.e., fully mixed), phytoplankton can freely circulate the depth of entire water column and the mixing depth of the water column is equivalent to the maximum depth of the lake. The depth of light penetration, or the euphotic depth, does not always exceed or fully encompass the mixing depth. When mixing is deeper than the euphotic depth, phytoplankton can experience periods with inadequate light (Figure 1.4; Kalff, 2002).

In freshwater ecosystems, light availability is often an important factor constraining phytoplankton growth and productivity (Guildford et al., 2000; Thrane et al., 2014). As photosynthetic organisms, phytoplankton require adequate amounts of light to grow and to generate energy for nutrient uptake and assimilation (Beardall et al., 2001). If the light environment cannot support photosynthesis (i.e., it is light-deficient), then, regardless of available nutrient supply, the phytoplankton will not have the energy to utilize the nutrients (Hecky and Guildford, 1984). Phytoplankton can sometimes photoacclimate to the light environment by adjusting how much of the primary light harvesting pigment, chla, is present in their cells. This adjustment regulates the amount of 
light energy reaching their photosystems (MacIntyre et al., 2002; Reynolds, 2006). As light intensity decreases, chla per cell increases to maximize capture of available light (Kirk 2011). Conversely, when light saturated, phytoplankton reduce chla, diverting excess energy away from the photosystems (Arrigo et al. 2010). Light-deficient phytoplankton, therefore, often produce more chla relative to their biomass (MacIntyre et al., 2002). Light-deficiency occurs if mean daily mixed layer irradiance $\left(\bar{E}_{24}\right)$, which is the average amount of light available over a 24 -hour period in the surface mixed layer, is less than what is needed by the phytoplankton for photosynthesis (Knowlton and Jones, 1996) and biomass accrual (Gosselin et al., 1985). When light is sufficient, phytoplankton dynamics are assumed to be under nutrient control (Dubourg et al., 2015).

\section{Nutrient Limitation}

In addition to light, phytoplankton also require macronutrients, such as carbon, $\mathrm{N}$, $\mathrm{P}$, and silica, as well as micronutrients, like iron, in order to conduct photosynthesis (Wetzel, 2001). Actual proportions and types of nutrients required for a community are complex and variable, depending on the species and distribution of the phytoplankton present (Lewis et al., 2011). Because of this variation, studies often focus on total biomass rather than on specific species-level production (Hecky and Kilham, 1988). Such studies have found that most experimental diagnoses of nutrient limitation on phytoplankton growth in inland waters are explained by two elements, $\mathrm{P}$ and $\mathrm{N}$ (Lewis et al., 2011). Assuming that growth is limited by just one factor, however, is a simplistic notion (Hecky and Kilham, 1988). Realistically, phytoplankton communities are more likely co-limited by more than one element, which may vary spatially and seasonally (Arrigo, 2005; Saito et al., 2008). 
When experiencing nutrient limitation, or nutrient deficiency, phytoplankton will exhibit physiological or morphological changes that reduce their ability to efficiently photosynthesize (Hecky and Kilham, 1988). Eventually, severe prolonged deficiency will cause physiological processes to cease and cells to expire (Wetzel, 2001). Some physiological changes are general responses to nutrient limitation of any kind, but other changes are specific to a particular nutrient (Hecky and Kilham, 1988). When physiological responses are nutrient specific, the limiting nutrient can be identified through the application of known nutrient deficiency indicators. These indicators are applied under the assumption that cellular constituents, nutrient uptake, and relevant enzymatic activities will respond predictably to the nutrient status of the phytoplankton (Healey and Hendzel, 1979a).

\section{Phosphorus}

P plays a major role in the metabolic processes driving life on Earth (Wetzel, 2001). A required macronutrient for primary productivity, $\mathrm{P}$ is a key constituent in the synthesis of adenosine triphosphate (ATP), and nucleotides, such as deoxyribonucleic acid (DNA) and ribonucleic acid (RNA), which drive most biochemical processes, facilitate genetic inheritance, and direct protein synthesis, respectively (Bjorkman and Karl, 2003). P is also integral to cellular structure, as cellular membranes are derived from phospholipids- another universally important P-containing compound. In fact, $\mathrm{P}$ in the leaf tissue of a healthy terrestrial plant will typically represent 0.2 to $0.4 \%$ of its dry biomass (Brady and Weil, 2008).

On Earth, P is widely distributed throughout the lithosphere. It is the tenth most abundant element on the planet, and it comprises $0.1 \%$ of the elemental abundance of 
Earth's crust by weight (Canfield et al., 2005). In the hydrosphere, however, it is present in relatively small amounts (Wetzel, 2001). Entering lakes externally through wastewater discharge, surface runoff (Canfield et al., 2005), erosion, and atmospheric deposition, $\mathrm{P}$ exists in particulate and dissolved forms. Particulate $\mathrm{P}$ includes the organic $\mathrm{P}$ in cells of living and dead phytoplankton, as well as the inorganic $\mathrm{P}$ absorbed onto mineral complexes of clays, carbonates, and ferric hydroxides. Likewise, dissolved P includes aqueous organic $\mathrm{P}$, such as polyphosphates from ATP, and inorganic $\mathrm{P}$, like orthophosphate. In lakes, orthophosphate, or dissolved reactive P (DRP), is the most significant form of $\mathrm{P}$ because it is the most biologically available (Wetzel, 2001).

P has long been considered the single most important limiting nutrient to phytoplankton in temperate freshwater ecosystems. In fact, it was once estimated that approximately $75 \%$ of freshwater systems were limited by P (Wetzel, 2001). This conclusion may be driven in part by a research bias favoring P (Lewis et al., 2011). Historically, more attention has been placed on $\mathrm{P}$ limitation compared to $\mathrm{N}$ limitation in inland waters largely because- without an atmospheric form- $\mathrm{P}$ was thought to be more easily managed than $\mathrm{N}$ (Kalff, 2002). Indeed, $\mathrm{P}$ has been effectively removed from commercial detergents (Schindler, 1974), and a large proportion of total P (TP) can be removed from wastewater effluent through the processes of sedimentation and flocculation (Lewis et al., 2011). However, P can be retained by the bottom sediments of a lake until conditions are right in the overlying water to facilitate its return to the water column. Dynamics of this phenomenon, known as internal loading, make P control in lakes and reservoirs potentially more difficult than previously thought (Nurnberg, 2009). 
Often cited as supporting evidence for the P paradigm, TP concentrations are often more strongly correlated with chlorophyll, a common index of phytoplankton biomass, than are concentrations of total N (TN; Lewis et al., 2011). This correlation, however, may be erroneously interpreted as causation. Since P and chlorophyll are necessary components of phytoplankton biomass, as is $\mathrm{N}$, all will be present together, regardless of nutrient status. Lower correlations between $\mathrm{N}$ and chlorophyll may simply be attributed to the dynamic chemical nature of $\mathrm{N}$ (e.g., higher analytical variability in $\mathrm{N}$ analyses, higher natural variability in N-bioavailability; Lewis and Wurtsbaugh, 2008). As compared to $\mathrm{P}$, a greater proportion of $\mathrm{N}$ in inland waters tends to be in a refractory, or non-bioavailable, form. Dissolved organic N, which was once thought to be entirely refractory (Lewis et al., 2011), has recently been highlighted as a potentially important, albeit variably bioavailable, $\mathrm{N}$-source for phytoplankton under nutrient stress (Belisle et al., 2016; Glibert et al., 2016; Paerl et al., 2016). Although inorganic forms of both P and $\mathrm{N}$ are commonly depleted from the surface mixed layers of lakes and reservoirs, the particulate nutrients incorporated into phytoplankton biomass are consistently accompanied by significant amounts of both dissolved organic P and $\mathrm{N}$ (Lewis and Wurtsbaugh, 2008). Therefore, the strength of the empirical relationships between total nutrients and chlorophyll do not necessarily indicate a strict preference for P limitation over N limitation (Lewis et al., 2011).

Finally, efforts to manage $\mathrm{N}$ are commonly assumed to be futile due to cyanobacteria's ability to fix atmospheric $\mathrm{N}$ when $\mathrm{N}$ supply is low. $\mathrm{N}$ fixation and $\mathrm{N}$ limitation, however, still coexist in some systems (Lewis et al., 2011). In a similar manner, phytoplankton can excrete an enzyme, known as phosphatase, that enables them 
to assimilate otherwise biologically unavailable $\mathrm{P}$ from organic matter when $\mathrm{P}$ supply is low (Lewis et al., 2011). Additionally, when $\mathrm{P}$ is plentiful, phytoplankton are capable of luxury consumption, which is to say they absorb $\mathrm{P}$ in excess of the amount needed for their immediate needs and store it for later use (Wetzel, 2001; de Mazancourt and Schwartz, 2012). By taking up as much as 10 times the minimum amount of $\mathrm{P}$ needed (Lewis et al., 2011), phytoplankton growth can still be maintained even when environmental P concentrations are very low (Wetzel, 2001). Thus, the P-only paradigm has shifted to explore the feasibility of managing for $\mathrm{N}$ as well as $\mathrm{P}$. Recent nutrient enrichment experiments support this notion, indicating that $\mathrm{N}$ limitation may be just as common as P limitation in freshwater lakes around the globe (Lewis et al., 2011).

\section{$\underline{\text { Nitrogen }}$}

Like $\mathrm{P}, \mathrm{N}$ is another element essential for metabolic processes and life on Earth. In primary producers, this macronutrient is a major component of DNA and RNA, as well as amino acids, proteins, carbohydrates, and chlorophyll. Healthy leaf tissue in terrestrial plants tend to contain 2.5 to $4.0 \% \mathrm{~N}$ by dry biomass, which is approximately 10 times more than the expected P content (Brady and Weil, 2008).

As the most abundant element in the atmosphere (Marshak, 2013), $\mathrm{N}$ is also abundant at the Earth's surface with a combined estimate of approximately 5 billion metric tons contained in the atmosphere, oceans, biota, soil organic matter, and sedimentary rocks. Only $2 \%$ of that $\mathrm{N}$, however, is biologically available to organisms. Seventy-eight percent is present as $\mathrm{N}_{2}$ gas in the atmosphere, while the remaining $20 \%$ is bound in sedimentary rock (Galloway, 1998). Atmospheric N can be converted to reactive forms of $\mathrm{N}$, such as nitrate, ammonium, and organic $\mathrm{N}$, through lightning and 
biological fixation. In freshwater ecosystems, sources of $\mathrm{N}$ include lightning and $\mathrm{N}_{2}$ fixation, as well as precipitation, surface and groundwater runoff, tributary inflow, and sewage effluent (Wetzel, 2001).

$\mathrm{N}$ exists in a variety of reduced and oxidized forms that are dynamically transformed and circulated through the environment via the N cycle (Wetzel, 2001). In lakes and reservoirs, $\mathrm{N}$ is most often present in the dissolved inorganic forms of nitrate $\left(\mathrm{NO}_{3}{ }^{-}\right)$, nitrite $\left(\mathrm{NO}_{2}-\right)$, and ammonium $\left(\mathrm{NH}_{4}{ }^{+}\right)$, as well as organic $\mathrm{N}$ forms, such as urea. $\mathrm{NH}_{4}{ }^{+}$is the most biologically available form of $\mathrm{N}$, making it the preferred form for plant and phytoplankton uptake. It is produced through the process of ammonification, or regeneration, from the dissolved organic $\mathrm{N}$ released upon excretion or death. Under anoxic conditions, such as those in the hypolimnions of many Missouri reservoirs, $\mathrm{NH}_{4}{ }^{+}$ may be produced via internal loading (i.e., resuspension of sediment-bound $\mathrm{N}$ to the water column) or lost to the atmosphere as $\mathrm{N}_{2}$ gas through the process of annamox. When oxygen is plentiful, $\mathrm{NH}_{4}{ }^{+}$is readily oxidized through the process of nitrification to form $\mathrm{NO}_{3}{ }^{-}$. Although it mostly happens in hypolimnions because it requires anoxia, $\mathrm{NO}_{3}{ }^{-}$may also be lost as $\mathrm{N}_{2}$ gas through the process of denitrification (Kalff, 2002).

As a result of chemical transformation (i.e., nitrification) and the rapid biological assimilation of $\mathrm{NH}_{4}{ }^{+}, \mathrm{NO}_{3}{ }^{-}$is the inorganic $\mathrm{N}$ form typically present in the highest concentrations in the surface mixed layer, while $\mathrm{NH}_{4}{ }^{+}$is often present in very miniscule, potentially limiting amounts. Therefore, when the reactive supply of $\mathrm{N}$ is low, $\mathrm{N}$ competition among the phytoplankton is largely based on $\mathrm{NH}_{4}{ }^{+}$uptake efficiency and the ability of certain species to utilize alternative sources of N. For example, some phytoplankton are capable of luxury consumption and storage of $\mathrm{NH}_{4}{ }^{+}$for later use 
(Glibert et al., 2016). Others utilize mechanisms to access the often abundant dissolved organic N pool (Bronk et al., 2006) or ever-present atmospheric N (Reynolds, 2006). Within the phytoplankton community, cyanobacteria are the only phytoplankton that have adapted to fix atmospheric $\mathrm{N}_{2}$ when dissolved $\mathrm{N}$ is scarce. However, in order to fix $\mathrm{N}$, cyanobacteria need relatively warm, stable water columns with sufficient light and a surplus of available iron (Howarth et al., 1988). $\mathrm{N}$ fixation by cyanobacteria is expected to occur in Missouri waters, as the state's abundant clay soils are assumed to be an adequate source of iron (Tidball, 1984; Hammer, 1997), and many of its reservoirs are warm and shallow with ample light and stable stratification. Furthermore, microscopic examination of the phytoplankton in Missouri reservoirs have indicated that cyanobacteria, including N-fixing taxa, are not only present but often dominant in the phytoplankton communities of eutrophic waters across the state (Jones et al., 2008b).

\section{Top-Down Predation: Grazing and the Zebra Mussel Effect}

Open water tends to offer phytoplankton little refuge against the variety of heterotrophic organisms who also call this habitat home (Reynolds, 2006). At the base of the aquatic food web, phytoplankton face consumption by herbivorous organisms, such as zooplankton, arthropods, crustaceans, mussels, and fish (Kalff, 2002). With differing feeding preferences and habitat demands, potential influence by consumers is broad and dynamic. Generally, however, such grazing interactions tend to make phytoplankton communities susceptible to physical biomass loss, as well as restrictive growth and slow biomass recovery (Reynolds, 2006). Those examining primary production through this top-down lens are doing so under the assumption that productivity is controlled by trophic interactions rather than by resource availability (Power, 1992). While I 
acknowledge this theory, my work adopts the assumptions of bottom-up theory, where resources drive production.

Although predation effects are not a focus of my work, at least three study reservoirs are known to contain an invasive species of dreissenid mussel, the zebra mussel (Dreissena polymorpha; Gaskill, 2021), which is an additional complicating factor that should be recognized, as it may impact aspects of this study. Originally native to Eurasia, the zebra mussel is an exotic species of freshwater shellfish-also known as a mollusk or bivalve. Its adaptability and ability to disperse is unrivaled by native species, making it a notoriously successful invader of freshwater systems across Europe and North America (Ozersky et al., 2013). Believed to have been accidentally introduced in ballast water shed from boats having sailed from Europe (Higgins and Vander Zanden, 2010), the first zebra mussels were reported in the Great Lakes area in the mid-1980s (Benson et al., 2021). In the decades that followed, dreissenids continued to spread across the continent via fluvial channels and watercraft, invading lakes and rivers alike (Mari et al., 2011). By 1991, the first invasive mussels had reached Missouri. Since then, their presence in the state has only increased (Benson et al., 2021). In a 2019 survey, two of the three invaded study reservoirs, Lake of the Ozarks and Smithville Lake, were estimated to contain an average of $64.72 \pm 32.42$ and $25.76 \pm 14.92$ zebra mussels per square meter, respectively (Gaskill, 2021).

When zebra mussels establish themselves in non-native ecosystems, they tend to facilitate dramatic, large-scale alterations to the invaded ecosystem. Particularly relevant to this work, dreissenids are known to modify distributions of nutrients, energy, and productivity within lake environments (Ozersky et al., 2013). As highly effective filter 
feeders, zebra mussels remove particulate nutrients and carbon from the water column (Ozersky et al., 2015). Such grazing reduces phytoplankton biomass, which increases water clarity and shifts primary productivity from open water to nearshore (Ozersky et al., 2013). Zebra mussels can also excrete ingested particulate nutrients as dissolved, bioavailable nutrients, such as phosphate and ammonium, making them potentially important nutrient sources (Ozersky et al., 2015). Their presence, therefore, may influence the light and nutrient regimes of the three inhabited study reservoirs.

\section{The Study Area: Missouri Regions and Reservoirs}

Thirty-two man-made freshwater reservoirs were sampled in conjunction with the monitoring efforts of the Missouri Statewide Lake Assessment Program during the summers of 2017 and 2018. The reservoirs span at least 25 Missouri counties and 4 major physiographic regions (i.e., Glacial Plains, Osage Plains, Ozark Border, Ozark Highlands; Thom and Wilson, 1980). The Glacial Plains region largely encompasses the northern half of the state, where past glaciation formed soils of loess and glacial till, and limestone and shale are the prominent bedrock. The unglaciated Osage Plains lie to the west and southwest, with geology characterized by limestone, sandstone, and shale. The Ozark Border region, with its highly productive alluvial and loess soils, brackets the Missouri River in central Missouri and borders the Mississippi River in the east. The remaining southern portion of the state, apart from the Bootheel, lie in the Ozark Highlands. This unglaciated region, which includes the St. Francois Mountains, has an interesting and complex geology. Generally, however, it is known for its thin, cherty soils and rugged, irregular topography (Unklesbay and Vineyard, 1992; Jones and Knowlton, 1993). 
Missouri's land-use is largely shaped by the geology of these regions (Jones and Knowlton, 1993), with $70 \%$ of the Plains in agriculture and $60 \%$ of the Highlands in forest as of 2016.

The study reservoirs were carefully selected to represent variation in reservoir condition across the state. Such variation includes differences in watershed land-use, as well as light, nutrients, and phytoplankton biomass. To fully capture these potential differences, I prioritized a subset of reservoirs that would collectively span the trophic gradient (i.e., trophic status, or lake productivity, ranging from oligotrophic to hypereutrophic). Although Missouri plays host to reservoirs at each extreme of the trophic gradient, roughly $80 \%$ of all reservoirs in the state are believed to be either mesotrophic or eutrophic (Jones et al., 2008b). My subset mirrors this distribution, with 5 oligotrophic study reservoirs, 13 mesotrophic, 12 eutrophic, and 2 hypereutrophic.

I defined trophic status using locally established classification thresholds for TP, TN, total chlorophyll- $a$ (TChl), and Secchi depth (Jones et al., 2008a). Although the reservoirs were initially selected based on assumed historical trophic states, final trophic status determinations were made using the 2017 and 2018 seasonal averages to better characterize lake conditions specific to my study period. A weighted evidence approach was utilized, in consultation with historical averages, wherein TP carried the most weight in determining the final trophic status (Table 1.1).

Chemical, biological, and physical water quality attributes vary across the trophic gradient. Historical averages for the study reservoirs overall range from 0.2 to $3.7 \mu \mathrm{mol}$ $\mathrm{L}^{-1} \mathrm{TP}, 14.3$ to $144.2 \mu \mathrm{mol} \mathrm{L}{ }^{-1} \mathrm{TN}, 1.2$ to $71.1 \mu \mathrm{g} \mathrm{L} \mathrm{L}^{-1} \mathrm{TChl}$, and 0.3 to $4.4 \mathrm{~m}$ Secchi depth (Jones et al., 2020a). Morphological characteristics, such age, elevation, surface area, lake volume, maximum depth, flushing rate, retention time, watershed area, and 
watershed to surface area ratio, also vary among the study reservoirs. Approximately 90 $\%$ of all Missouri reservoirs have been constructed within the last 60 years (Jones et al., 2008b). Of the study reservoirs, the average age is 56 years with the oldest built in 1930 and the most recent in the early 1990s. Surface areas range from 2.4 to 21,777 ha. Although exact volumes and depths are unknown due to a lack of contemporary bathymetric data, estimated volumes and maximum depths range from 98,678 to 2,491,629,600 $\mathrm{m}^{3}$ and 2.8 to $29 \mathrm{~m}$, respectively (MoDNR, 2018). Missouri reservoirs have large watersheds consistent with typical reservoir design, which help to support stable water levels (Jones et al., 2020b). Study watersheds are estimated to range in size from 60 to 2,499,333 hectares with watershed to reservoir surface area ratios ranging from 10 to 592. Subsequently, estimated flushing rates range from 0.4 to 86 times per year, which translate to approximate water retention times of 4 days to 2.5 years (Table 1.2; MoDNR, 2018).

In Missouri, mean annual air temperatures differ by approximately $3{ }^{\circ} \mathrm{C}$ from north to south. This contributes to a latitudinal gradient in mixing regimes across the state's reservoirs. Systems in the northern reaches tend to be dimictic, where they fully mix twice a year in the spring and fall. Central and southern systems are largely warm monomictic, fully mixing just once a year from fall through spring. All reservoirs in this work are warm monomictic, except for one shallow polymictic reservoir, Lake Niangua, which frequently oscillates between being stratified and mixed due to hydroelectric operations. Typically, however, by mid-May, most Missouri reservoirs have stably stratified and will remain so until September, with summer surface water temperatures ranging from roughly 20 to $30^{\circ} \mathrm{C}\left(68\right.$ to $86^{\circ} \mathrm{F}$; Jones et al., 2011). 


\section{Tables}

Table 1.1. Trophic status as determined by the seasonal and two-year combined averages of Secchi depth (Secchi), total chlorophyll (TChl), total phosphorus (TP), and total nitrogen (TN), and the trophic status classification thresholds established by Jones et al., 2008a.

\begin{tabular}{|c|c|c|c|c|c|c|c|c|c|c|c|c|c|c|c|}
\hline \multirow[b]{2}{*}{ Lake } & \multicolumn{5}{|c|}{$\underline{2017}$} & \multicolumn{5}{|c|}{$\underline{2018}$} & \multicolumn{5}{|c|}{2 Year Average } \\
\hline & $\begin{array}{c}\text { Secchi } \\
(m)\end{array}$ & $\begin{array}{c}\text { TChl } \\
\left(\mu g L^{-1}\right)\end{array}$ & $\begin{array}{c}T P \\
\left(\mu m o l ~ L^{-1}\right)\end{array}$ & $\begin{array}{c}\text { TN } \\
\left(\mu \mathrm{mol} \mathrm{L}^{-1}\right)\end{array}$ & $\begin{array}{c}2017 \\
\text { Status }\end{array}$ & $\begin{array}{c}\text { Secchi } \\
(m)\end{array}$ & $\begin{array}{c}T C h l \\
\left(\mu g L^{-1}\right)\end{array}$ & $\begin{array}{c}\text { TP } \\
\left(\mu \mathrm{mol} \mathrm{L} L^{-1}\right)\end{array}$ & $\begin{array}{c}T N \\
\left(\mu m o l ~ L^{-1}\right)\end{array}$ & $\begin{array}{c}2018 \\
\text { Status }\end{array}$ & $\begin{array}{c}\text { Secchi } \\
(\mathrm{m})\end{array}$ & $\begin{array}{r}T C h l \\
\left(\mu g L^{-1}\right)\end{array}$ & $\begin{array}{c}\text { TP } \\
\left(\mu \mathrm{mol} \mathrm{L} L^{-1}\right)\end{array}$ & $\begin{array}{c}\text { TN } \\
\left(\mu \mathrm{mol} \mathrm{L} L^{-1}\right)\end{array}$ & $\begin{array}{c}\text { Avg. } \\
\text { Status }\end{array}$ \\
\hline Austin* & 0.97 & 50.83 & 1.52 & 70.68 & $\mathbf{E}$ & & & & & & & & & & \\
\hline Binder* & & & & & & 0.85 & 33.37 & 1.61 & 64.25 & $\mathbf{E}$ & & & & & \\
\hline Bowling Green & 1.55 & 6.03 & 0.58 & 32.13 & M & 2.28 & 2.72 & 0.45 & 27.13 & M & 1.91 & 4.37 & 0.51 & 29.99 & M \\
\hline Capri & 4.47 & 1.59 & 0.16 & 22.13 & $\mathrm{O}$ & 4.74 & 2.23 & 0.16 & 23.56 & $\mathrm{O}$ & 4.60 & 1.91 & 0.17 & 22.85 & $\mathbf{O}$ \\
\hline Council Bluff & 2.58 & 2.80 & 0.19 & 17.85 & $\mathrm{O}$ & 3.66 & 1.58 & 0.19 & 15.71 & $\mathrm{O}$ & 3.12 & 2.19 & 0.19 & 16.42 & $\mathbf{O}$ \\
\hline Dairy Farm \#1 & 0.62 & 61.45 & 3.00 & 96.38 & $\mathrm{H}$ & 0.65 & 87.32 & 3.13 & 100.66 & $\mathrm{H}$ & 0.64 & 74.39 & 3.06 & 98.52 & $\mathbf{H}$ \\
\hline Fellows & 2.52 & 4.66 & 0.36 & 23.56 & $\mathrm{O}$ & 2.55 & 5.40 & 0.26 & 23.56 & $\mathrm{O}$ & 2.53 & 5.03 & 0.31 & 23.56 & $\mathbf{O}$ \\
\hline Hunnewell & 0.66 & 29.48 & 1.26 & 59.26 & $\mathrm{E}$ & 1.38 & 8.95 & 0.81 & 44.98 & M & 1.02 & 19.21 & 1.03 & 52.12 & $\mathbf{E}$ \\
\hline Lamar & & 58.62 & 2.39 & 80.67 & $\mathrm{E}$ & 0.73 & 43.74 & 2.00 & 84.24 & E & 0.73 & 51.18 & 2.20 & 82.82 & $\mathbf{E}$ \\
\hline Lincoln & 1.52 & 5.02 & 0.45 & 27.84 & M & 2.38 & 3.62 & 0.32 & 27.13 & $\mathrm{O}$ & 1.95 & 4.32 & 0.39 & 27.13 & M \\
\hline Little Dixie & 0.51 & 39.29 & 1.78 & 66.40 & $\mathrm{E}$ & 0.94 & 33.06 & 1.65 & 72.82 & $\mathrm{E}$ & 0.73 & 36.18 & 1.71 & 69.25 & $\mathbf{E}$ \\
\hline Little Prairie & 1.80 & 7.47 & 0.55 & 36.41 & M & 1.38 & 18.03 & 0.77 & 44.26 & M & 1.59 & 12.75 & 0.66 & 39.98 & M \\
\hline Manito & 0.48 & 15.83 & 2.65 & 61.40 & E & 0.96 & 22.26 & 1.49 & 61.40 & E & 0.72 & 19.05 & 2.06 & 61.40 & $\mathbf{E}$ \\
\hline Mark Twain & 0.83 & 29.42 & 1.49 & 109.23 & E & 1.19 & 14.83 & 1.13 & 80.67 & $\mathrm{E}$ & 1.01 & 22.12 & 1.31 & 94.95 & $\mathbf{E}$ \\
\hline Miller* & 1.16 & 16.20 & 0.77 & 34.27 & $\mathbf{M}$ & & & & & & & & & & \\
\hline Niangua & 0.45 & 12.61 & 1.65 & 49.26 & $\mathrm{E}$ & 0.49 & 19.85 & 1.78 & 47.83 & $\mathrm{E}$ & 0.47 & 16.23 & 1.71 & 48.55 & $\mathbf{E}$ \\
\hline Noblett* & 2.44 & 5.99 & 0.39 & 12.85 & M & & & & & & & & & & \\
\hline Ozark & 1.76 & 17.22 & 0.90 & 33.55 & $\mathrm{E}$ & 2.11 & 10.43 & 0.55 & 31.41 & M & 1.93 & 13.82 & 0.71 & 32.13 & M \\
\hline Pomme De Terre & 1.34 & 19.14 & 0.74 & 34.27 & M & 1.04 & 18.39 & 0.61 & 39.98 & M & 1.19 & 18.76 & 0.68 & 37.12 & $\mathbf{M}$ \\
\hline Prairie Home & 2.70 & 6.24 & 0.65 & 33.55 & M & 1.96 & 5.72 & 0.48 & 34.27 & M & 2.33 & 5.98 & 0.57 & 34.27 & $\mathbf{M}$ \\
\hline Roby* & 2.23 & 3.40 & 0.39 & 27.13 & M & & & 0.00 & & & & & & & \\
\hline Shawnee/Turner & 1.53 & 6.50 & 0.42 & 24.99 & M & 1.21 & 13.74 & 0.55 & 30.70 & M & 1.37 & 10.12 & 0.49 & 27.84 & M \\
\hline Shayne & & 2.15 & 0.16 & 20.70 & $\mathrm{O}$ & 3.83 & 1.74 & 0.19 & 24.27 & $\mathrm{O}$ & 3.83 & 1.94 & 0.18 & 22.13 & $\mathbf{O}$ \\
\hline Shelbina & 0.50 & 48.53 & 3.07 & 87.81 & $\mathrm{H}$ & 0.42 & 68.42 & 3.49 & 82.82 & $\mathrm{H}$ & 0.46 & 58.47 & 3.29 & 85.67 & $\mathbf{H}$ \\
\hline Sims Valley* & 4.18 & 5.35 & 0.32 & 20.70 & $\mathbf{O}$ & & & & & & & & & & \\
\hline Smithville* & & & & & & 1.17 & 21.00 & 0.94 & 47.83 & $\mathbf{E}$ & & & & & \\
\hline Stockton & 1.91 & 12.84 & 0.61 & 32.13 & M & 2.68 & 6.15 & 0.36 & 18.56 & M & 2.29 & 9.49 & 0.48 & 25.70 & M \\
\hline Truman & 1.06 & 29.45 & 1.42 & 42.12 & E & 1.29 & 19.11 & 1.03 & 48.55 & E & 1.18 & 24.28 & 1.23 & 45.69 & $\mathbf{E}$ \\
\hline Watkins Mill* & & & & & & 1.45 & 15.99 & 0.94 & 44.26 & $\mathbf{E}$ & & & & & \\
\hline Whiteside & 0.86 & 19.36 & 0.94 & 56.40 & E & 1.86 & 9.35 & 0.68 & 47.83 & M & 1.36 & 14.35 & 0.81 & 52.12 & $\mathbf{E}$ \\
\hline Winegar & 1.73 & 8.28 & 0.77 & 39.27 & M & 1.63 & 13.92 & 0.81 & 39.27 & M & 1.68 & 11.10 & 0.79 & 39.27 & M \\
\hline Ziske & 1.21 & 6.91 & 0.48 & 24.99 & M & 1.45 & 7.61 & 0.52 & 31.41 & M & 1.33 & 7.26 & 0.51 & 27.84 & M \\
\hline
\end{tabular}

An asterisk (*) indicates lakes only sampled for one year. Each parameter is classified according to Jones et. al., 2008a. Final trophic status determinations,

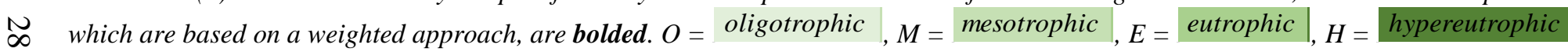


Table 1.2. Summary of trophic status, geographic location, designated use, morphology and watershed land-use for the 32 study reservoirs.

\begin{tabular}{|c|c|c|c|c|c|c|c|c|c|c|}
\hline & \multirow{2}{*}{$\begin{array}{l}\text { (Latitude, } \\
\text { Longitude) }\end{array}$} & \multirow{2}{*}{$\begin{array}{l}\text { Physiographic } \\
\text { Region }\end{array}$} & \multirow{2}{*}{$\begin{array}{l}\text { Designated } \\
\text { Use }\end{array}$} & \multirow{2}{*}{$\begin{array}{c}\text { Elevation } \\
(m)\end{array}$} & \multirow{2}{*}{$\begin{array}{l}\text { Max. depth } \\
(\mathrm{m})\end{array}$} & \multirow{2}{*}{$\begin{array}{c}\text { Surface area } \\
\text { (ha) }\end{array}$} & \multirow{2}{*}{$\begin{array}{l}\text { Watershed area } \\
\text { (ha) }\end{array}$} & \multicolumn{3}{|c|}{ Percent watershed land-use } \\
\hline & & & & & & & & $\%$ Forest & $\%$ Pasture & \% Crop \\
\hline \multicolumn{11}{|l|}{ Oligotrophic } \\
\hline Capri & $(37.90,-90.63)$ & Ozark Highland & $\operatorname{Rec}$ & 254 & 29.6 & 42 & 139 & 52 & 3 & 0 \\
\hline Council Bluff & $(37.73,-90.91)$ & Ozark Highland & $\operatorname{Rec}$ & 334 & 33.5 & 172 & 3,463 & 97 & 1 & 0 \\
\hline Fellows & $(37.32,-93.23)$ & Ozark Highland & DW, Rec & 383 & 30.5 & 286 & 5,069 & 42 & 49 & 0 \\
\hline Shayne & $(37.90,-90.64)$ & Ozark Highland & $\operatorname{Rec}$ & 271 & 21.9 & 30 & 206 & 57 & 8 & 0 \\
\hline Sims Valley 2017 & $(37.01,-91.85)$ & Ozark Highland & Rec & 372 & 10.1 & 16 & 241 & 56 & 38 & 0 \\
\hline \multicolumn{11}{|l|}{ Mesotrophic } \\
\hline Bowling Green & $(39.34,-91.15)$ & Glacial Plain & DW, Rec & 242 & 22.3 & 9 & 331 & 52 & 31 & 14 \\
\hline Ozark* & $(38.20,-92.62)$ & Ozark Highland & Rec & 176 & 45.1 & 20,774 & 464,073 & 65 & 25 & 1 \\
\hline Lincoln & $(39.02,-90.92)$ & Glacial Plain & $\operatorname{Rec}$ & 172 & 21.0 & 13 & 389 & 85 & 4 & 0 \\
\hline Little Prairie & $(37.99,-91.69)$ & Ozark Highland & Rec & 305 & 14.6 & 39 & 618 & 60 & 33 & 0 \\
\hline Miller 2017 & $(37.05,-90.91)$ & Ozark Highland & Rec & 259 & 8.2 & 8 & 120 & 60 & 18 & 0 \\
\hline Noblett ${ }^{2017}$ & $(36.91,-92.10)$ & Ozark Highland & Rec & 297 & 9.1 & 11 & 6,334 & 83 & 13 & 0 \\
\hline Pomme De Terre & $(37.91,-93.32)$ & Ozark Highland & Rec & 270 & 47.2 & 3,766 & 161,758 & 38 & 53 & 1 \\
\hline Prairie Home & $(38.78,-92.60)$ & Border & DW, Rec & 249 & 6.9 & 6 & 96 & 55 & 34 & 6 \\
\hline Roby 2017 & $(37.52,-92.12)$ & Ozark Highland & Rec & 373 & 4.6 & 4 & 109 & 89 & 2 & 0 \\
\hline Stockton & $(37.69,-93.77)$ & Ozark Highland & DW, Rec & 264 & 49.1 & 11,227 & 282,392 & 32 & 58 & 2 \\
\hline Shawnee/Turner & $(37.65,-91.51)$ & Ozark Highland & $\operatorname{Rec}$ & 356 & 9.8 & 6 & 28 & 58 & 33 & 0 \\
\hline Winegar & $(38.48,-92.40)$ & Border & Rec & 210 & 8.5 & 2 & 42 & 57 & 38 & 0 \\
\hline Ziske & $(37.65,-91.51)$ & Ozark Highland & $\operatorname{Rec}$ & 358 & 7.3 & 10 & 141 & 83 & 8 & 0 \\
\hline \multicolumn{11}{|l|}{ Eutrophic } \\
\hline A ustin 2017 & $(37.16,-92.19)$ & Ozark Highland & $\operatorname{Rec}$ & 444 & 8.2 & 9 & 90 & 38 & 54 & 0 \\
\hline Binder $^{2018}$ & $(38.60,-92.30)$ & Border & Rec & 197 & 14.6 & 59 & 1,557 & 33 & 27 & 0 \\
\hline Hunnewell & $(39.71,-91.86)$ & Glacial Plain & Rec & 208 & 11.0 & 78 & 1,040 & 33 & 28 & 35 \\
\hline Lamar & $(37.48,-94.26)$ & Osage Plain & DW, Rec & 293 & 7.9 & 49 & 1,101 & 13 & 70 & 11 \\
\hline Little Dixie & $(38.91,-92.12)$ & Glacial Plain & $\operatorname{Rec}$ & 255 & 12.8 & 78 & 919 & 36 & 37 & 23 \\
\hline Manito & $(38.59,-92.81)$ & Border & $\operatorname{Rec}$ & 261 & 13.1 & 31 & 604 & 38 & 40 & 15 \\
\hline Mark Twain & $(39.52,-91.65)$ & Glacial Plain & DW, Rec & 185 & 34.1 & 7,496 & 581,442 & 18 & 30 & 44 \\
\hline Niangua & $(37.94,-92.85)$ & Ozark Highland & Rec & 217 & 6.1 & 93 & 152,818 & 58 & 36 & 0 \\
\hline Smithville*2018 & $(39.40,-94.56)$ & Glacial Plain & DW, Rec & 270 & 32.0 & 2,868 & 53,399 & 13 & 44 & 35 \\
\hline Truman* & $(38.26,-93.41)$ & Osage Plain & DW, Rec & 215 & 38.4 & 21,778 & $2,397,033$ & 21 & 43 & 21 \\
\hline Watkins Mill 2018 & $(39.39,-94.26)$ & Glacial Plain & $\mathrm{Rec}$ & 273 & 15.8 & 44 & 755 & 41 & 38 & 14 \\
\hline $\begin{array}{c}\text { Whiteside } \\
\text { Hypereutrophic }\end{array}$ & $(39.17,-91.01)$ & Glacial Plain & Rec & 229 & 12.2 & 9 & 103 & 54 & 34 & 4 \\
\hline Dairy Farm \#1 & $(38.99,-92.49)$ & Border & $\operatorname{Rec}$ & 238 & 5.1 & 6 & 58 & 1 & 28 & 70 \\
\hline Shelbina & $(39.73,-92.04)$ & Glacial Plain & DW, Rec & 216 & 8.5 & 17 & 202 & 12 & 28 & 36 \\
\hline
\end{tabular}

An asterisk (*) indicates confirmed zebra mussel (Dreissena polymorpha) presence. Superscripts indicate the year sampled when only sampled for one year. The specified designated uses include drinking water $(D W)$ and recreation $(R e c)$ in the form of whole body and/or secondary contact recreation, although all the reservoirs also have aquatic life uses, fish consumption uses, irrigational uses, and livestock or wildlife watering uses. 


\section{Figures}

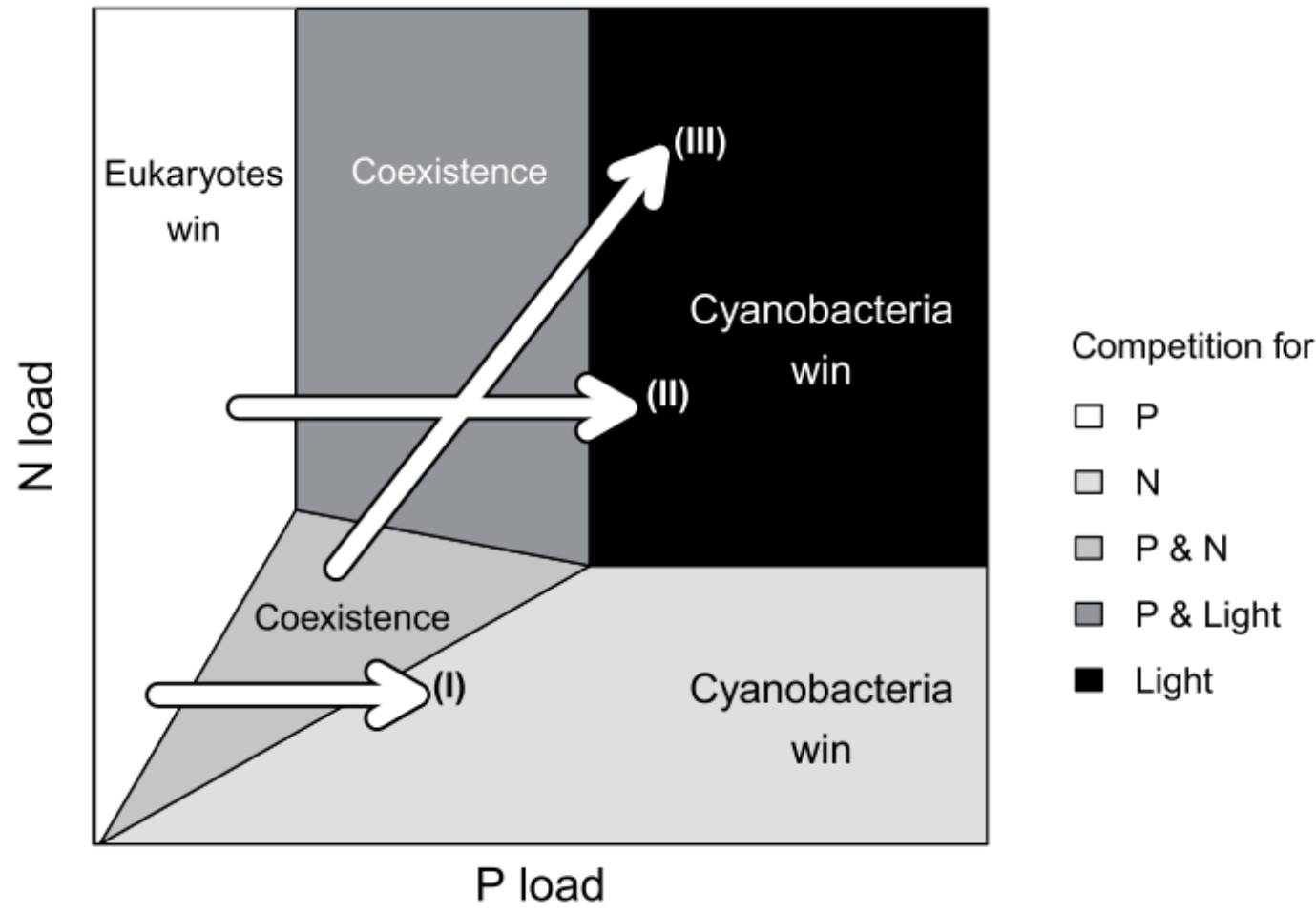

Figure 1.1. (From Brauer et al., 2012) Competition for light, nitrogen (N), and phosphorus (P) between phytoplankton, as predicted by the resource competition theory under various nutrient loading scenarios. According to this theory, cyanobacteria are favored when high nutrient loads of both $\mathrm{N}$ and $\mathrm{P}$ lead to competition for light, as well as if $\mathrm{N}$ loads are low (limited) relative to an excess of $\mathrm{P}$.

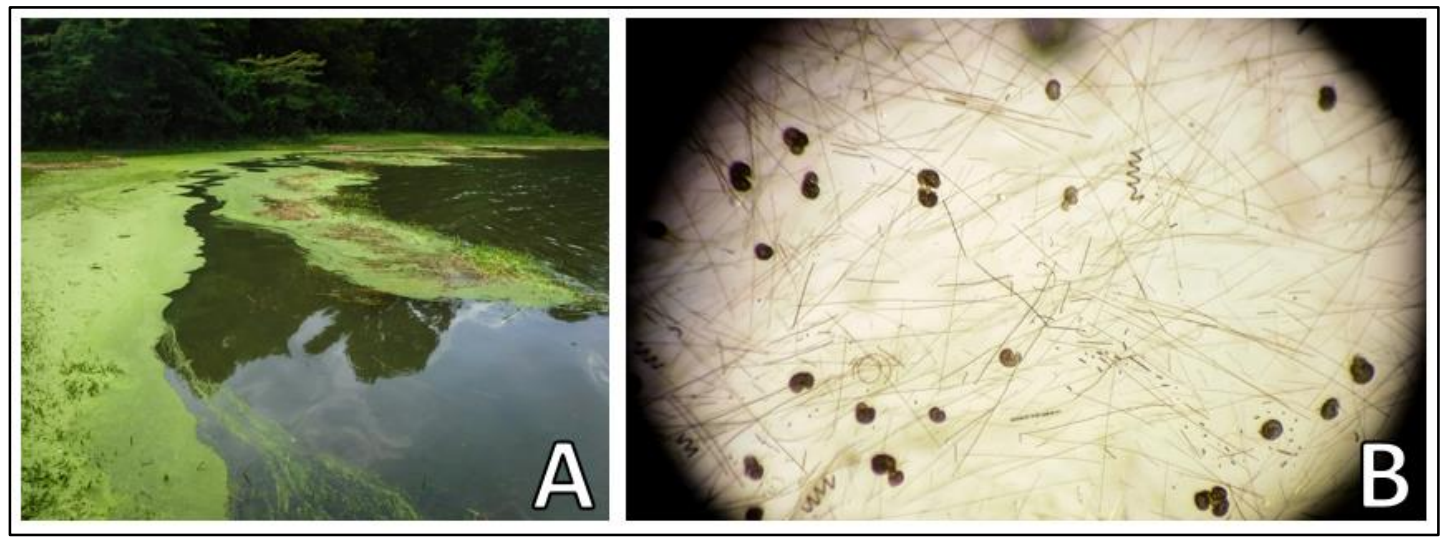

Figure 1.2. A blooming phytoplankton community (A) as seen in situ with the naked eye, and (B) as seen under a compound microscope. Both eukaryotic algae and cyanobacteria are present. 


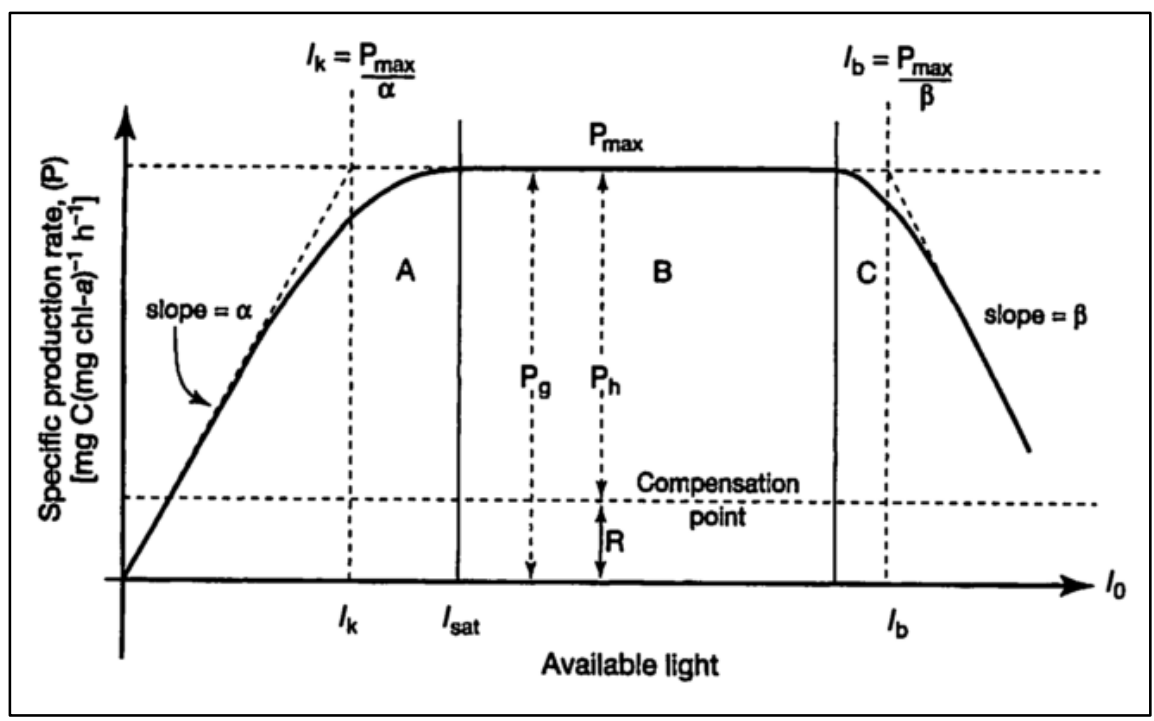

Figure 1.3. (From Kalff, 2002) The P-E curve, formerly known as the P-I curve, describes a rectangular hyperbola that plots intensity of light against rate of primary production per unit of biomass (chlorophylla). As light availability increases, the production rate slope (slope $\alpha$ ) increases linearly while the phytoplankton become increasingly light saturated. The maximum photosynthetic rate $\left(\mathrm{P}_{\max }\right)$ occurs when the phytoplankton are at photosynthetic capacity. At supersaturated intensities, the phytoplankton begin to exhibit photoinhibition and production rates decrease (slope $\beta$ ). Sections A, B, and C represent light limitation, light saturation, and light inhibition, respectively. Gross primary productivity and net primary productivity are described by $\mathrm{P}_{\mathrm{g}}$ and $\mathrm{P}_{\mathrm{n}}$, respectively. The compensation point is where rates of respiration and photosynthesis are equal. $\mathrm{E}_{\mathrm{k}}$, or $\mathrm{I}_{\mathrm{k}}$ as depicted in this figure, is an important measure of how much light the phytoplankton can handle and a good indicator of general nutrient and light stress.

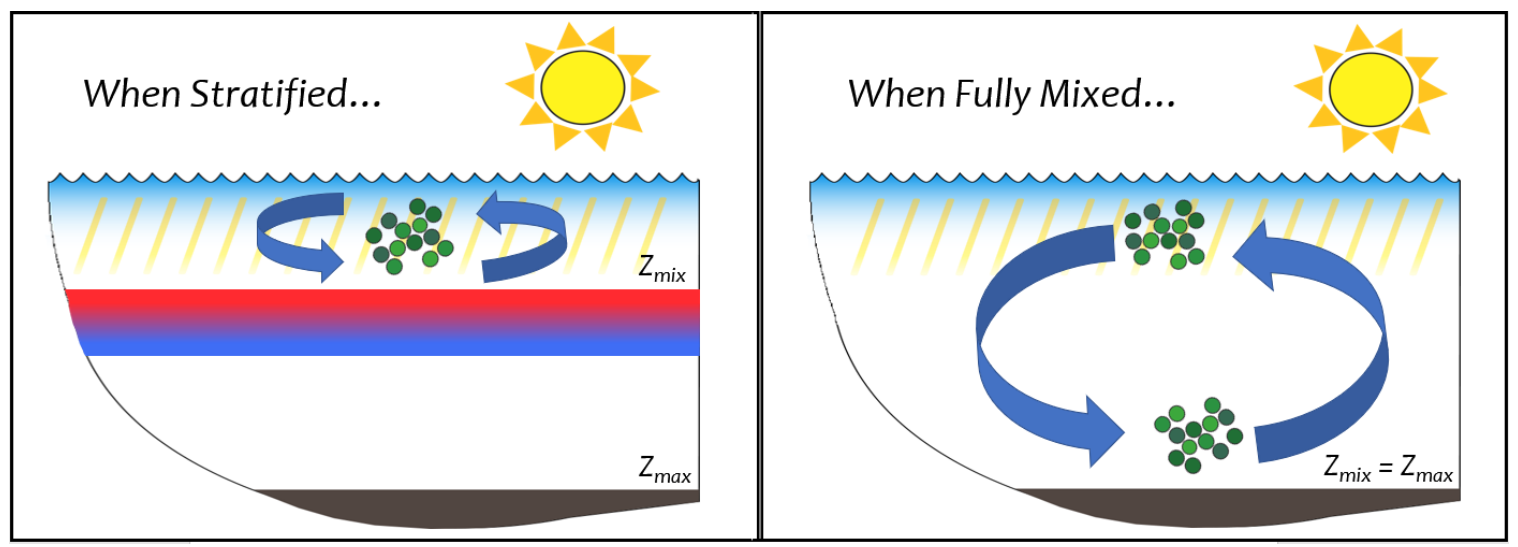

Figure 1.4. An illustration of how thermal stratification influences phytoplankton light availability. When a lake stratifies (left), phytoplankton are limited by the depth of the thermocline (red-blue gradated bar) and are thereby constrained to the surface mixed layer, or the epilimnion. When a lake is isothermal or fully mixed (right), phytoplankton can mix to the bottom of the lake. In this example, phytoplankton in the stratified lake are constantly circulated within the euphotic zone where there is sufficient light for photosynthesis (euphotic depth = yellow diagonal lines). In contrast, phytoplankton in the mixed lake circulate down to depths where there is no light. When the mixing depth is greater than the euphotic depth, phytoplankton experience light deficiency. 


\title{
Chapter 2: \\ The Proximate Light and Nutrient Status of Phytoplankton Communities in Missouri Reservoirs
}

\begin{abstract}
Climate change promotes warmer surface water temperatures in lakes and reservoirs, causing stronger thermal stability and lower hypolimnetic oxygen concentrations. Additionally, increased anthropogenic land-use and precipitation enhance aquatic nutrient and sediment supply to such systems. Together, these effects alter the light and nutrient regimes constraining phytoplankton dynamics. Despite indications that processes sometimes differ between natural lakes and manmade reservoirs, as well as a global uptick in reservoir construction to address continually increasing water demands, reservoir-centric studies remain underrepresented in limnology. With the ubiquitous reservoirs of the agricultural Midwest frequently experiencing eutrophy and hypolimnetic anoxia, such conditions likely represent the future of inland water quality, forewarning how future light and nutrient regimes might influence phytoplankton dynamics in other waters. Contributing to the hotly contested lake-nutrient management debate, I explore the influence of climate, eutrophication, and land-use on the proximate light and nutrient status of phytoplankton in 32 Missouri reservoirs; and I determine if phytoplankton biomass and productivity are constrained by light, phosphorus $(\mathrm{P})$, nitrogen $(\mathrm{N})$, or a combination thereof, across gradients of trophic status and land-use during two contrasting wet and dry summers (2017 and 2018, respectively). Deficiencies of light, P, and $\mathrm{N}$ are assessed via general indicators of water quality and physiological stress, which include mixed layer irradiance, nutrient stoichiometry/debts, photosynthetic efficiency, and photosynthetic-irradiance (P-E) parameters. As expected, high proportions of
\end{abstract}


agricultural land-use correspond to high in-reservoir total $\mathrm{N}$ and $\mathrm{P}$ concentrations. Overall mean epilimnetic nitrate and ammonium concentrations, however, are relatively low ( 2.5 and $0.8 \mu \mathrm{mol} \mathrm{L}{ }^{-1}$, respectively), and yet, P-deficiency is more prominent than either N- or light-deficiency. In 2018, 46\% of samples were P-deficient, with 20\% suggesting alternative deficiency or co-deficiency combinations, and $\sim 33 \%$ indicating sufficiency. Primary productivity demonstrates negative relationships with nutrients, biomass, and turbidity, and positive relationships with light. Thus, productivity is highest in oligotrophic reservoirs where light utilization efficiency is also highest. Overall, phytoplankton biomass and productivity in Missouri reservoirs appear constrained by $\mathrm{P}$ and light, respectively. If these conditions do in fact represent the future of inland waters affected by climate change and eutrophication, both $\mathrm{P}$ and light will be important regulators of phytoplankton dynamics and subsequent water quality.

\section{Introduction}

Inland freshwaters, such as lakes and reservoirs, are viewed as sensitive and valuable sentinels of climatic change (Williamson et al., 2009a). Although they encompass only $3 \%$ of Earth's total surface area (Downing et al., 2006), lakes and reservoirs are intrinsically linked to their terrestrial watersheds, as well as to each other through the global water, nutrient, and energy cycles (Williamson et al., 2008, 2009b). These linkages make inland waters instrumental in understanding how a changing climate impacts patterns and mechanisms in both terrestrial and aquatic ecosystems (Williamson et al., 2008), as well as in the global biogeochemical cycle (Williamson et al., 2009b).

Climate forcing is primarily driven by altered patterns of incident solar radiation, air temperature, and precipitation (Williamson et al., 2009b). With air temperature 
increases projected globally, temperatures in the United States (US) are expected to increase $1.4{ }^{\circ} \mathrm{C}\left(34.5^{\circ} \mathrm{F}\right)$ within the next decade, and 1.6 to $6.6^{\circ} \mathrm{C}\left(34.9\right.$ to $\left.43.9^{\circ} \mathrm{F}\right)$ by the end of the century, with proportionate increases in high temperature extremes (Hayhoe et al., 2018). In connection to the rising air temperatures, worldwide evidence elicits that lakes are warming as well (O’Reilly et al., 2015; Schmid et al., 2014). Substantial shifts in thermal structures and stratification phenology of inland waters have been observed alongside the global increases in air temperature (Woolway et al., 2018). While exact responses vary across systems (Woolway and Merchant, 2017; O’Reilly et al., 2015), long-term incremental increases in global air temperature are promoting earlier, stronger, and extended stratification in (Woolway and Merchant, 2019), as well as widespread deoxygenation of, many inland surface waters (Jane et al., 2021). Warmed waters have a reduced holding capacity for dissolved oxygen (Carpenter et al., 2011), and increased thermal stability reduces vertical mixing potential, further contributing to hypolimnetic anoxia and subsequent internal nutrient loading (Verburg and Hecky, 2009; Wagner and Adrian, 2009). As such, climate-induced alterations to vertical mixing and stratification are expected to change in-lake productivity (O'Reilly et al., 2003; O'Beirne et al., 2017), impacting light and nutrient dynamics through increases in both nutrient limitation and water transparency (Verburg and Hecky, 2009; Williamson et al., 2009b).

Climate and anthropogenic activity mutually contribute to intensifying freshwater eutrophication (Jeppesen et al., 2010) largely by altering biogeochemical cycles (Vitousek et al., 1997). Watershed land-use and regional precipitation patterns affect the supply of nutrients and sediment transported to- and transformed within- lakes and reservoirs (Hayes et al., 2015). Agriculture and urbanization have drastically increased 
proportions of the bioavailable macronutrients, phosphorus $(\mathrm{P})$ and nitrogen $(\mathrm{N})$, on the landscape and within aquatic ecosystems (Bennett et al., 2001; Galloway et al., 2008; Howarth et al., 2012). Watersheds dominated by cropland agriculture typically export nutrients and sediment to lakes and reservoirs at higher rates and concentrations than do undisturbed and/or forested watersheds (Knowlton and Jones, 1995; Knoll et al., 2003). In the central US, more intense rainfall events resulting from climate-induced changes in precipitation are expected to enhance episodic pulses of nutrient and sediment carried to inland waters in surface runoff, while prolonged climate-induced droughts will increase nutrient and water residence times in those same inland waters. These interactions influence aquatic light conditions and increase the quantity of $\mathrm{P}$ and $\mathrm{N}$ available to phytoplankton communities in lakes and reservoirs (Paerl and Scott, 2010).

Variations in light availability as well as $\mathrm{P}$ and $\mathrm{N}$ supply can impact the light and nutrient status of a phytoplankton community where a balance of light and nutrients is needed for photosynthesis, nutrient uptake, and assimilation. As such, deficiencies in light and/or nutrients play a key role in controlling phytoplankton community structure, growth, and productivity (Titman, 1976). The relative importance of $\mathrm{P}$ and $\mathrm{N}$ as controls in freshwater ecosystems, however, has been hotly contested for decades (Elser et al., 1990; Paerl et al., 2016; Schindler, 1977; Schindler et al., 2008). The traditional paradigm designates $\mathrm{P}$ as the single primary macronutrient contributing to phytoplankton growth and productivity in temperate freshwater lakes (Schindler, 1974, 1977; Guildford and Hecky, 2000), but there is evidence that $\mathrm{N}$, too, has a role to play (Morris and Lewis, 1988; Elser et al., 1990; Lewis and Wurtsbaugh, 2008; Abell et al., 2010). Numerous inland studies suggest simultaneous control between P and N (Elser et al., 2007; North et 
al., 2007; Sterner, 2008; Rowland et al., 2019) and/or light, which is another factor vital for phytoplankton growth and production in freshwaters (Millard et al., 1996; Guildford et al., 2000; Knowlton and Jones, 2000; Dubourg et al., 2015).

Lakes and reservoirs were once considered synonymous (Hutchinson, 1957). Contemporary limnology, however, has shown that even though they possess many shared characteristics, reservoir processes sometimes differ from those of natural lakes (Kimmel and Groeger, 1984; Hayes et al., 2017). For example, reservoirs tend to have larger watersheds with greater contributions of nutrients and sediment that promote increased productivity and reduced water clarity (Hayes et al., 2017). Despite potential divergences, reservoir-centric studies remain underrepresented relative to natural lake studies in limnology. As global reservoir and dam construction intensify to meet continually growing water demands (Zarfl et al., 2014), it may become increasingly important that we equally understand the processes of both lakes and reservoirs, particularly as they relate to climate change and eutrophication. Being the primary lentic habitat in the central US (Thornton, 1990), the ubiquitous midwestern reservoir may serve as climate analogs for future aquatic ecosystems. High eutrophication rates in the agriculturally dominated Midwest (Mitsch et al., 2001; Jones et al., 2008a) make these reservoirs precursors of future surface water quality, as $\sim 94 \%$ of reservoirs in the study region are considered eutrophied (Jones et al., 2008b). Moreover, since midwestern reservoirs regularly experience hypolimnetic anoxia during summer stratification (Jones et al., 2011), they may also forewarn how future light and nutrient regimes will affect phytoplankton biomass and primary productivity via internal nutrient cycling. 
Here, I explore influences of climate, eutrophication, and land-use on the proximate light and nutrient status of phytoplankton communities in 32 midwestern reservoirs. By evaluating general indicators of water quality and proximate physiological deficiencies in the phytoplankton communities (Table 2.1), I determine if chlorophyll- $a$ (chla), as a proxy for phytoplankton biomass, and primary productivity are constrained by light, $\mathrm{P}, \mathrm{N}$, or a combination thereof. I explore these constraints across gradients of trophic status and land-use, which reflect gradients in nutrient regimes as well as ambient light environments, during the climatically contrasting summers of 2017 (wet) and 2018 (dry). Decades of previous work on midwestern reservoirs utilized Liebig's Law of the Minimum (Von Liebig, 1840) to identify important empirical relationships between concentrations of chla, and $\mathrm{P}\left(r^{2}=0.83\right)$ and $\mathrm{N}\left(r^{2}=0.78\right.$; Jones et al., 2008b). This study applies the concept of Blackman limitation (Blackman, 1905), or rate limitation, to describe the condition(s) by which rates of phytoplankton growth, productivity, and photosynthetic responses are constrained by resource availability. I describe limitation in terms of proximate deficiency, which considers the phytoplankton communities' local or instantaneous responses to constraining resources such as light or nutrients (Tyrrell, 1999). I also invoke the term co-deficiency to describe simultaneous constraint by more than one resource (Saito et al., 2008), whether that be by light and a nutrient or by multiple nutrients (Healey, 1985). Building off previously elucidated relationships (Jones et al., 2008b), I predict that, regardless of climatic year, light and both $\mathrm{P}$ and $\mathrm{N}$ will be prevalent proximate constraints on the phytoplankton. Light-deficiency will predominate eutrophic and hypereutrophic reservoirs, nutrient deficiency in oligotrophic. Phytoplankton biomass and productivity will peak in hypereutrophic reservoirs. 


\section{Materials and methods}

\section{Study site description}

Through the Statewide Lake Assessment Program (SLAP), 32 mid-continental, mid-latitude manmade reservoirs were sampled during the summers of 2017 and 2018. The reservoirs are located throughout Missouri, a midwestern state in the central US (Figure 2.1), which is characterized by five main physiographic regions (Thom and Wilson, 1980). Missouri's physiographic regions, based upon the state's underlying geology, correspond generally to a gradient in dominant land-use (i.e., agriculture dominates the north, forests dominate the south; Jones and Knowlton, 1993). Spanning four of the five physiographic regions, the study reservoirs reflect differences in land-use and subsequently, trophic status (Jones et al., 2008a, 2008b) with 5 being oligotrophic reservoirs, 13 mesotrophic, 12 eutrophic, and 2 hypereutrophic. Trophic classification is based upon mean total phosphorus (TP) concentrations during the two-summer sampling window (criteria from Jones et al., 2008b). The reservoirs were chosen to represent a range in nutrient concentrations, light conditions, phytoplankton biomass, reservoir morphology, and watershed land-use (Tables 2.2, 2.3). All have warm monomictic mixing regimes, except for Lake Niangua, which is a shallow, polymictic reservoir heavily influenced by hydropower activity (Table 1.1).

Watershed land-use/land-cover (LULC) data was derived from the 2016 National Land Cover Database, a product of the Multi-Resolution Land Characteristics Consortium (NLCD, 2016). I selected the appropriate watershed boundaries from the Missouri 2019 Lake Numeric Nutrient Criteria Watersheds dataset developed by the Missouri Department of Natural Resources (MoDNR; MoDNR, 2019). Watersheds not included in this dataset were manually digitized using flow direction and flow 
accumulation grids generated from 10-meter resolution digital elevation models in ESRI ArcGIS 10.5. I zonally tabulated LULC for each watershed in ArcGIS, and calculated LULC as percent developed, barren, forest, rangeland, wetland, and agriculture which also contained pasture and cropland subclasses. Watersheds were categorically generalized as either agriculture (pasture or cropland), forest, or mixed based on the dominant ( $>50 \%)$ LULC. When a watershed contained $>50 \%$ agriculture, the watershed was specified as either ag-pasture or ag-crop to denote the subclass with the greater contribution. A mixed classification was assigned to any watershed with no single LULC greater than $50 \%$. Barren ( 0 to $2 \%$ ), rangeland (0 to $10 \%$ ), wetland (0 to $3 \%$ ), and developed ( 0 to $10 \%$, except for 4 watersheds with 22 to $44 \%$ ) were considered minor contributions to overall LULC and were not included as unique LULC categories.

Each year, during a period of established thermal stratification, SLAP sampled the reservoirs 3 to 4 times between mid-May and mid-September. Throughout these months, Missouri's climate was characterized by the Palmer Drought Severity Index (PDSI) to be mid-range to very moist in 2017 (statewide monthly average range for April through September: -0.88 to 2.36 ) and mid-range to severe-drought in 2018 (statewide monthly average range for April through September -2.07 to 0.55; NOAA, 2019). Indicators of water quality and nutrient status were assessed on 29 reservoirs in 2017, followed by a more in-depth collection of water chemistry and phytoplankton physiology on 27 reservoirs in 2018. Most reservoirs $(n=24)$ were sampled in both years, with overlapping parameters allowing the influence of climate (i.e., wet versus dry) on phytoplankton light and nutrient status to be explored (Table 2.3). 


\section{Field sampling}

Sampling occurred at maximum volume and depth near the dam of each reservoir. Secchi transparency depths were recorded. Photosynthetically active radiation (PAR) profiles were collected in 0.25 -meter increments using a cosine corrected underwater quantum sensor (LI-192, Li-Cor Biosciences, Lincoln, Nebraska, US). The vertical attenuation coefficient $\left(\mathrm{K}_{\mathrm{d}}\right)$ was calculated from the PAR profiles using the linear regression of the natural logarithm of irradiance to depth (Kirk, 2011). A Yellow Springs Instruments EXO3 multi-parameter sonde (Yellow Springs, Ohio, US) was deployed to collect depth profiles (0.001-meter resolution) of temperature $\left(0.001{ }^{\circ} \mathrm{C}\right.$ resolution with an accuracy of $\pm 0.01^{\circ} \mathrm{C}$ ) and dissolved oxygen (DO) measured with an optical sensor (0.01 $\mathrm{mg} \mathrm{L}^{-1}$ resolution with an accuracy of $\left.\pm 0.1 \mathrm{mg} \mathrm{L}^{-1}\right)$. Integrated epilimnetic whole water samples were collected via peristaltic pump from the surface to one-meter above the thermocline, where thermoclines were defined in the field by vertical temperature gradients $\geq 1.0^{\circ} \mathrm{C} \mathrm{m}^{-1}$. Discrete hypolimnetic whole water samples were collected via Van Dorn sampler from 1-meter off bottom. During isothermal conditions (e.g., polymictic Lake Niangua), a single integrated sample was taken from the surface to onemeter off bottom via peristaltic pump. All water samples were collected into acid-washed high-density polyethylene (HDPE) containers, placed in coolers, and returned to the University of Missouri Limnology Laboratory within 12-hours of collection where they were then processed, stored, and later analyzed.

\section{Laboratory analyses and data processing}

\section{Physical parameters}

Maximum depth $\left(\mathrm{Z}_{\max }\right)$ was based on records of dam height provided by MoDNR (MoDNR, 2018). Water column mixing depth $\left(\mathrm{Z}_{\mathrm{mix}}\right)$ was determined using the 
'rLakeAnalyzer' R-package (Winslow et al., 2017) and reported as the depth from surface to the top of the thermocline. Based on sampling date and site geography (i.e., latitude, longitude, elevation), daily incident irradiance was modeled in 1-minute increments and scaled to PAR ( $\mu$ mol photons $\mathrm{m}^{-2} \mathrm{~s}^{-1}$ ) using the 'phytotools' R-package (Silsbe and Malkin, 2015). Mean daily incident irradiance $\left(\overline{\mathrm{E}}_{0}\right)$, or the 24-hour average, was then calculated assuming cloud-free conditions. Following Guildford et al. (2000), I derived mean daily mixed layer irradiance $\left(\overline{\mathrm{E}}_{24}\right)$ from $\mathrm{K}_{\mathrm{d}}, \mathrm{Z}_{\mathrm{mix}}$, and $\overline{\mathrm{E}}_{0}$ :

$$
\overline{\mathrm{E}}_{24}=\overline{\mathrm{E}}_{0} \times\left(1-\exp \left(-1 \times \mathrm{K}_{d} \times \mathrm{Z}_{\text {mix }}\right)\right) \times\left(\mathrm{K}_{d} \times \mathrm{Z}_{m i x}\right)^{-1}
$$

where $\overline{\mathrm{E}}_{24}$ describes the amount of light experienced in the mixed layer by the phytoplankton over a 24-hour period.

\section{Chemical parameters}

Water samples were processed and analyzed to measure total nutrients as TP and total nitrogen (TN); dissolved nutrients as total dissolved phosphorus (TDP), total dissolved nitrogen (TDN), dissolved reactive phosphorus (DRP), ammonium $\left(\mathrm{NH}_{4}{ }^{+}\right)$, nitrate $\left(\mathrm{NO}_{3}{ }^{-}\right)$, dissolved organic carbon (DOC); and particulate nutrients as particulate phosphorus (PP) and particulate nitrogen (PN). Whole water aliquots for TP and TN were pipetted directly into glass test tubes and refrigerated. All dissolved nutrient samples were filtered through glass-fiber filters (GFF, $0.7 \mu \mathrm{m}$ pore). Like TP and TN, filtrate for TDP and TDN were refrigerated in glass test tubes, while filtrate for DRP, $\mathrm{NH}_{4}{ }^{+}, \mathrm{NO}_{3}{ }^{-}$and DOC were frozen in acid-washed HDPE bottles. The filters used to process DOC filtrate, which also captured PP and PN, were pre-combusted at $550{ }^{\circ} \mathrm{C}$ for 4 hours. PP samples were placed in glass test tubes. PN samples were dried at 55 to $60{ }^{\circ} \mathrm{C}$ and stored with desiccant. 
All P analytes were analyzed spectrophotometrically using an ascorbic acid colorimetric method (APHA, 2017; 4500-P E). TP, TDP, and DRP were analyzed in triplicate, PP in duplicate. Prior to analysis, TP, TDP, and PP were digested according to an ammonium peroxydisulfate method (APHA, 2017; 4500-P B). DRP was analyzed without digestion. Detection limits for all $\mathrm{P}$ analyses are $0.03 \mu \mathrm{mol} \mathrm{L}^{-1}$.

TN and TDN were analyzed in triplicate using the second derivative spectroscopy method (Crumpton et al., 1992). $\mathrm{NH}_{4}{ }^{+}$and $\mathrm{NO}_{3}{ }^{-}$were analyzed in duplicate on a Lachat QuikChem Flow Injection Analyzer (Hach, Loveland, Colorado, US) using Lachat method 10-107-06-1-K for $\mathrm{NH}_{4}{ }^{+}$and a slightly modified Lachat method for $\mathrm{NO}_{3}^{-}$(10107-04-1-B/C). Detection limits were $2.50 \mu \mathrm{mol} \mathrm{L}^{-1}$ for TN and TDN, $0.71 \mu \mathrm{mol} \mathrm{L}^{-1}$ for $\mathrm{NH}_{4}{ }^{+}$, and $0.36 \mu \mathrm{mol} \mathrm{L}-1$ for $\mathrm{NO}_{3}{ }^{-}$. Dissolved organic $\mathrm{N}(\mathrm{DON})$ was calculated by difference from $\mathrm{TDN}, \mathrm{NH}_{4}{ }^{+}$, and $\mathrm{NO}_{3}{ }^{-}$. PN was analyzed at the University of California (UC), Davis' Stable Isotope Facility using an Elementar Vario EL Cube or Micro Cube elemental analyzer (Elementar Analysensysteme GmbH, Hanau, Germany) interfaced to a PDZ Europa 20-20 isotope ratio mass spectrometer (Sercon Ltd., Cheshire, United Kingdom) with a detection limit of $0.7 \mu \mathrm{mol}$ N.

DOC was analyzed in duplicate using a total organic carbon analyzer (TOCVCPH, Shimadzu Scientific Instruments, Columbia, Maryland, US) and a combustioninfrared method (APHA, 2017; 5310 B) with a detection limit of $16.7 \mu \mathrm{mol} \mathrm{L}^{-1}$.

Seston was collected on Whatman 934-AH filters ( $1.5 \mu \mathrm{m}$ pore) in duplicate and analyzed for total suspended solids (TSS) using a standard tared-weight method (APHA, 2017; 2540-D E) with a detection limit of $0.1 \mathrm{mg} \mathrm{L}^{-1}$. Oven-dried filters $\left(105^{\circ} \mathrm{C}\right)$ were weighed to determine TSS, then placed in a muffle furnace at $550{ }^{\circ} \mathrm{C}$ for 20 minutes to 
burn off particulate organic matter (POM). Filters were weighed again to determine particulate inorganic matter (PIM). POM was calculated by difference from TSS and PIM.

\section{Biological parameters}

Chla, used as a proxy for phytoplankton biomass, was collected by passing whole water through $0.7 \mu \mathrm{m}$ GFF filters. The filters were immediately frozen and stored with desiccant. After ethanol extraction and pheophytin acid-correction, chla concentrations were determined fluorometrically with a Turner Design Fluorometer (TD700, San Jose, California, US; Knowlton, 1984; Sartory and Grobbelaar, 1984). The detection limit for chla was $0.09 \mu \mathrm{g} \mathrm{L}{ }^{-1}$.

Particulate organic carbon (POC), another proxy for phytoplankton biomass, was collected on pre-combusted GFF filters $(0.7 \mu \mathrm{m}$ pore). Inorganic carbonates were removed from samples following a modified fumigation method based on Brodie et al. (2011) wherein filters were continuously subjected to concentrated $37 \%$ hydrochloric acid fumes for 4 hours. After fumigation, samples were dried at 55 to $60{ }^{\circ} \mathrm{C}$ and stored with desiccant. POC was analyzed at the UC Davis Stable Isotope Facility using an Elementar Vario EL Cube or Micro Cube elemental analyzer (Elementar Analysensysteme GmbH, Hanau, Germany) interfaced to a PDZ Europa 20-20 isotope ratio mass spectrometer (Sercon Ltd., Cheshire, United Kingdom) with a detection limit of $1.7 \mu \mathrm{mol}$ C.

The quantitative filter technique (Tassan and Ferrari, 1995) was used to determine the areal pigment absorption coefficient $\left(\mathrm{a}_{\phi}\right)$, which provides an estimate of crosssectional light absorption via chla for photochemistry and photosynthesis. Briefly, whole water was passed through GFF filters ( $0.7 \mu \mathrm{m}$ pore) which were immediately placed in foil-wrapped petri dishes to limit light exposure and frozen. Retained particulate 
absorbance was measured before and after depigmentation via sodium hypochlorite solution (4 to $5 \%$ active chlorine) on a scanning spectrophotometer (Agilent Cary60 UV/VIS, Santa Clara, California, US) in $1 \mathrm{~nm}$ increments from wavelengths 350 to 750 nm. I calculated $\mathrm{a}_{\phi}$ based on Silsbe et al. (2012):

$$
\mathrm{a}_{\phi}=2.303 \times\left(\mathrm{A}_{P}-\mathrm{A}_{N A P}\right) \times \beta^{-1} \times\left(\mathrm{V}_{f} / \mathrm{A}_{f}\right)^{-1}
$$

where $A_{P}$ and $A_{N A P}$ are sestonic absorption before and after depigmentation, respectively; $\beta$, equaling 2 , is the path-length amplification factor adjusting for absorption differences between filter and water; $\mathrm{V}_{\mathrm{f}} / \mathrm{A}_{\mathrm{f}}$ is the ratio of filter volume to circumferential area of filtered particulates.

\section{Light and nutrient status indicators}

Phytoplankton light and nutrient status were assessed using a suite of deficiency indicators, which included $\overline{\mathrm{E}}_{24} ; \overline{\mathrm{E}}_{24} / \mathrm{E}_{\mathrm{k}}$; POC:chla; stoichiometric nutrient ratios (TN:TP, POC:PP, PN:PP, POC:PN); P-, $\mathrm{NH}_{4}{ }^{+}-\mathrm{N}$, and $\mathrm{NO}_{3}{ }^{-}-\mathrm{N}$ debts; and photosynthetic efficiency experiments. Many of these indicators have previously established, literature-supported thresholds for estimating proximate deficiencies of light, $\mathrm{P}$, and $\mathrm{N}$ (Table 2.4; Guildford and Hecky, 2000; Healey and Hendzel, 1979). Thresholds based on Healey and Hendzel (1979) were applied to measurements of $\mathrm{P}_{\text {and }} \mathrm{NH}_{4}{ }^{+}-\mathrm{N}$ debt, as well as to POC:PP, PN:PP, POC:PN, and POC:chla. These thresholds were developed in laboratory culture experiments (Healey and Hendzel, 1979b), but have been successfully applied and compared across a diverse range of lake systems worldwide (e.g., Dubourg et al., 2015; Guildford et al., 2000; North et al., 2008). Sometimes, individual indicators vary due to influences from species composition and non-algal particulate matter (Hecky et al., 
1993). Implementing a suite of indicators, however, strengthens assessment confidence, especially when agreement occurs between $\geq 2$ indicators (Hecky and Kilham, 1988).

\section{Light-deficiency}

My light-deficiency thresholds $\left(\overline{\mathrm{E}}_{24}, \overline{\mathrm{E}}_{24} / \mathrm{E}_{\mathrm{k}}\right)$ were developed, in part, on a turbid Canadian reservoir where the onset of P-deficiency occurred when $\bar{E}_{24}$ was between 41.7 and $58.3 \mu \mathrm{mol}$ photon $\mathrm{m}^{-2} \mathrm{~s}^{-1}$ (Hecky and Guildford, 1984). Knowlton and Jones (1996), who focused on the turbid Missouri reservoir, Mark Twain, as well as Millard et al. (1996), who worked on Lake Ontario, suggested that co-limitation by light and nutrients could occur at irradiances $\leq 69.4 \mu \mathrm{mol}$ photon $\mathrm{m}^{-2} \mathrm{~s}^{-1}$. This irradiance threshold for codeficiency has been supported in other applications of shallow, turbid inland waters (Schallenberg and Burns, 2004). I have, therefore, adopted an $\bar{E}_{24}$ threshold of $69.4 \mu \mathrm{mol}$

photon $\mathrm{m}^{-2} \mathrm{~s}^{-1}$ to represent moderate light-deficiency and the Hecky and Guildford (1984) threshold of 41.7 to represent extreme light-deficiency of the phytoplankton (Table 2.4).

I also applied the ratio of $\overline{\mathrm{E}}_{24} / \mathrm{E}_{\mathrm{k}}$ to assess light-deficiency, where $\overline{\mathrm{E}}_{24}$ represents mean daily mixed layer irradiance and $\mathrm{E}_{\mathrm{k}}$, the light curve (LC)-derived light saturation parameter. With a light-deficiency threshold of 1 (Table 2.4), when $\bar{E}_{24}>E_{k}$, there is theoretically enough light for unhindered photosynthesis; alternatively, when $\overline{\mathrm{E}}_{24}<\mathrm{E}_{\mathrm{k}}$, phytoplankton may experience light-deficient conditions (Hecky and Guildford, 1984).

\section{Nutrient-deficiency}

In addition to the stoichiometric ratios, nutrient debt experiments based on Healey (1977) were conducted to assess nutrient deficiency. In the laboratory, 1-liter subsamples of epilimnetic whole water were placed in acid-washed cubitainers and spiked with $\sim 5 \mu \mathrm{M}$ of $\mathrm{KH}_{2} \mathrm{PO}_{4}, \mathrm{NH}_{4} \mathrm{Cl}$, or $\mathrm{KNO}_{3}$. The four treatments (control receiving no nutrient addition, 
$+\mathrm{P},+\mathrm{NH}_{4}{ }^{+},+\mathrm{NO}_{3}{ }^{-}$) were incubated in an environmental chamber for 18 to 24 hours under darkened conditions ( 0.001 to $0.008 \mu \mathrm{mol}$ photons $\left.\mathrm{m}^{-2} \mathrm{~s}^{-1}\right)$ at average ambient epilimnetic water temperatures $\left(23\right.$ to $30{ }^{\circ} \mathrm{C}$ ). $\mathrm{DRP}, \mathrm{NH}_{4}{ }^{+}$, and $\mathrm{NO}_{3}{ }^{-}$samples were collected from the $+\mathrm{P},+\mathrm{NH}_{4}{ }^{+}$, and $+\mathrm{NO}_{3}{ }^{-}$treatments, respectively, before and after incubation. DRP, $\mathrm{NH}_{4}{ }^{+}$, and $\mathrm{NO}_{3}{ }^{-}$samples were also collected from each control treatment. $\mathrm{P}$ debt, $\mathrm{NH}_{4}{ }^{+}-\mathrm{N}$ debt, and $\mathrm{NO}_{3}{ }^{-}-\mathrm{N}$ debt, as indicators of nutrient uptake, were calculated as the change in nutrient concentration per unit of chla before and after incubation.

Additional photosynthetic efficiency experiments were performed to complement the nutrient debts. These experiments assess the phytoplanktons' physiological response to nutrient additions and can provide additional evidence of nutrient deficiency. The nutrient additions and incubations for the photosynthetic efficiency experiments, which also included $+\mathrm{P}+\mathrm{NH}_{4}{ }^{+}$treatments, were otherwise identical to those described above for the debt experiments. Following incubation, maximum quantum yields of photosystem II

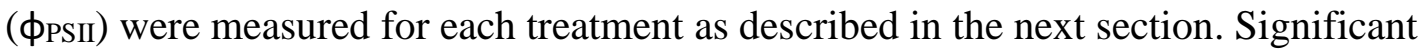
increases in $\phi_{\mathrm{PSII}}$ from control to a nutrient treatment suggests deficiency of that nutrient.

\section{Photosynthetic-Irradiance (P-E) parameters}

I measured $\phi_{\text {PSII }}$ and rapid LCs to evaluate the phytoplanktons' capability to absorb and utilize light energy for photosynthesis via PSII. The empirical optimum value of $\sim 0.65$ (Kolber and Falkowski, 1993) was used to assess overall phytoplankton stress. Following a 30-minute dark adaptation period, both $\$$ PSII and LCs were measured from whole water samples in triplicate with a Water-Pulse Amplitude Modulated (WaterPAM) Fluorometer (Heinz Walz GmbH, Effeltrich, Germany) interfaced to WinControl software (version 3.26). I corrected for non-algal background fluorescence with sample 
filtrate that had been passed through a $0.2 \mu \mathrm{m}$ pore GFF filter. LCs were measured in nine 1-minute intervals wherein light intensity steadily increased from 21 to $1,420 \mu \mathrm{mol}$ photons $\mathrm{m}^{-2} \mathrm{~s}^{-1}$. Photosynthetic-irradiance (P-E) parameters describing light utilization efficiency $(\alpha)$ and light saturation $\left(E_{k}\right)$ were derived by fitting each LC to a normalized irradiance model (Webb et al., 1974) in the 'phytotools' R-package (Silsbe and Malkin, 2015). The maximum relative electron transport rate through PSII ( $\left.\mathrm{rETR}_{\max }\right)$ was then calculated as the product of $\alpha$ and $\mathrm{E}_{\mathrm{k}}$. For comparison across systems, $\alpha$ and $\mathrm{E}_{\mathrm{k}}$ were normalized to chla $\left(\alpha^{\mathrm{B}}, \mathrm{E}_{\mathrm{k}}^{\mathrm{B}}\right)$.

\section{Gross primary productivity}

Areal rates of gross primary productivity (GPP) for the phytoplankton communities were estimated based on the Fee (1990) primary production model. With the 'phytoprod' function of the 'phytotools' R-package (Silsbe and Malkin, 2015), I calculated GPP from $\alpha, \mathrm{E}_{\mathrm{k}}, \operatorname{chl} a, \mathrm{a}_{\phi}, \mathrm{K}_{\mathrm{d}}$, and $\overline{\mathrm{E}}_{0}$. Final units of $\mathrm{mmol} \mathrm{O}_{2} \mathrm{~m}^{-2} \mathrm{day}^{-1}$ were reached by multiplying the 'phytoprod' output by the molecular weight of $\mathrm{O}_{2}$ as well as the quantum yield of $\mathrm{O}_{2}$ evolution, which $\mathrm{I}$ assume is $0.25 \mathrm{~mol} \mathrm{O}_{2}[\mathrm{~mol} \mathrm{e}]^{-1}$. For comparison across systems, GPP was normalized to $\operatorname{chl} a\left(\mathrm{GPP}^{\mathrm{B}}\right)$.

I conducted a survey of relevant lake and reservoir studies to identify existing GPP values in the literature. Mean areal rates were collected directly from tables and text, or estimated by digitizing figures with the web-based software, WebPlotDigitizer (Rohatgi, 2019). Rates reported in units of carbon were converted to oxygen using the assumed photosynthetic quotient of 1.2. Where possible, volumetric rates were converted to areal rates using photic depth $\left(Z_{\mathrm{eu}}\right)$ or double the Secchi depth (proxy for $Z_{\mathrm{eu}}$ ).

Literature GPP rates were also normalized to chl $a$ when possible. 


\section{Statistical analyses}

All data were assessed for normality using the Shapiro-Wilk test. If I accepted the null hypothesis of the Shapiro-Wilk test $(p<0.05)$, data were transformed accordingly (e.g., common log, square root, reciprocal), whenever possible, to achieve normality prior to any statistical analysis. If I rejected the null hypothesis of the Shapiro-Wilk test ( $p>$ 0.05), data were assumed normal and no transformations applied.

To explore relationships between continuous parametric variables, I used Pearson's correlation coefficients $(r)$. To assess differences across temporal gradients (between years and/or sampling events), as well as across the trophic and land-use gradients for each reservoir, I ran linear mixed effect (LME) models with the 'nlme' Rpackage (Pinheiro et al., 2018). Parameters collected in both 2017 and 2018 were analyzed using the following model structure:

$$
\begin{gathered}
Y_{i}=\beta_{0}+\beta_{1} \text { Year }+\beta_{2} \text { SamplingEvent }+\beta_{3} \text { Year*SamplingEvent }+ \\
\beta_{4} \text { TrophicStatus }+\beta_{5} \text { LandUse }+ \text { Reservoir }+\varepsilon_{i}
\end{gathered}
$$

where $Y_{i}$ was the normally-distributed parameter $Y$ at reservoir $i$, while Year (2017, 2018), SamplingEvent (1 to 4), TrophicStatus (oligotrophic to hypereutrophic), and LandUse (forested, mixed, ag-pasture/crop) were fixed effects. Reservoir was a random effect that created a new baseline for each sampling location. Random effects and the residual error were assumed to be drawn from a normal distribution. A simplified model lacking Year and the interaction term (Year*SamplingEvent) was applied for parameters collected in a single year.

Each LME was subjected to an analysis of variance (ANOVA). If the ANOVA identified statistically significant effects in the LME $(p<0.05)$, I conducted a Tukey's Honest Significant Difference post-hoc test to compare factor levels for significance. All 
post-hoc results are indicated by lowercase letters on figures and in tables, unless otherwise noted. Different lowercase letters indicate significant differences between factor levels. Letters are ordered alphabetically and indicate trend direction where, for example, "a" represents the lowest mean and "d" represents the highest mean.

To generally assess significant differences across sampling events, trophic status, and watershed land-use for the nutrient debt experiments, I conducted non-parametric Kruskal Wallis one-way ANOVAs. If an ANOVA tested significant $(p<0.05)$, a Dunn's multiple comparisons post-hoc test was implemented to identify significant differences between factor levels. I also used one-way ANOVAs to test for significant differences among treatments for each $\phi_{\text {PSII }}$ experiment. If significant $(p<0.05)$, a 2-sided Dunnetttest (pairwise comparison) was conducted to identify significant positive responses to nutrient addition treatments relative to control treatments.

\section{Results}

The Plains of northern Missouri lie in $70 \%$ agriculture, while the Ozarks of the south are $60 \%$ forested (Figure 2.1; NLCD, 2016). Well-characterized by trophic status (Jones et al., 2008b), TP concentrations in Missouri reservoirs are significantly correlated with percent forest $(p<0.001, r=-0.65)$, ag-crop $(p<0.001, r=0.65)$, and ag-pasture $(p$ $<0.001, r=0.31)$. As percent forest increases, lower TP concentrations and more oligoand mesotrophic systems are observed. Alternatively, as percent agriculture increases, I observe higher TP concentrations and more eutro- and hypereutrophic systems.

\section{Physical parameters}

Missouri reservoirs are relatively shallow. $Z_{\max }$ in the study reservoirs range from 4.6 to 49.1 meters (Table 2.2), with $63 \%$ shallower than 20 meters and only $9 \%$ deeper 
than 40 meters. Mean $Z_{\text {mix }}$ is $\sim 27$ to $30 \%$ of the water column in oligo-, meso-, and eutrophic reservoirs, and $51 \%$ in hypereutrophic reservoirs. There is a significant negative correlation between $\mathrm{Z}_{\max }$ and trophic status $(p<0.001, r=-0.47)$, wherein shallower reservoirs are hypereutrophic and deeper reservoirs are oligotrophic. Similarly, $\mathrm{Z}_{\mathrm{mix}}$ is significantly shallower in eutrophic systems than oligotrophic (Table 2.5). Regardless of trophic status, hypolimnetic anoxia is common in Missouri reservoirs during summer stratification (Jones et al., 2011). I observed this during both summers, wherein every warm monomictic reservoir $(n=31)$ had hypolimnions with DO concentrations $<0.5 \mathrm{mg} \mathrm{L}^{-1}$. Water columns in these reservoirs were 27 to $87 \%$ anoxic, with the mean water column being $\sim 65 \%$ anoxic.

Reservoir light environments differed significantly from 2017 to 2018, although $\mathrm{Z}_{\mathrm{mix}}$ did not. Water clarity was highest in oligotrophic reservoirs in the drier year (2018), although Secchi depths were significantly deeper, $\mathrm{K}_{\mathrm{d}}$ significantly smaller, and TSS significantly lower across all reservoirs in 2018. In oligotrophic systems, regardless of year, Secchi depths were $\sim 6$ to $7 \mathrm{x}$ deeper and $\mathrm{K}_{\mathrm{d}} \sim 73$ to $82 \%$ smaller than in hypereutrophic systems. From 2017 to 2018, TSS decreased $25 \%$ in oligo- and $10 \%$ in both meso- and eutrophic reservoirs. These relationships fall apart, however, in hypereutrophic systems where I saw no significant differences in Secchi, $\mathrm{K}_{\mathrm{d}}$, nor TSS from 2017 to 2018 (Table 2.5).

\section{Light-deficiency}

For many reservoirs, light-deficiency was not prominent during the summers of 2017 and 2018. $\overline{\mathrm{E}}_{24}$ trophic means ranged from 65.9 to $227.3 \mu \mathrm{mol}$ photons $\mathrm{m}^{-2} \mathrm{~s}^{-1}$, and, while there were no significant differences between trophic status or year, $\overline{\mathrm{E}}_{24}$ was 
generally lower during the wetter year and decreased with increasing eutrophication. Only $6 \%$ (2017) and $3 \%$ (2018) of individual samples fell below the threshold for extreme light-deficiency $\left(41.7 \mu \mathrm{mol}\right.$ photons $\mathrm{m}^{-2} \mathrm{~s}^{-1}$; Figure 2.2). No reservoir with samples below this threshold in 2017 fell below it again in 2018. The mean $\overline{\mathrm{E}}_{24}$ for the 2017 hypereutrophic reservoirs $\left(65.9 \mu \mathrm{mol}\right.$ photons $\left.\mathrm{m}^{-2} \mathrm{~s}^{-1}\right)$ was the only trophic mean below the moderate light-deficiency threshold ( $69.4 \mu \mathrm{mol}$ photons $\mathrm{m}^{-2} \mathrm{~s}^{-1}$; Table 2.3). Approximately $27 \%$ of individual samples were below the moderate threshold in 2017 compared to $\sim 19 \%$ in 2018 (Figure 2.2). Eight of the nine reservoirs with samples falling below the moderate light-deficiency threshold in 2018 also had at least one sample below the threshold in the prior summer. Unlike trophic status or year, $\overline{\mathrm{E}}_{24}$ did vary significantly between sampling event and land-use. $\overline{\mathrm{E}}_{24}$ was significantly higher during the May/June sampling event and in forested watersheds, than during the August/September sampling event or in ag-pasture watersheds (Table 2.5).

With consideration to the light saturation parameter $\left(\mathrm{E}_{\mathrm{k}}\right)$, the $\overline{\mathrm{E}}_{24} / \mathrm{E}_{\mathrm{k}}$ ratio indicates, in contrast, that light-deficiency dominated in these systems. Means for $\overline{\mathrm{E}}_{24} / \mathrm{E}_{\mathrm{k}}$ across the trophic groupings ranged from 0.28 to 0.80 and were below the $\bar{E}_{24} / \mathrm{E}_{k}$ light-deficiency threshold (Table 2.3). Only calculated for the reservoirs sampled in 2018, it indicates that the demand for light exceeded the supply $\left(\overline{\mathrm{E}}_{24} / \mathrm{E}_{\mathrm{k}}<1\right)$ for $92 \%$ of samples across all reservoirs; $75 \%$ in oligo-, $91 \%$ in meso-, $97 \%$ in eutro-, and $100 \%$ in hypereutrophic reservoirs. All 29 reservoirs, regardless of trophic status, were light-deficient by this metric at least once. All individual samples below the $\overline{\mathrm{E}}_{24}$ moderate deficiency threshold in 2018 were also deemed light-deficient by $\overline{\mathrm{E}}_{24} / \mathrm{E}_{\mathrm{k}}$. There was, however, no significant correlation between $\overline{\mathrm{E}}_{24}$ and $\mathrm{E}_{\mathrm{k}}(p=0.220, r=0.13)$. 
No evidence of photoacclimation (MacIntyre et al., 2002) was found to support widespread light-deficiency. While POC:chl $a$ demonstrated a positive linear relationship in 2017 ( $p<0.001, r=0.78$ ) as well as $2018(p<0.001, r=0.90)$, chl $a$ was consistently present in lesser amounts relative to POC. Because the phytoplankton did not upregulate their light-harvesting pigments to compensate for lesser light conditions, I conclude that the phytoplankton were largely light-sufficient. Furthermore, peak POC:chl $a$ ratios occurred above the deficiency threshold, when $\overline{\mathrm{E}}_{24}$ was $\sim 50$ to $150 \mu \mathrm{mol}$ photons $\mathrm{m}^{-2} \mathrm{~s}^{-1}$, indicating nutrient deficiency instead (Table 2.4). Results from individual samples support this, with more than $96 \%$ of samples exceeding the threshold each summer.

\section{Chemical parameters}

Nutrient concentrations were positively related to trophic status for most forms of P and N (TDP, DRP, PP; TN, TDN, DON, PN). Climatic variation in TP, DOC, and the particulate nutrients $(\mathrm{PP}, \mathrm{PN})$ demonstrate significantly higher trophic means during the wetter year (Table 2.5), barring hypereutrophic reservoirs where the relationship weakened (Table 2.3). Only DOC showed a significant decrease in concentration from the beginning of summer to the end (as estimated by sampling event; Table 2.5).

Across all forms of P (TP, TDP, DRP, PP), epilimnetic concentrations generally increased with increasing trophic status. Mean epilimnetic TP concentrations ranged from $0.23 \mu \mathrm{mol} \mathrm{L}{ }^{-1}$ in oligotrophic to $3.21 \mu \mathrm{mol} \mathrm{L}{ }^{-1} 1$ in hypereutrophic reservoirs. On average, across the trophic gradient, $\sim 60$ to $85 \%$ of epilimnetic TP was present in the form of PP. Of the TDP fraction of TP, 20 to $65 \%$ existed as bioavailable DRP, on average, with oligo- and hypereutrophic reservoirs at the lower and upper ends, respectively (Table 2.3). 
Although slightly less conspicuous than $\mathrm{P}$, most forms of $\mathrm{N}$ also generally increased with increasing trophic status. Mean epilimnetic TN concentrations ranged from $21.35 \mu \mathrm{mol} \mathrm{L}^{-1}$ in oligotrophic to $95.25 \mu \mathrm{mol} \mathrm{L}^{-1}$ in hypereutrophic reservoirs. TDN comprised the majority of TN in most reservoirs, with PN constituting, on average, $~ 25$ to $40 \%$ of TN in oligo-, meso-, and eutrophic reservoirs and $63 \%$ in hypereutrophic reservoirs. DON represented the largest fraction of epilimnetic TDN, with $\mathrm{NO}_{3}{ }^{-}$and $\mathrm{NH}_{4}{ }^{+}$ often accounting for only 3 to $18 \%$ of epilimnetic TDN (Table 2.3). The majority of epilimnetic $\mathrm{NH}_{4}{ }^{+}(68 \%)$ and $\mathrm{NO}_{3}{ }^{-}(79 \%)$ samples were below method detection, even though the 2018 mean epilimnetic $\mathrm{NO}_{3}{ }^{-}$and $\mathrm{NH}_{4}{ }^{+}$concentrations were 1.75 and 0.89 $\mu$ mol L ${ }^{-1}$, respectively. Concentrations of $\mathrm{NO}_{3}{ }^{-}$were often higher than $\mathrm{NH}_{4}{ }^{+}$in ag-crop watersheds, whereas in many forested, mixed, and ag-pasture watersheds, $\mathrm{NH}_{4}{ }^{+}$was higher than $\mathrm{NO}_{3}{ }^{-}$. Hypereutrophic reservoirs, compared to any other trophic status, also had more $\mathrm{NH}_{4}{ }^{+}$relative to $\mathrm{NO}_{3}{ }^{-}$(Table 2.9).

Across the trophic gradient, mean hypolimnetic TDP, TDN, $\mathrm{NO}_{3}{ }^{-}$, and $\mathrm{NH}_{4}{ }^{+}$ concentrations were consistently higher than their epilimnetic equivalents. Mean hypolimnetic TDP was 20 to $70 \%$ higher than epilimnetic TDP in oligo- and hypereutrophic systems, and $\sim 5.3$ to $5.8 \mathrm{x}$ higher in meso- and eutrophic systems. Hypolimnetic DRP was not measured because of anticipated interference from presumably high iron concentrations (Tidball, 1984; Hammer, 1997). Hypolimnetic TDN in the form of $\mathrm{NO}_{3}{ }^{-}$was 2 to $2.5 \mathrm{x}$ higher than epilimnetic $\mathrm{NO}_{3}{ }^{-}$in eutro- and hypereutrophic systems, and 13 to $15 x$ higher in meso- and oligotrophic systems. Moreover, compared to epilimnetic concentrations, $\mathrm{NH}_{4}{ }^{+}$was $32 \mathrm{x}$ higher in oligo- and 78 to 90x higher in meso-, eutro- and hypereutrophic hypolimnions. Hypereutrophic 
hypolimnions contained $277 \mathrm{x}$ more $\mathrm{NH}_{4}{ }^{+}$than $\mathrm{NO}_{3}{ }^{-}$. The remaining trophic classes had $\sim 2$ to $14 \mathrm{x}$ more hypolimnetic $\mathrm{NH}_{4}{ }^{+}$than $\mathrm{NO}_{3}$. Unlike other dissolved nutrients, mean hypolimnetic DON was not significantly higher than epilimnetic DON for any trophic status (Table 2.9).

\section{Biological parameters}

Phytoplankton biomass, by proxy of chla and POC, was higher as the state of eutrophy increased across the study reservoirs. Trophic means for chla ranged from 2.5 to $2.9 \mu \mathrm{g} \mathrm{L}^{-1}$ in oligo- to 48.1 to $69.7 \mu \mathrm{g} \mathrm{L}^{-1}$ in hypereutrophic reservoirs (Table 2.3), with reservoirs of forested and ag-pasture watersheds having the lowest and highest concentrations, respectively. Although year also showed an effect on chla (Table 2.5), climatic variation made no difference on chla means for oligo- or mesotrophic reservoirs. Relative to 2018, mean chla was $44 \%$ higher for eutrophic reservoirs in 2017 and $31 \%$ lower for hypereutrophic reservoirs. Differences between year were more pronounced across the trophic gradient for means of POC. With trophic means ranging from $\sim 38.6$ to $68.5 \mu \mathrm{mol} \mathrm{L}^{-1}$ in oligotrophic reservoirs to $\sim 284.8$ to $474.5 \mu \mathrm{mol} \mathrm{L}^{-1}$ in hypereutrophic reservoirs, overall POC means were higher in the wetter year relative to the drier year for all but the hypereutrophic reservoirs. The same held true for POM, which dominated TSS in $\sim 85 \%$ of samples (Table 2.3 ). Reservoirs in forested watersheds had the least POM, while those in mixed watersheds had the most (Table 2.5).

\section{Nutrient status}

\section{Phosphorus-deficiency}

Most nutrient status indicators suggest that P-deficiency is prevalent in the phytoplankton communities of Missouri reservoirs (Table 2.10). Stoichiometric TN:TP ratios largely favored P-deficiency in both years with $57 \%$ of samples indicating P- 
deficiency. Although TN:TP ratios were significantly higher during the drier year (2018), climatic variation did not influence the stoichiometric ratios of either POC:PP or PN:PP (Table 2.5). All three indicators, as well as P debt, showed decreases in P-deficiency as eutrophy increased with oligotrophic reservoirs experiencing more frequent and extreme P-deficiency than the other reservoirs (Tables 2.5, 2.6; Figure 2.4). Exceedances of the Pdeficiency thresholds occurred in $83 \%$ of POC:PP samples and $65 \%$ of PN:PP samples. As such, according to POC:PP, all oligotrophic samples were P-deficient, as well as $88 \%$ of meso-, $76 \%$ of eutro- and $67 \%$ of hypereutrophic samples. Similarly, according to PN:PP, P-deficiency occurred in $95 \%$ of oligotrophic reservoirs and 40 to $69 \%$ of the remaining trophic classes (Figures 2.4A,B).

P debt results further supported P-deficiency, with $61 \%$ of samples exceeding the P-deficiency threshold in 2018. All but one oligotrophic debt sample, as well as $70 \%$ of meso- and $44 \%$ of eutro- samples imparted P-deficiency (Figure 2.4C). On multiple occasions, the recovered P debt nutrient spikes were consistently lower for certain highnutrient reservoirs. It is possible, therefore, that $\mathrm{P}$ debt may not effectively evaluate $\mathrm{P}$ deficiency for some eutrophic and hypereutrophic systems due to competition with heterotrophic bacteria (Thorpe and Jones, 2005). Of the four P-indicators, the $+\mathrm{P}$ фPSII experiments provided the least evidence of P-deficiency, with only $11 \%$ of $+\mathrm{P}$ samples exhibiting significantly positive increases in $\phi_{P S I I}$ relative to their controls (Figure 2.4D).

\section{Nitrogen-deficiency}

Support for N-deficiency is lacking in comparison to P-deficiency, as most of the nutrient status indicators suggest that $\mathrm{N}$-deficiency is not common in the phytoplankton communities of Missouri reservoirs (Figure 2.5). Stoichiometric TN:TP ratios were 
significantly lower in 2017 relative to 2018, but not low enough to favor N-deficiency over P-deficiency with only $2 \%$ of TN:TP samples below the N-deficiency threshold. Furthermore, the stoichiometric POC:PN ratio, which was the only N-indicator used in both years, showed no statistical difference between years (Table 2.5), and revealed that $\mathrm{N}$-deficiency occurred in $35 \%$ of samples (Figure 2.5A). Although trophic status did not have a significant effect on POC:PN, 51 to $55 \%$ of meso- and oligotrophic samples and 17 to $20 \%$ eutro- and hypereutrophic samples were implicated as N-deficient.

$\mathrm{N}$ debts and $\phi_{\mathrm{PSII}}$ experiments provided little additional support for $\mathrm{N}$-deficiency when they were applied in 2018 . Only $7 \%$ of $\mathrm{NH}_{4}{ }^{+}-\mathrm{N}$ debts were above the $\mathrm{NH}_{4}{ }^{+}-$ deficiency threshold (Figure 2.5B), and $1 \%$ of $\mathrm{NO}_{3}^{-}-\mathrm{N}$ debts elicited meaningful responses to $+\mathrm{NO}_{3}-$ - (Figure $2.5 \mathrm{D}$ ). Significantly positive increases in $\phi_{\mathrm{PSII}}$ following $+\mathrm{NH}_{4}{ }^{+}$and $+\mathrm{NO}_{3}{ }^{-}$treatments only occurred in $\sim 6 \%$ and $\sim 9 \%$ of samples, respectively (Tables 2.7, 2.10; Figures 2.5C, 2.5E). Significant differences in $\mathrm{NH}_{4}{ }^{+}-\mathrm{N}$ debt occurred between land-uses, with ag-pasture resulting in higher $\mathrm{NH}_{4}{ }^{+}-\mathrm{N}$ debt than forested (Table 2.6). Although trophic status showed no significant effect on the $\mathrm{N}$ debts or $\phi_{\mathrm{PSII}}$ experiments, nutrient addition responses occurred more often in oligo- and mesotrophic reservoirs for the debts and in meso- and eutrophic reservoirs for the $\phi_{\mathrm{PSII}}$ experiments (Table 2.10). Samples from certain oligotrophic reservoirs also consistently showed rapid $\mathrm{NH}_{4}{ }^{+}$depletion following the nutrient spike in $\mathrm{NH}_{4}{ }^{+}-\mathrm{N}$ debts, either due to rapid uptake or interference from an unknown source. Likewise, in hypereutrophic samples, $\mathrm{NH}_{4}{ }^{+}-\mathrm{N}$ debts often accumulated more $\mathrm{NH}_{4}{ }^{+}$than was given in the nutrient spike.

Phytoplankton communities in Missouri reservoirs are, therefore, primarily Pdeficient. When plotted on a coordinate plane, the $\mathrm{P}$ debt and $\mathrm{NH}_{4}{ }^{+}-\mathrm{N}$ debt thresholds 
create a four-quadrant grid. From which, we can estimate N-only deficiency, NP codeficiency, P-only deficiency, and sufficiency of both $\mathrm{N}$ and P (Figure 2.6). No community indicated N-only deficiency, and only $8 \%$ suggested NP co-deficiency. Most samples implicated P-only deficiency (51\%) or N and P sufficiency (41\%).

\section{Indicator Agreement}

In 2017, POC:PP and PN:PP were the primary P-status indicators with $54 \%$ of applications favoring P-deficiency, $26 \%$ favoring P-sufficiency, and the remaining being inconclusive in a 50/50 split. During the first year, there was $100 \%$ agreement in favor of P-deficiency in oligotrophic reservoirs. The percent agreement for P-deficiency decreased from $59 \%$ in mesotrophic to $47 \%$ in eutrophic to $13 \%$ in hypereutrophic reservoirs, and results were inconclusive 19 to $25 \%$ of the time. Hypereutrophic reservoirs were the only group with the majority of samples (63\%) favoring P-sufficiency (Table 2.11).

In 2018, P-indicators were expanded to include $\mathrm{P}$ debt and $+\mathrm{P}$ \$PSII experiments, and $19 \%$ of samples showed complete agreement between all four indicators. Of those samples in complete agreement, nearly 2/3 favored P-deficiency. Most samples in 2018 (56\%) had agreement from three of the four indicators, with 4/5 favoring P-deficiency, while $\sim 25 \%$ of the remaining samples were inconclusive (i.e., 50/50 split). All but one oligotrophic sample favored P-deficiency, as well as $66 \%$ of mesotrophic and $44 \%$ of eutrophic samples. Meso- and eutrophic samples were inconclusive 24 to $28 \%$ of the time. Unlike in 2017, most 2018 hypereutrophic samples (42\%) were inconclusive, and only $29 \%$ favored P-sufficiency (Table 2.11).

$\mathrm{N}$ debt and $\mathrm{N}$-addition $\phi_{\mathrm{PSII}}$ experiments accompanied POC:PN in 2018 to determine if $\mathrm{N}$-deficiency occurred as $\mathrm{NH}_{4}{ }^{+}$or $\mathrm{NO}_{3}{ }^{-}$deficiency. Of the samples thought 
to be N-deficient based on POC:PN in 2018, only $10 \%$ were supported by an additional $\mathrm{NH}_{4}{ }^{+}$or $\mathrm{NO}_{3}{ }^{-}$indicator. Overall agreement, however, was much higher for $\mathrm{N}$-indicators than P-indicators with all $\mathrm{N}$-indicators agreeing 63 to $64 \%$ of the time. $\mathrm{N}$-sufficiency was favored in $88 \%$ of indicator applications for $\mathrm{NH}_{4}{ }^{+}$and $95 \%$ of applications for $\mathrm{NO}_{3}{ }^{-}$ . Occurring mostly in oligo- and mesotrophic reservoirs, ten samples favored $\mathrm{NH}_{4}{ }^{+}-\mathrm{N}$ deficiency and five favored $\mathrm{NO}_{3}{ }^{-} \mathrm{N}$ deficiency (Table 2.11).

\section{P-E parameters}

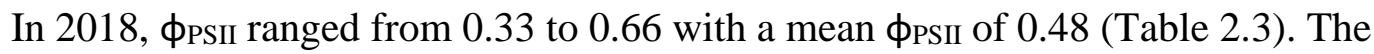
$\phi_{\text {PSII }}$ of all but one sample fell below the empirical optimum value of $\sim 0.65$. Only $8 \%$ of samples had values $>0.60$. Land-use had a significant effect on $\phi_{\text {PSII }}$, where ag-pasture had the lowest mean $\phi_{\text {PSII }}$ and forested had the highest. There was, however, no significant relationship between $\phi_{\text {PSII }}$ and trophic status (Table 2.5).

No relationship existed between trophic status and $\alpha$, either; although a significant relationship did exist between $\alpha$, land-use, and sampling event. Phytoplankton in reservoirs of forested watersheds were the most efficient at utilizing light, whereas those in ag-pasture watersheds were the least efficient. Efficiency was highest early in the sampling season (May/June) and lowest late in the sampling season (August/September;

Table 2.5). After normalization to chl $a, \alpha^{\mathrm{B}}$ differed significantly across trophic status with phytoplankton of oligotrophic reservoirs being more efficient than those of meso-, eutro-, or hypereutrophic reservoirs (Figure 2.3A-B). Similarly, $\alpha^{\mathrm{B}}$ demonstrated that efficiency was also significantly higher in May/June and in forested watersheds than it was late in August/September or in reservoirs of ag-pasture watersheds (Table 2.5). 
Ranging from 92.68 to 491.34 with an average of $292.63 \mu \mathrm{mol}$ photons $\mathrm{m}^{-2} \mathrm{~s}^{-1}$ (Table 2.3), $\mathrm{E}_{\mathrm{k}}$ demonstrated no significant relationship with trophic status. Sampling event, however, had a significant effect on $\mathrm{E}_{\mathrm{k}}$ as well as $\mathrm{rETR}_{\max }$, wherein both peaked early in May/June and reached their lowest values by July/August. Per unit of chla, $\mathrm{E}_{\mathrm{k}}{ }^{\mathrm{B}}$ was significantly higher for phytoplankton in oligo- compared to meso-, eutro-, or hypereutrophic reservoirs. $\mathrm{E}_{\mathrm{k}}{ }^{\mathrm{B}}$ was also significantly higher in May/June but was not notably influenced by land-use (Table 2.5).

\section{Gross primary productivity}

Ranging from 668 to $701 \mathrm{mmol} \mathrm{O}_{2} \mathrm{~m}^{-2}$ day $^{-1}$, mean GPP rates were similar between oligo-, meso-, and eutrophic reservoirs. With the mean GPP for hypereutrophic reservoirs slightly lower, at $607 \mathrm{mmol} \mathrm{O}_{2} \mathrm{~m}^{-2}$ day $^{-1}$, trophic status had no significant effect on GPP. Across individual samples, GPP ranged from $\sim 33$ to 2,668 $\mathrm{mmol} \mathrm{O}_{2} \mathrm{~m}^{-2}$ day $^{-1}$ (Table 2.3). GPP correlated significantly with the P-E parameters, as well as some physical parameters, but there were no significant correlations with any chemical or biological parameter. Of the P-E parameters, GPP had a positive relationship with $\mathrm{E}_{\mathrm{k}}(p<$ $0.01, r=0.31)$ and a negative relationship with $\phi_{\mathrm{PSII}}(p<0.01, r=-0.30)$ as well as $\alpha(p$ $<0.01, r=-0.30)$. Likewise, of the physical parameters, GPP had positive relationships with $\mathrm{Z}_{\max }(p<0.001, r=0.45)$ and $\mathrm{Z}_{\operatorname{mix}}(p<0.001, r=0.40)$, and a negative relationship with $\mathrm{K}_{\mathrm{d}}(p=0.02, r=-0.25)$.

Rates of GPP normalized to chla $\left(\mathrm{GPP}^{\mathrm{B}}\right)$ were negatively related to trophic status, where $\mathrm{GPP}^{\mathrm{B}}$ was highest in oligotrophic reservoirs and decreased as eutrophy increased (Table 2.5). While trophic mean $\mathrm{GPP}^{\mathrm{B}}$ rates ranged from $\sim 10$ to $430 \mathrm{mmol} \mathrm{O}_{2}\left(\mathrm{mg} \mathrm{Chl} \mathrm{a}^{-}\right.$ ${ }^{1}$ ) $\mathrm{m}^{-1}$ day $^{-1}$, the mean $\mathrm{GPP}^{\mathrm{B}}$ in oligotrophic reservoirs was $\sim 3, \sim 7$, and $\sim 44 \mathrm{x}$ higher than 
those in meso-, eutro-, and hypereutrophic reservoirs, respectively (Table 2.3; Figure 2.3C). Significant correlations with $\mathrm{GPP}^{\mathrm{B}}$ were largely positive for physical/P-E parameters and negative for chemical/biological parameters. Namely, higher $\mathrm{GPP}^{\mathrm{B}}$ rates correlated to higher light availability and P-E activity, and lower turbidity, nutrients, and proxies for phytoplankton biomass (Table 2.8).

\section{Discussion}

Missouri reservoirs vary in light availability, nutrient chemistry, phytoplankton biomass (by proxy of chla and POC), photosynthetic capability and rates of GPP both across the trophic gradient and between the climatically contrasting summers of 2017 (wet) and 2018 (dry). P-deficiency was the predominant constraint on phytoplankton biomass in Missouri reservoirs, regardless of climatic year, with N-deficiency estimated in, at most, $35 \%$ of samples, and light-deficiency in $23 \%$ of samples. Any combination of co-deficiency between light, $\mathrm{N}$, and/or P was evidenced in $\sim 12 \%$ of samples in 2018 . Higher nutrient concentrations supported more phytoplankton biomass but increased trophic status did not enhance primary productivity. Mean $\mathrm{GPP}^{\mathrm{B}}, \mathrm{E}_{k}{ }^{\mathrm{B}}$, and $\alpha^{\mathrm{B}}$ were instead highest in oligotrophic reservoirs and decreased with increasing eutrophy. As such, light availability constrained primary productivity in Missouri reservoirs, presumably effectuated by self-shading of the phytoplankton communities.

\section{The physical light environment as a constraint on phytoplankton biomass}

Reservoirs serve as repositories for freshly eroded soil and displaced stream sediment (Søballe and Kimmel, 1987). As a consequence, reservoirs are commonly more turbid than natural lakes (Hayes et al., 2017). Increased surface runoff and heightened flow associated with climatically-induced increases in precipitation will further 
accentuate sediment deposition in reservoirs (Jeppesen et al., 2010). Suspended sediment (e.g., TSS, PIM, POM) can impede the physical light environment via absorption and scatter, which reduces light availability, potentially constraining phytoplankton biomass and/or productivity (Hoyer and Jones, 1983; Knowlton and Jones, 1995).

Missouri reservoirs are known to be turbid systems (Jones and Knowlton, 2005). Many exhibited characteristically high TSS and low water clarity, yet $\overline{\mathrm{E}}_{24}$ indicated that most reservoirs were light-sufficient. In inland waters, turbidity is most often associated with elevated PIM (Kirk, 1985), however, in Missouri reservoirs, light conditions can be strongly influenced by either suspended clay-sized PIM or algal POM (Jones and Hubbart, 2011). During this study, I observed $\bar{E}_{24}$ to decrease as both PIM and POM increased, but the light environment was likely driven by POM, as it most often dominated TSS. Although proportions of PIM and POM vary seasonally and physiographically, PIM historically dominated summer seston in Missouri reservoirs (29 to $87 \%$ of TSS; Jones and Knowlton, 1993; Knowlton and Jones, 1995, 2000). In the last decade, however, Missouri's in-reservoir PIM concentrations have been trending downward (R. Voss, pers. comm. 2020), perhaps due to improvements in soil conservation practices and watershed management.

Based on a fundamental interplay between light and N (Healey, 1985), low TN:TP ratios suggesting $\mathrm{N}$-deficiency in Missouri reservoirs had previously been correlated with high PIM and low water clarity (Jones and Knowlton, 1993). My TN:TP ratios were consistent with these relationships, but near-parallel relationships also existed between TN:TP and POM. Even though low TN:TP ratios were observed in communities with low $\overline{\mathrm{E}}_{24}$, less than $6 \%$ of N-deficient samples (according to either TN:TP or POC:PN) 
coincided with light-deficiency. In contrast to previous studies wherein the prevalence of PIM in Missouri reservoirs was tied to N-deficiency (Jones and Knowlton, 1993), my findings of POM prevalence correspond with infrequent $\mathrm{N}$ - and light- deficiency.

Lower $\overline{\mathrm{E}}_{24}$ corresponded to elevated concentrations of chl $a$ and POC in Missouri reservoirs, wherein peak phytoplankton biomass occurred when $\overline{\mathrm{E}}_{24}$ was between $\sim 50$ and $150 \mu \mathrm{mol}$ photons $\mathrm{m}^{-2} \mathrm{sec}^{-1}$. Light-deficient samples were often from chlorophyll-rich eutro- and hypereutrophic reservoirs, typically in agricultural watersheds. Samples from watersheds dominated by ag-crop, followed by those dominated by ag-pasture, had the highest chla concentrations and often the lowest $\overline{\mathrm{E}}_{24}$. While most agricultural land-uses enhance nutrient export to surface waters, row-crop agriculture, in particular, is associated with higher nutrient enrichment than lower-intensity livestock production (Strayer et al., 2003). In light-deficient samples from agricultural watersheds, my nutrient status indicators showed that $\mathrm{P}$ and $\mathrm{N}$ were generally adequate to support phytoplankton biomass. I believe the biomass itself is the predominant contributor to light attenuation and $\overline{\mathrm{E}}_{24}$ reduction in light-deficient samples. Although high-nutrient systems had more PIM than did low-nutrient systems, POM concentrations were notably higher than PIM concentrations in nearly all samples. Thus, when light-deficiency occurred, it was induced by self-shading of the phytoplankton rather than mineral turbidity.

Photoacclimation was not evidenced by the linear relationship observed between POC and chla. Instead, the elevated POC:chl $a$ ratios supported light-sufficiency and implicated nutrient deficiency (MacIntyre et al., 2002). With PIM so low relative to POM in the study reservoirs, biological demand likely exceeded inorganic nutrient supply. My nutrient status indicators, namely the nutrient addition debt experiments measuring 
nutrient uptake, confirmed that nutrient demand was greater than supply in many samples. Stoichiometric ratios also supported nutrient deficiency.

Considerable disagreement occurred between my light-deficiency indicators, $\overline{\mathrm{E}}_{24}$ and $\overline{\mathrm{E}}_{24}: \mathrm{E}_{\mathrm{k}}$. According to $\overline{\mathrm{E}}_{24}$, most samples were light-sufficient. This conclusion was further supported by POC:chla ratios and can likely be attributed to the reservoirs' shallow mixing depths, which ensure that the phytoplankton spend sufficient time in the euphotic zone. Results from $\overline{\mathrm{E}}_{24}: \mathrm{E}_{\mathrm{k}}$ contradictorily indicate that most samples were lightdeficient. While I recognize $\overline{\mathrm{E}}_{24}: \mathrm{E}_{\mathrm{k}}$ as a potential indicator of light-deficiency, $\overline{\mathrm{E}}_{24}: \mathrm{E}_{\mathrm{k}}$ does not carry as much weight in my assessment as $\overline{\mathrm{E}}_{24}$. Other applications of $\overline{\mathrm{E}}_{24}: \mathrm{E}_{\mathrm{k}}$, wherein the ratio was frequently below the deficiency threshold, concluded that it inaccurately predicted light-limitation (Millard et al., 1996) and noted that effective thresholds could vary seasonally due to changes in species composition (Healey, 1985). My methodology may also lend itself to inaccuracies in $\overline{\mathrm{E}}_{24}: \mathrm{E}_{\mathrm{k}}$, since the indicator was originally developed using C-incorporation methods (Hecky and Guildford, 1984). $\mathrm{E}_{\mathrm{k}}$ derived from fluorometry is often higher than $\mathrm{E}_{\mathrm{k}}$ derived by $\mathrm{C}$-incorporation (Napoléon and Claquin, 2012). Nutrient deficiency, in particular, perturbs the relationship between electron transport rate and $\mathrm{C}$ from which fluorometric- $\mathrm{E}_{\mathrm{k}}$ is derived (Napoléon et al., 2013). Fluorometrically derived $\overline{\mathrm{E}}_{24}: \mathrm{E}_{\mathrm{k}}$ may, therefore, overestimate light-deficiency.

\section{Nutrient constraint on phytoplankton biomass in an agricultural state}

Agriculture is prominent on the Missouri landscape, with $63 \%$ or 27.8 million of its acres in farmland (USDA, 2019). As a result, I would expect $P$ to be of ample supply in its surface waters (Daniel et al., 1998). Yet, P-deficiency is prevalent in the phytoplankton communities of Missouri reservoirs. I observe high concentrations of the most bioavailable form of P, DRP, in eutro- and hypereutrophic reservoirs within 
agricultural watersheds. Conservation tillage and surface broadcasting of fertilizer resulted in a $218 \%$ increase in concentrations of DRP in Lake Erie (Michalak et al., 2013), and similar practices in Pennsylvania caused aquatic DRP to increase 3 to $28 x$ background levels following fertilizer application (Kleinman et al., 2009). Precipitation, which increases surface and subsurface $\mathrm{P}$ losses from the landscape, was also a substantial contributor to DRP loads in Lake Erie (Michalak et al., 2013). Although I did not measure DRP in 2017, other forms of P (TP and PP) proved to be significantly higher during the wetter summer. Previous studies in Indiana and Ohio demonstrate that approximately half of TP and half of DRP losses from agricultural fields occur via tile drainage, which are common throughout Missouri and the Midwest (King et al., 2015; Smith et al., 2015). Even though P loss via tile drainage is often DRP-dominated, PP loss can also be substantial (King et al., 2015); therefore, the elevated DRP and PP in eutroand hypereutrophic reservoirs may reflect tile drainage in their agricultural watersheds.

Phytoplankton are capable of luxury consumption and storage of P (Reynolds, 1984), but the prevalence of P-deficiency in Missouri phytoplankton suggests that, relative to $\mathrm{N}$, supplies of biologically available $\mathrm{P}$ are limiting in the environment. Dissolved P bound up in non-algal suspended solids is made unavailable for phytoplankton uptake (Hoyer and Jones, 1983; Jones and Knowlton, 1993). I did not directly measure or quantify P absorption by non-algal particles, but because Missouri's PIM is mainly clay minerals with large sorption potentials (Hoyer and Jones, 1983), it does offer a plausible explanation for P-deficiency in nutrient-rich Missouri reservoirs. Additional inputs of DRP in the reservoirs, however, could still increase phytoplankton biomass. To prevent such increases in phytoplankton biomass, beneficial management 
practices (BMPs) that target retention and reduction of DRP runoff should be implemented on the landscape (Sharpley et al., 2013). Unfortunately, improvements in water quality may not be immediately evident after implementing these watershed-based nutrient management efforts. High hypolimnetic TDP concentrations observed in these reservoirs during summer stratification suggest that, although DRP can be and is tied up in the sediment, under anoxic conditions, sediment-bound $\mathrm{P}$ is also being resuspended in the water column via internal loading (Søndergaard et al., 2003). With hypolimnetic anoxia widespread in Missouri reservoirs, internal P loading rates are likely high, and extended stratification under a future climate (Woolway and Merchant, 2019) will further exacerbate internal P loading (North et al., 2014).

Increased focus on mitigating non-point source $\mathrm{P}$ inputs are recommended as these reservoirs appear to be effective at $\mathrm{N}$ removal via denitrification, resulting in low epilimnetic dissolved inorganic N (DIN) concentrations (Gooding and Baulch, 2017). Around the world, growing N-based fertilizer use is increasing surface water $\mathrm{N}$ concentrations- relative to P- in excess of phytoplankton demand (Glibert et al., 2016). This is evidenced in midwestern water bodies wherein $\mathrm{N}$ is commonly present in greater abundance than P (Jones and Knowlton, 1993; Jones et al., 2008a). Despite these trends, studies in Kansas and Arkansas have identified $\mathrm{N}$ as a potentially important constraint on phytoplankton biomass in midwestern reservoirs (Dzialowski et al., 2005; Scott and Grantz, 2013). Given the low ambient concentrations of $\mathrm{NO}_{3}{ }^{-}$and $\mathrm{NH}_{4}{ }^{+}$observed in many of the study reservoirs, I anticipated more phytoplankton communities to be $\mathrm{N}$ deficient than I found. In warm-water reservoirs, it is common for epilimnetic DIN to be diminished during summer stratification (Wetzel, 2001). Typically, such reductions in 
bioavailable $\mathrm{NO}_{3}{ }^{-}$and $\mathrm{NH}_{4}{ }^{+}$would contribute to $\mathrm{N}$-deficiency (Søndergaard et al., 2017).

In these systems, however, TDN was largely comprised of DON.

The DON in these systems likely reflect urea fertilizer use on the landscape. Mean epilimnetic DON concentrations in reservoirs with watersheds dominated by ag-crop were nearly double those of forested watersheds. Globally, urea fertilizer use has increased more than 100-fold in the last four decades (Glibert et al., 2006), and in the US, nearly $90 \%$ of applied N-based fertilizer is in the form of urea instead of ammonium nitrate (Paerl et al., 2016). Although urea was once thought to be a minor constituent of DON, recent data shows that urea can sometimes exceed $40 \%$ of the DON pool (Glibert et al., 2006). While historical concentrations of urea and DON are not known for Missouri reservoirs, previous studies estimated a high proportion (45\%) of Missouri reservoirs to have low TN:TP ratios (Jones and Knowlton, 1993), which indicate some Ndeficiency (Guildford and Hecky, 2000). Within aquatic ecosystems, urea can be mobile and as a result, urea sometimes serves as a significant source of $\mathrm{N}$ for phytoplankton. If urea represents a large percentage of the DON pool, then there would be a high degree of bioavailable DON in these systems (Glibert et al., 2006). This would alleviate the potential $\mathrm{N}$-deficiency anticipated from low epilimnetic $\mathrm{NO}_{3}{ }^{-}$and $\mathrm{NH}_{4}{ }^{+}$concentrations.

\section{How photosynthetic response informs light and nutrient status}

As a physiological measurement, $\phi_{P S I}$ is often used as a general indicator of phytoplankton stress to inform light and/or nutrient deficiency (Kromkamp and Forster, 2003; Falkowski and Raven, 2007). When $\phi_{\text {PSII }}$ is less than the optimum 0.65, as most of my samples were, it indicates that phytoplankton are exhibiting physiological stress. Physiological stress in phytoplankton typically results from imbalanced growing 
conditions, such as inadequate light, nutrients, and/or temperature, that hinder photosynthetic capacity (Kromkamp et al., 2008). My фPSII observations were, on average, highest in oligo- and mesotrophic reservoirs of forested watersheds and lowest in eutro- and hypereutrophic reservoirs of agricultural watersheds. Given that the lowest

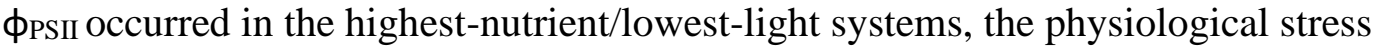
probably does not reflect a lack of nutrients, but rather a lack of light.

Further support for light as the driver behind low $\phi_{P S I I}$ was interpreted from my photosynthetic efficiency experiments. Notably, if the phytoplankton were stressed due to nutrient deficiency, there would have been significant increases in $\phi_{P S I I}$ post-nutrient addition. Instead, overall responses to nutrient additions were low (i.e., $\phi$ PSII significantly increased in $<10 \%$ of samples). Of those that responded to nutrient additions, the greatest increases in $\phi_{P S I I}$ occurred in oligo- and mesotrophic samples wherein ambient nutrient concentrations were lower and nutrient deficiency was higher. Nutrient additions in eutro- and hypereutrophic samples, however, yielded next to no response in $\phi$ PsII, which likely reflect the already high ambient nutrient concentrations. In most samples, low $\phi_{\mathrm{PSII}}$ persists after nutrient additions and indicates that the phytoplanktons' stress is not prompted by nutrient deficiency but instead prompted by light, temperature, or an unknown factor. Given the lack of response in light-deficient eutro- and hypereutrophic samples, I surmise low $\phi_{\text {PSII }}$ most likely reflects poor light-environments, such as those caused by abundant phytoplankton biomass and self-shading.

Although low $\phi_{P S I I}$ is commonly used as a metric of assessing physiological

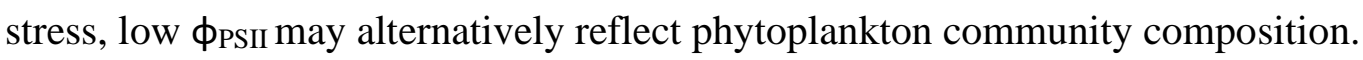
Cyanobacteria, in particular, are known to exhibit significantly lower $\phi_{P S I}$ than true-algae 
(Campbell et al., 1998). While the members of my present-day phytoplankton communities are unknown, it has been previously demonstrated that cyanobacterial abundance increases with trophic status in Missouri reservoirs (Jones et al., 2008b). Field measurements of phycocyanin, the pigments produced by cyanobacteria, in the study reservoirs in 2018 support this relationship. Phycocyanin, as a proxy for cyanobacterial abundance, increased with increasing TP concentrations. Subsequently, hypereutrophic reservoirs had the highest measurements of phycocyanin relative to the other trophic classes. It is, therefore, plausible for cyanobacteria to be influencing $\phi_{\text {PSII, }}$ at least in hypereutrophic samples (this study, data not shown).

\section{The disconnect between phytoplankton biomass and primary productivity}

Chla concentrations in the study reservoirs range from 0.9 to $125.7 \mu \mathrm{g} \mathrm{L}^{-1}$ with a median of 9 and a mean of $16 \mu \mathrm{g} \mathrm{L}^{-1}$. Compared to other lakes and reservoirs, Missouri's mean chla concentration is $\sim 1.5 \mathrm{x}$ higher than the median chla concentration reported in a study of 2,239 midwestern and northeastern US lakes (Oliver et al., 2017), as well as a study of 1,316 lakes worldwide (Abell et al., 2012). Neither study differentiates between lakes and reservoirs, although reservoirs tend to be more productive systems with higher phytoplankton biomass (Kimmel and Groeger, 1984). Here in the Midwest, a study of 139 Iowa lakes ( $75 \%$ manmade.) reported a median chla concentration of 26 and a mean concentration of $40 \mu \mathrm{g} \mathrm{L}^{-1}$ (Filstrup and Downing, 2017), 3 and 2.5x higher than my study reservoirs in Missouri, respectively. Furthermore, a study of 19 reservoirs in Kansas (Dzialowski et al., 2005) also demonstrates elevated chl $a$ concentrations comparable to those reported in Iowa. 
Just as $\mathrm{P}$ is assumed to be the primary constraint on biomass (Schindler, 1974), a similar paradigm exists for lake productivity (Vollenweider, 1976). Global lake observations support the paradigm, showing strong positive relationships between GPP and TP (Hanson et al., 2003; Solomon et al., 2013). While most Missouri reservoirs are consistent with the P-paradigm for biomass accrual, their productivity diverges from the lake-centric model by GPP and GPP ${ }^{\mathrm{B}}$ having, respectively, no relationship and a strongly negative relationship with TP (Table 2.8). The ratio of production to biomass across the trophic gradient is high at low TP (oligotrophic) and low at high TP (hypereutrophic). A similar negative relationship between $\mathrm{GPP}^{\mathrm{B}}$ and $\mathrm{TP}$ was also observed in a study of seven Wisconsin lakes wherein $\mathrm{GPP}^{\mathrm{B}}$ decreased with increasing eutrophy. Measured with light/dark bottle incubations, their median $\mathrm{GPP}^{\mathrm{B}}$ was $21.9,8.4,5.7$, and $0.7 \mathrm{mmol} \mathrm{O}_{2}(\mathrm{mg}$ $\operatorname{chl} a)^{-1} \mathrm{~m}^{-1}$ day $^{-1}$ for oligo-, meso-, eutro-, and dystrophic lakes, respectively. They also reported a wide, albeit lower, range in GPP (9 to $179 \mathrm{mmol} \mathrm{O}_{2} \mathrm{~m}^{-2}$ day $^{-1}$ ), as well as $\mathrm{GPP}^{\mathrm{B}}$ (1 to $320 \mathrm{mmol} \mathrm{O}_{2}(\mathrm{mg} \operatorname{chl} a)^{-1} \mathrm{~m} \mathrm{day}^{-1}$; Lauster et al., 2006). The wide range I observed in GPP (33 to 2,668 $\mathrm{mmol} \mathrm{O}_{2} \mathrm{~m}^{-2}$ day $^{-1}$ ) is also higher than rates observed across a global assemblage of lakes and reservoirs ( 3 to $1,100 \mathrm{mmol} \mathrm{O}_{2} \mathrm{~m}^{-2}$ day $^{-1}, n=72$; Hoellein et al., 2013). Compared to lake studies that also derived GPP fluorometrically, my mean GPP was $\sim 4$ to $24 x$ higher (Table 2.12 ). With higher productivity expected in reservoirs (Kimmel and Groeger, 1984), my rates are more comparable to those of other temperate reservoirs, for which productivity studies are rare. In large, oligo-mesotrophic Lake Diefenbaker (LD; Canada) fluorometrically derived GPP rates (11 to $746 \mathrm{mmol} \mathrm{O}_{2}$ $\mathrm{m}^{-2}$ day $^{-1}$ ) overlapped the range of rates in my oligotrophic reservoirs, but its mean GPP was $\sim 6 \mathrm{x}$ smaller. Similar chla averages between my reservoirs and LD $(2.5$ and $3.0 \mu \mathrm{g} \mathrm{L}-$ 
${ }^{1}$, respectively) shortened the gap between mean $\mathrm{GPP}^{\mathrm{B}}$ rates, but LD rates were still $\sim 3 \mathrm{x}$ smaller than those of my oligotrophic systems (Dubourg et al., 2015). Considering reservoir construction has increased by an order of magnitude in the past half century (Zarfl et al., 2014), it is important that these elevated reservoir rates are considered in global carbon modeling exercises. Such high GPP rates will also have important implications for ecological functioning and food webs in reservoirs.

Variance between reported productivity estimates may be attributed not only to intersystem differences, but also to methodological differences. I derived my estimates fluorometrically, as did others, but tradition methods rely on diel changes in $\mathrm{O}_{2}$, light/dark bottle incubations and/or ${ }^{14} \mathrm{C}$ (Table 2.12). Fluorometric methods predict GPP quite accurately, however, this method predicts GPP 1.6x higher than actual C-fixation (Kromkamp et al., 2008). When comparing fluorometrically estimated productivity rates, it is important to remember that the irradiance used to excite fluorescence can vary with the composition of the sampled phytoplankton community. Fluorometric comparisons can be especially problematic when phytoplankton communities are subject to dynamic changes in species composition (Kromkamp and Forster, 2003) because the relationship between light and photosynthetic activity is dependent, in part, on characteristics specific to different algal groups. Even photosynthetic parameters used to calculate GPP, such as $a_{\phi}$ and $\alpha$, are known to vary between species (Falkowski and Raven, 2007). The differences in rates I have observed, therefore, may be attributed to differences in algal communities, as well as to any possible errors arising from rate calculations, $\mathrm{C}$ to $\mathrm{O}_{2}$ conversions, and data comparisons of temporally and geographically separated systems (del Giorgio and Peters, 1993). 
In Missouri, phytoplankton from low-P systems were more productive and more efficient at photosynthetically utilizing light energy than those from high-P systems. More P corresponded to more chla, and both correlated to reduced light environments. By evaluating $\overline{\mathrm{E}}_{24}$ and $\phi_{\mathrm{PSII}}$ I establish that, despite stimulating biomass, increasing eutrophy in Missouri reservoirs begets increases in light-deficiency and decreases in the photosynthetic capability of the phytoplankton. As a photosynthetic process, productivity has been distinctly linked to irradiance- particularly in northern temperate lakes (Staehr and Sand-Jensen, 2007; Torremorell et al., 2009; Staehr et al., 2010; Laas et al., 2012). Here, productivity exhibits notable positive and negative interactions with $\overline{\mathrm{E}}_{24}$ and turbidity, respectively, which further supports light as the proximate constraint on productivity. Typically, low productivity in turbid waters is caused by high PIM and its associated rapid light attenuation (Grobbelaar, 1989). Samples with the lowest GPP ${ }^{\mathrm{B}}$ are, indeed, among those with the highest PIM and $\mathrm{K}_{\mathrm{d}}$, but light in Missouri reservoirs is presently driven by POM. In high-P reservoirs, abundant phytoplankton biomass have inhibitory effects on light and, subsequently, productivity. Increased turbidity via elevated biomass accrual and self-shading have previously been evidenced by negative correlations of both $\mathrm{GPP}^{\mathrm{B}}$ and $\alpha^{\mathrm{B}}$ with chl $a$ and $\mathrm{K}_{\mathrm{d}}$ (Kromkamp et al., 2008). These interactions, also observed in my Missouri samples, demonstrate the classical light-shade acclimation response (Kromkamp et al., 2008).

Pheophytin (pheo), the degradation pigment produced by dead or dying phytoplankton, represent non-photosynthetically active algal cells (Erikson, 1999). Although my hypereutrophic samples had the highest chla concentrations, they also had the highest pheo concentrations. Large concentrations of pheo, which are included in 
POM, would increase shading of photosynthetically active phytoplankton without contributing to productivity. Inactive algal cells would act much like PIM, absorbing light and inhibiting productivity. Frequently high proportions of pheo to chla in Missouri reservoirs has suggested that low-quality algal pigment is common, namely in meso-, eutro-, and hypereutrophic reservoirs (Jones et al., 2008b). Observations of decreasing $\phi_{\text {PSII }}$ with increasing pheo concentrations support photosynthetic inhibition, but may also reflect the low-quality algal pigments (Fuchs et al., 2002). Alternatively, high pheophytin concentrations could indicate high grazing rates (Wetzel, 2001). Although I did not directly measure grazing in this study, previous work on these reservoirs indicate that they lack the large Daphnia (>1mm; Canfield and Jones, 1996) most commonly associated with grazing control (Mazumder, 1994). Grazing, therefore, is assumed to have negligible impacts on phytoplankton dynamics.

\section{Light and nutrients constraining phytoplankton dynamics in a changing world}

The increase in rainfall intensity associated with climate change, accompanied by the pervasiveness of agriculture and urbanization, will contribute greater proportions of bioavailable $\mathrm{P}$ and $\mathrm{N}$ to inland waters. As a result of this accelerated eutrophication, an overall shift in trophic status is expected, begetting more eutro- and hypereutrophic waters. Simultaneously, climate-induced stronger and longer-lasting thermal stratification is anticipated to increase hypolimnetic oxygen depletion. Bottom-water anoxia stimulates internal loading, which amplifies hypolimnetic nutrient concentrations. Combined with accelerated surface-water eutrophication, amplified hypolimnetic eutrophication will have an additive effect on epilimnetic nutrient levels during mixing and at the beginning

of the next stratification season. Such changes in nutrient concentrations will not only 
contribute to a shift in trophic status but will also influence the proximate deficiencies constraining phytoplankton biomass and productivity. Given that 94 \% of Missouri reservoirs are already meso-, eutro-, or hypereutrophic and most quickly develop hypolimnetic anoxia during summer stratification, these midwestern systems represent potential climate analogs and precursors of the light and nutrient conditions impacting future reservoir phytoplankton dynamics.

In an agricultural region like the Midwest, the impact of precipitation on the quantity of nutrients and quality of light available to phytoplankton should be evident. When a wet sampling year is compared to a dry sampling year, particulate nutrients are significantly higher during the wetter year and light conditions are significantly lower. Degree of physiological nutrient deficiency, however, is the same regardless of wet or dry year. Even the degree of light-deficiency remains unchanged, despite the wetter year yielding poorer light environments with shallower Secchi depths, higher $\mathrm{K}_{\mathrm{d}}$, more suspended solids, and lower $\overline{\mathrm{E}}_{24}$. This suggests that, at least on a proximate scale, phytoplankton dynamics in midwestern reservoirs are relatively stable in the face of variable climatic influences.

Missouri reservoirs demonstrate shallow mixing and strong metalimnetic thermal gradients despite being shallow relative to their surface area, a condition which would not typically promote stratification in similarly sized, shallow natural lakes (Jones et al., 2011). Strong thermal stratification limits phytoplankton to the mixed surface layer, cutting them off from the nutrient-rich bottom waters during the summer growing season. Subsequently, Missouri reservoirs may have ample nutrients in the hypolimnion while phytoplankton face nutrient deficiency in the epilimnion. For phytoplankton biomass 
accrual, P-deficiency was the prominent constraint, even in nutrient-rich eutro- and hypereutrophic reservoirs. N-deficiency was less frequent, but it occurred more often alongside P-deficiency in oligo- and mesotrophic reservoirs. Thus, at least in Midwestern reservoirs, if surface water eutrophication continues, phytoplankton biomass will be more likely constrained by P than N. Light-deficiency will also increase as a possible constraint. Although light-deficiency may be alleviated due to shallower mixing depths, most of these characteristically turbid systems will likely still have enough light to support phytoplankton growth, photosynthesis, and nutrient uptake.

While P constrains phytoplankton biomass accrual at low concentrations in these reservoirs, even low $\mathrm{P}$ is enough to adequately support phytoplankton primary productivity. Light, rather than nutrient supply, constrains GPP. In high-nutrient systems, such as eutro- and hypereutrophic reservoirs, phytoplankton are self-shaded by their own biomass which causes competition for available light, inhibits their $\alpha$ and, thus, decreases their productivity. If the future of surface waters is green, with a shift to more eutro- and hypereutrophic waters, then the resulting phytoplankton communities will likely be overcrowded, less efficient at utilizing light, and overall, less productive. As the base of the aquatic food web, such depreciation of primary productivity will have ecological effects beyond just those of the phytoplankton community.

\section{Conclusions}

Under current climatic and anthropogenic influences, both $\mathrm{P}$ and light play active roles in controlling phytoplankton biomass and primary productivity, at least in midwestern reservoirs. Phytoplankton biomass is predominantly constrained by $\mathrm{P}$ concentrations during summer stratification, despite the abundance of both $\mathrm{P}$ and $\mathrm{N}$ in the 
agriculturally dominant region. Although this conclusion aligns with the traditionally accepted P-paradigm for freshwater ecosystems, the demonstration of co-deficiency between light, $\mathrm{P}$, and $\mathrm{N}$ should also be acknowledged, especially within the context of the $\mathrm{P}$ versus $\mathrm{N}$ and $\mathrm{P}$ management debate. Conversely, primary productivity in midwestern reservoirs contradicts the traditional P-paradigm for lake productivity.

Spatial and temporal variation is evidenced across systems, especially as they relate to land-use. With high hypolimnetic nutrient stores during summer stratification, I anticipate that summer nutrient deficiencies will be remedied, or shifted, upon shoulder season mixing. If the nutrient supply can support high biomass accrual into the shoulder season, self-shading and competition for sunlight may increase light-deficiency as daylight hours shorten and productivity lessens. Although lakes and reservoirs are similar, perhaps there are differences that warrant separate consideration of the resources influencing phytoplankton dynamics. We see that prioritization of phytoplankton biomass and primary productivity may also warrant separate management considerations with respect to the end use of the water (e.g., drinking water, recreation, fish production). Moreover, this work offers further evidence for the need to evaluate the application of traditional lake-centric paradigms to all systems across time and space, especially as we see shifts in climate patterns and anthropogenic activity that will ultimately alter the light and nutrient regimes of future aquatic ecosystems. 


\section{Tables}

Table 2.1. List of parameter definitions, abbreviations, and units.

\begin{tabular}{|c|c|c|c|}
\hline & Defined Parameter & Abbreviation & Unit \\
\hline \multirow{7}{*}{ Physical } & Maximum depth & $\mathrm{Z}_{\max }$ & meters \\
\hline & Mixing depth & $\mathrm{Z}_{\operatorname{mix}}$ & meters \\
\hline & Secchi disk depth & Secchi & meters \\
\hline & Photosynthetically active radiation & PAR & $\mu \mathrm{mol}$ photons $\mathrm{m}^{-2} \mathrm{sec}^{-1}$ \\
\hline & Vertical light attenuation coefficient & $K_{d}$ & meters $^{-1}$ \\
\hline & Mean daily incident irradiance & $\mathrm{E}_{0}$ & $\mu \mathrm{mol}$ photons $\mathrm{m}^{-2} \mathrm{sec}^{-1}$ \\
\hline & Mean daily mixed layer irradiance & $\overline{\mathrm{E}}_{24}$ & $\mu \mathrm{mol}$ photons $\mathrm{m}^{-2} \mathrm{sec}^{-1}$ \\
\hline \multirow{14}{*}{ Chemical } & Total phosphorus & TP & $\mu \mathrm{mol} \mathrm{L}-1$ \\
\hline & Total dissolved phosphorus & TDP & $\mu \mathrm{mol} \mathrm{L}-1$ \\
\hline & Dissolved reactive phosphorus & DRP & $\mu \mathrm{mol} \mathrm{L}-1$ \\
\hline & Particulate phosphorus & PP & $\mu \mathrm{mol} \mathrm{L}-1$ \\
\hline & Total nitrogen & $\mathrm{TN}$ & $\mu \mathrm{mol} \mathrm{L}-1$ \\
\hline & Total dissolved nitrogen & TDN & $\mu \mathrm{mol} \mathrm{L}-1$ \\
\hline & Ammonium & $\mathrm{NH}_{4}^{+}$ & $\mu \mathrm{mol} \mathrm{L}-1$ \\
\hline & Nitrate & $\mathrm{NO}_{3}^{-}$ & $\mu \mathrm{mol} \mathrm{L}-1$ \\
\hline & Dissolved organic nitrogen & DON & $\mu \mathrm{mol} \mathrm{L}-1$ \\
\hline & Particulate nitrogen & PN & $\mu \mathrm{mol} \mathrm{L}-1$ \\
\hline & Dissolved organic carbon & DOC & $\mu \mathrm{mol} \mathrm{L}-1$ \\
\hline & Total suspended solids & TSS & $\mu \mathrm{g} \mathrm{L}^{-1}$ \\
\hline & Particulate organic matter & POM & $\mu \mathrm{g} \mathrm{L}^{-1}$ \\
\hline & Particulate inorganic matter & PIM & $\mu \mathrm{g} \mathrm{L}^{-1}$ \\
\hline \multirow{7}{*}{ Biological } & Total-Chlorophyll & TChl & $\mu \mathrm{g} \mathrm{L}^{-1}$ \\
\hline & Chlorophyll- $a$ & $\operatorname{chl} a$ & $\mu \mathrm{g} \mathrm{L}^{-1}$ \\
\hline & Pheophytin & pheo & $\mu \mathrm{g} \mathrm{L}^{-1}$ \\
\hline & Particulate organic carbon & POC & $\mu \mathrm{mol} \mathrm{L} \mathrm{L}^{-1}$ \\
\hline & Areal pigment absorption coefficient & $a_{\phi}$ & $\mathrm{m}^{-2} \mathrm{mg} \operatorname{chl} a^{-1}$ \\
\hline & Daily gross primary productivity rate & GPP & $\mathrm{mmol} \mathrm{O}_{2} \mathrm{~m}^{-2}$ day $^{-1}$ \\
\hline & Daily gross primary productivity rate normalized to chlorophyll- $a$ & $\mathrm{GPP}^{\mathrm{B}}$ & $\mathrm{mmol} \mathrm{O}_{2}(\mathrm{mg} \mathrm{chl} a)^{-1} \mathrm{~m}$ day $^{-1}$ \\
\hline \multirow{8}{*}{$\begin{array}{l}\text { Nutrient } \\
\text { Status }\end{array}$} & Particulate organic carbon to chlorophyll- $a$ ratio & POC:chla & $\mu \mathrm{mol} \mathrm{C} \mu \mathrm{g}$ chl $a^{-1}$ \\
\hline & Total nitrogen to total phosphorus ratio & TN:TP & molar ratio \\
\hline & Particulate organic carbon to particulate phosphorus ratio & POC:PP & molar ratio \\
\hline & Particulate nitrogen to particulate phosphorus ratio & $\mathrm{PN}: \mathrm{PP}$ & molar ratio \\
\hline & Particulate organic carbon to particulate nitrogen ratio & POC:PN & molar ratio \\
\hline & Indicator of phosphorus uptake & P debt & $\mu \mathrm{mol} \mathrm{P} \mu \mathrm{g} \operatorname{chl} a^{-1}$ \\
\hline & Indicator of ammonium uptake & $\mathrm{NH}_{4}{ }^{+}-\mathrm{N}$ debt & $\mu \mathrm{mol} \mathrm{N} \mu \mathrm{g} \operatorname{chl} a^{-1}$ \\
\hline & Indicator of nitrate uptake & $\mathrm{NO}_{3}{ }^{-}-\mathrm{N}$ debt & $\mu \mathrm{mol} \mathrm{N} \mu \mathrm{g} \operatorname{chl} a^{-1}$ \\
\hline \multirow{7}{*}{$\begin{array}{l}P-E \\
\text { Parameters }\end{array}$} & Maximum quantum yield of photosystem II (PSII) for photochemistry & & unitless \\
\hline & Light utilization efficiency (light limited slope of P-E curve) & & photons reemitted photons absorbed $d^{-1} / \mu \mathrm{mol}$ photons $\mathrm{m}^{-2} \mathrm{sec}^{-1}$ \\
\hline & Light utilization efficiency normalized to chlorophyll- $a$ & $\alpha^{\mathrm{B}}$ & photons reemitted photons absorbed ${ }^{-1} / \mu \mathrm{mol}$ photons $(\mathrm{mg} \mathrm{chl} a)^{-1} \mathrm{~m} \mathrm{sec}^{-1}$ \\
\hline & Light saturation parameter & $E_{k}$ & $\mu \mathrm{mol}$ photons $\mathrm{m}^{-2} \mathrm{sec}^{-1}$ \\
\hline & Light saturation parameter normalized to chlorophyll- $a$ & & $\mu \mathrm{mol}$ photons $(\mathrm{mg} \operatorname{chl} a)^{-1} \mathrm{~m} \mathrm{sec}^{-1}$ \\
\hline & Maximum relative electron transport rate through PSII & $\mathrm{rETR}_{\max }$ & photons reemitted photons absorbed ${ }^{-1}$ \\
\hline & Light-deficiency threshold & $\overline{\mathrm{E}}_{24} / \mathrm{E}_{\mathrm{k}}$ & unitless \\
\hline
\end{tabular}


Table 2.2. Summary of morphology and watershed land-use (generalized by trophic status) for the 32 study reservoirs.

\begin{tabular}{|c|c|c|c|c|c|}
\hline & & $\begin{array}{c}\text { Oligotrophic } \\
n=5\end{array}$ & $\begin{array}{c}\text { Mesotrophic } \\
n=13\end{array}$ & $\begin{array}{c}\text { Eutrophic } \\
n=12\end{array}$ & $\begin{array}{l}\text { Hypereutrophic } \\
\qquad n=2\end{array}$ \\
\hline \multirow{3}{*}{ Morphology } & $\begin{array}{r}\text { Maximum Depth } \\
(\mathrm{m})\end{array}$ & $\begin{array}{c}25.1 \\
(10.1-33.5)\end{array}$ & $\begin{array}{c}19.5 \\
(4.6-49.1)\end{array}$ & $\begin{array}{c}17.2 \\
(6.1-38.4)\end{array}$ & $\begin{array}{c}6.8 \\
(5.1-8.5)\end{array}$ \\
\hline & $\begin{array}{r}\text { Surface Area } \\
\text { (ha) }\end{array}$ & $\begin{array}{c}109 \\
(16-286)\end{array}$ & $\begin{array}{c}2,759 \\
(2-20,774)\end{array}$ & $\begin{array}{c}2,716 \\
(9-21,778)\end{array}$ & $\begin{array}{c}11 \\
(6-17)\end{array}$ \\
\hline & $\begin{array}{r}\text { Watershed Area } \\
\text { (ha) }\end{array}$ & $\begin{array}{c}1,824 \\
(139-5,069)\end{array}$ & $\begin{array}{c}70,495 \\
(28-464,073)\end{array}$ & $\begin{array}{c}265,905 \\
(90-2,397,033)\end{array}$ & $\begin{array}{c}130 \\
(58-202)\end{array}$ \\
\hline \multirow{3}{*}{$\begin{array}{l}\text { Watershed } \\
\text { Land-Use }\end{array}$} & $\%$ Forest & $\begin{array}{c}61 \\
(42-97)\end{array}$ & $\begin{array}{c}63 \\
(32-89)\end{array}$ & $\begin{array}{c}33 \\
(13-58)\end{array}$ & $\begin{array}{c}6 \\
(1-12)\end{array}$ \\
\hline & $\%$ Pasture & $\begin{array}{c}20 \\
(1-49)\end{array}$ & $\begin{array}{c}27 \\
(2-58)\end{array}$ & $\begin{array}{c}40 \\
(27-70)\end{array}$ & $\begin{array}{c}28 \\
(28-28)\end{array}$ \\
\hline & \% Crop & $\begin{array}{c}0 \\
(0-0)\end{array}$ & $\begin{array}{c}2 \\
(0-14)\end{array}$ & $\begin{array}{c}17 \\
(0-44)\end{array}$ & $\begin{array}{c}53 \\
(36-70)\end{array}$ \\
\hline
\end{tabular}

Shown are arithmetic means and ranges (minimum-maximum) of $n$ reservoirs grouped along the trophic gradient. 
Table 2.3. Summary of limnological parameters and epilimnetic nutrient chemistry (generalized by trophic status) for the 32 study reservoirs.

\begin{tabular}{|c|c|c|c|c|c|c|c|c|}
\hline & \multicolumn{2}{|c|}{ Oligotrophic } & \multicolumn{2}{|c|}{ Mesotrophic } & \multicolumn{2}{|c|}{ Eutrophic } & \multicolumn{2}{|c|}{ Hypereutrophic } \\
\hline & $\begin{array}{c}2017 \\
n=20\end{array}$ & $\begin{array}{c}2018 \\
n=16\end{array}$ & $\begin{array}{c}2017 \\
n=50\end{array}$ & $\begin{array}{c}2018 \\
n=38\end{array}$ & $\begin{array}{c}2017 \\
n=34\end{array}$ & $\begin{array}{c}2018 \\
n=41\end{array}$ & $\begin{array}{l}2017 \\
n=8\end{array}$ & $\begin{array}{c}2018 \\
n=8\end{array}$ \\
\hline$\frac{\text { Physical }}{\mathrm{Z}_{\operatorname{mix}}}$ & $\begin{array}{c}7.52 \\
(3.89-15.9)\end{array}$ & $\begin{array}{c}6.16 \\
(4.00-8.45)\end{array}$ & $\begin{array}{c}5.41^{49} \\
(0.03-25.08)\end{array}$ & $\begin{array}{c}6.43 \\
(2.62-23.43)\end{array}$ & $\begin{array}{c}4.43^{33} \\
(0.04-11.31)\end{array}$ & $\begin{array}{c}5.26 \\
(0.09-12.24)\end{array}$ & $\begin{array}{c}3.87 \\
(2.69-4.47)\end{array}$ & $\begin{array}{c}3.06 \\
(1.94-3.82)\end{array}$ \\
\hline $\begin{array}{r}\text { Secchi } \\
(m)\end{array}$ & $\begin{array}{c}3.43^{16} \\
(1.77-7.57)\end{array}$ & $\begin{array}{c}3.69 \\
(1.67-5.40)\end{array}$ & $\begin{array}{c}1.78 \\
(0.76-6.2)\end{array}$ & $\begin{array}{c}1.78 \\
(0.94-2.90)\end{array}$ & $\begin{array}{c}0.71^{31} \\
(0.29-1.95)\end{array}$ & $\begin{array}{c}1.08 \\
(0.18-2.25)\end{array}$ & $\begin{array}{c}0.56 \\
(0.35-0.88)\end{array}$ & $\begin{array}{c}0.52 \\
(0.31-0.98)\end{array}$ \\
\hline$\underset{\left(m^{-l}\right)}{\mathrm{K}_{\mathrm{d}}}$ & $\begin{array}{c}0.72 \\
(0.36-1.32)\end{array}$ & $\begin{array}{c}0.50 \\
(0.27-0.96)\end{array}$ & $\begin{array}{c}1.35 \\
(0.58-3.08)\end{array}$ & $\begin{array}{c}1.08^{37} \\
(0.44-1.77)\end{array}$ & $\begin{array}{c}2.19 \\
(1.23-5.08)\end{array}$ & $\begin{array}{c}1.71^{40} \\
(0.78-8.50)\end{array}$ & $\begin{array}{c}2.70^{7} \\
(1.61-3.55)\end{array}$ & $\begin{array}{c}2.81 \\
(1.34-4.07)\end{array}$ \\
\hline $\begin{array}{r}\overline{\mathrm{E}}_{0} \\
\text { (umol photons } m^{-2} s^{-1} \text { ) }\end{array}$ & $\begin{array}{c}678.70 \\
(631.60-699.60)\end{array}$ & $\begin{array}{c}671.10 \\
(616.40-698.30)\end{array}$ & $\begin{array}{c}658.50 \\
(514.00-699.60)\end{array}$ & $\begin{array}{c}644.90 \\
(477.20-698.40)\end{array}$ & $\begin{array}{c}660.10 \\
(581.90-701.40)\end{array}$ & $\begin{array}{c}657.20 \\
(477.60-696.70)\end{array}$ & $\begin{array}{c}663.00 \\
(598.20-693.20)\end{array}$ & $\begin{array}{c}659.90 \\
(575.40-695.30)\end{array}$ \\
\hline $\begin{array}{r}\overline{\mathrm{E}}_{24} \\
\left(\mu \mathrm{mol} \text { photons } m^{-2} s^{-1}\right)\end{array}$ & $\begin{array}{c}154.90 \\
(54.90-268.80)\end{array}$ & $\begin{array}{c}227.30 \\
(110.10-422.20)\end{array}$ & $\begin{array}{c}156.90^{49} \\
(25.90-690.60)\end{array}$ & $\begin{array}{c}132.70^{37} \\
(53.30-291.20)\end{array}$ & $\begin{array}{c}107.80^{33} \\
(37.90-649.20)\end{array}$ & $\begin{array}{c}108.40^{40} \\
(13.00-629.90)\end{array}$ & $\begin{array}{c}65.90^{7} \\
(51.40-127.10)\end{array}$ & $\begin{array}{c}88.30 \\
(41.40-135.70)\end{array}$ \\
\hline $\begin{array}{r}\frac{\text { Chemical }}{\mathrm{TP}} \\
\left(\mu \mathrm{mol} L^{-I}\right)\end{array}$ & $\begin{array}{c}0.24 \\
(0.10-0.50)\end{array}$ & $\begin{array}{c}0.22 \\
(0.10-0.30)\end{array}$ & $\begin{array}{c}0.58 \\
(0.30-1.20)\end{array}$ & $\begin{array}{c}0.54 \\
(0.20-1.40)\end{array}$ & $\begin{array}{c}1.65 \\
(0.80-4.40)\end{array}$ & $\begin{array}{c}1.31 \\
(0.50-3.40)\end{array}$ & $\begin{array}{c}3.09 \\
(2.10-3.90)\end{array}$ & $\begin{array}{c}3.34 \\
(2.40-3.70)\end{array}$ \\
\hline $\begin{array}{r}\text { DRP } \\
\left(\mu m o l L^{-I}\right)\end{array}$ & -- & $\begin{array}{c}0.06^{15} \\
(0.03-0.11)\end{array}$ & -- & $\begin{array}{c}0.07^{37} \\
\left(0.03^{*}-0.15\right)\end{array}$ & -- & $\begin{array}{c}0.11^{38} \\
(0.04-0.77)\end{array}$ & -- & $\begin{array}{c}0.15^{7} \\
(0.10-0.18)\end{array}$ \\
\hline $\begin{array}{r}\text { PP } \\
\left(\mu \mathrm{mol} L^{-I}\right)\end{array}$ & $\begin{array}{c}0.18^{7} \\
(0.03-0.46)\end{array}$ & $\begin{array}{c}0.13^{15} \\
(0.03-0.44)\end{array}$ & $\begin{array}{c}0.47^{45} \\
(0.14-1.29)\end{array}$ & $\begin{array}{c}0.36 \\
(0.15-0.86)\end{array}$ & $\begin{array}{c}1.40^{31} \\
(0.48-7.25)\end{array}$ & $\begin{array}{c}0.97^{39} \\
(0.21-2.04)\end{array}$ & $\begin{array}{c}2.46 \\
(1.55-3.24)\end{array}$ & $\begin{array}{c}2.64^{7} \\
(1.74-2.95)\end{array}$ \\
\hline $\begin{array}{r}\mathrm{TN} \\
\left(\mu \mathrm{mol} L^{-1}\right)\end{array}$ & $\begin{array}{c}20.88 \\
(16.57-26.68)\end{array}$ & $\begin{array}{c}21.93 \\
(13.59-29.44)\end{array}$ & $\begin{array}{c}29.96 \\
(8.83-43.51)\end{array}$ & $\begin{array}{c}32.88 \\
(18.21-50.67)\end{array}$ & $\begin{array}{c}66.46 \\
(30.11-141.31)\end{array}$ & $\begin{array}{c}59.82 \\
(36.65-122.80)\end{array}$ & $\begin{array}{c}94.71 \\
(75.65-116.16)\end{array}$ & $\begin{array}{c}84.76^{7} \\
(37.48-116.47)\end{array}$ \\
\hline $\begin{array}{r}\mathrm{PN} \\
\left(\text { umol L } L^{-1}\right)\end{array}$ & $\begin{array}{c}8.01^{7} \\
(5.53-16.99)\end{array}$ & $\begin{array}{c}4.64^{15} \\
(2.11-11.48)\end{array}$ & $\begin{array}{c}11.28^{43} \\
(4.13-41.12)\end{array}$ & $\begin{array}{c}10.02^{37} \\
(4.10-21.39)\end{array}$ & $\begin{array}{c}26.96^{31} \\
(12.26-56.83)\end{array}$ & $\begin{array}{c}22.91^{39} \\
(5.91-51.41)\end{array}$ & $\begin{array}{c}43.68 \\
(5.47-69.51)\end{array}$ & $\begin{array}{c}66.08^{7} \\
(43.58-92.11)\end{array}$ \\
\hline $\begin{array}{r}\mathrm{DOC} \\
\left(\mu m o l L^{-1}\right)\end{array}$ & $\begin{array}{c}293.3^{6} \\
(238.0-342.4)\end{array}$ & $\begin{array}{c}244.2^{15} \\
(197.5-307.7)\end{array}$ & $\begin{array}{c}379.5^{42} \\
(51.5-559.7)\end{array}$ & $\begin{array}{c}394.86 \\
(185.6-608.5)\end{array}$ & $\begin{array}{c}490.1^{28} \\
(98.12-733.0)\end{array}$ & $\begin{array}{c}445.6^{39} \\
(72.6-672.2)\end{array}$ & $\begin{array}{c}509.5^{4} \\
(430.9-580.93)\end{array}$ & $\begin{array}{c}601.1^{4} \\
(525.8-774.0)\end{array}$ \\
\hline $\begin{array}{r}\text { TSS } \\
\left(\mu g L^{-I}\right)\end{array}$ & $\begin{array}{c}2.00^{19} \\
(1.10-3.30)\end{array}$ & $\begin{array}{c}1.50 \\
(0.80-4.10)\end{array}$ & $\begin{array}{c}3.20^{48} \\
(1.10-6.80)\end{array}$ & $\begin{array}{c}2.90 \\
(1.20-8.20)\end{array}$ & $\begin{array}{c}9.00^{32} \\
(3.20-22.10)\end{array}$ & $\begin{array}{c}8.00 \\
(1.90-76.50)\end{array}$ & $\begin{array}{c}12.20 \\
(8.10-20.00)\end{array}$ & $\begin{array}{c}15.00 \\
(6.70-23.60)\end{array}$ \\
\hline $\begin{array}{r}\text { PIM } \\
\left(\mu g L^{-I}\right)\end{array}$ & $\begin{array}{c}0.80 \\
(0.20-1.70)\end{array}$ & $\begin{array}{c}0.70 \\
(0.20-1.60)\end{array}$ & $\begin{array}{c}1.00 \\
(0.10-2.70)\end{array}$ & $\begin{array}{c}0.80 \\
(0.20-4.50)\end{array}$ & $\begin{array}{c}4.00 \\
(0.70-18.50)\end{array}$ & $\begin{array}{c}3.90 \\
(0.30-67.00)\end{array}$ & $\begin{array}{c}4.50 \\
(0.70-11.80)\end{array}$ & $\begin{array}{c}3.10 \\
(0.60-7.40)\end{array}$ \\
\hline $\begin{array}{r}\text { POM } \\
\left(\mu \mathrm{g} L^{-I}\right)\end{array}$ & $\begin{array}{c}1.20^{19} \\
(0.60-2.20)\end{array}$ & $\begin{array}{c}0.80 \\
(0.40-2.50)\end{array}$ & $\begin{array}{c}2.20^{48} \\
(0.60-5.40)\end{array}$ & $\begin{array}{c}2.10 \\
(0.70-4.50)\end{array}$ & $\begin{array}{c}5.40^{32} \\
(2.40-16.50)\end{array}$ & $\begin{array}{c}4.10 \\
(1.20-9.90)\end{array}$ & $\begin{array}{c}7.70 \\
(5.00-9.90)\end{array}$ & $\begin{array}{c}12.00 \\
(6.10-16.20)\end{array}$ \\
\hline
\end{tabular}




\begin{tabular}{|c|c|c|c|c|c|c|c|c|}
\hline \multicolumn{9}{|l|}{ Biological } \\
\hline $\begin{array}{r}\operatorname{chl} a \\
\left(\mu \mathrm{g} L^{-I}\right)\end{array}$ & $\begin{array}{c}2.90 \\
(0.90-9.60)\end{array}$ & $\begin{array}{c}2.50 \\
(1.00-12.40)\end{array}$ & $\begin{array}{c}7.40 \\
(1.00-19.30)\end{array}$ & $\begin{array}{c}8.70 \\
(1.00-22.70)\end{array}$ & $\begin{array}{c}27.00 \\
(5.40-125.70)\end{array}$ & $\begin{array}{c}18.80 \\
(2.20-54.80)\end{array}$ & $\begin{array}{c}48.10 \\
(18.60-71.10)\end{array}$ & $\begin{array}{c}69.70 \\
(46.00-99.60)\end{array}$ \\
\hline $\begin{array}{r}\text { pheo } \\
\left(\mu \mathrm{g} L^{-1}\right)\end{array}$ & $\begin{array}{c}1.03 \\
(0.30-2.80)\end{array}$ & $\begin{array}{c}0.68 \\
(0.23-2.30)\end{array}$ & $\begin{array}{c}3.75 \\
(0.40-12.70)\end{array}$ & $\begin{array}{c}3.82 \\
(0.23-11.40)\end{array}$ & $\begin{array}{c}10.73 \\
(2.10-34.70)\end{array}$ & $\begin{array}{c}8.91 \\
(0.90-30.00)\end{array}$ & $\begin{array}{c}17.95 \\
(6.90-28.70)\end{array}$ & $\begin{array}{c}33.61 \\
(17.00-66.60)\end{array}$ \\
\hline $\begin{array}{r}\mathrm{POC} \\
\left(\mu m o l L^{-I}\right)\end{array}$ & $\begin{array}{c}68.54^{7} \\
(39.2-113.26)\end{array}$ & $\begin{array}{c}38.56^{15} \\
(20.36-98.61)\end{array}$ & $\begin{array}{c}89.66^{44} \\
(33.00-224.22)\end{array}$ & $\begin{array}{c}82.66 \\
(29.56-188.69)\end{array}$ & $\begin{array}{c}204.05^{31} \\
(87.30-461.89)\end{array}$ & $\begin{array}{c}160.41^{39} \\
(38.61-360.6)\end{array}$ & $\begin{array}{c}284.82 \\
(31.69-423.65)\end{array}$ & $\begin{array}{c}474.48^{7} \\
(259.95-616.25)\end{array}$ \\
\hline $\begin{array}{r}\text { GPP } \\
\left(m m o l ~ \mathrm{O}_{2} m^{-2} d^{-1}\right)\end{array}$ & -- & $\begin{array}{c}668.00^{12} \\
(89.93-1,628.73)\end{array}$ & -- & $\begin{array}{c}701.47^{31} \\
(33.36-2,668.00)\end{array}$ & -- & $\begin{array}{c}681.86^{36} \\
(38.86-1,820.05)\end{array}$ & -- & $\begin{array}{c}607.42^{5} \\
(458.47-768.31)\end{array}$ \\
\hline $\begin{array}{r}\mathrm{GPP}^{\mathrm{B}} \\
\left(m m o l O_{2}(m g \text { chla })^{-1} m d^{-1}\right)\end{array}$ & -- & $\begin{array}{c}429.01^{12} \\
(39.62-1,661.97)\end{array}$ & -- & $\begin{array}{c}134.54^{31} \\
(9.83-630.11)\end{array}$ & -- & $\begin{array}{c}63.83^{36} \\
(5.34-430.61)\end{array}$ & -- & $\begin{array}{c}9.79^{5} \\
(4.60-13.82)\end{array}$ \\
\hline \multicolumn{9}{|l|}{ Nutrient Status } \\
\hline $\begin{array}{r}\text { POC:chla } \\
\left(\mu \mathrm{mol} C \mu \mathrm{g} \mathrm{chla}^{-1}\right)\end{array}$ & $\begin{array}{c}22.74^{7} \\
(10.24-55.32)\end{array}$ & $\begin{array}{c}18.42^{15} \\
(7.93-27.16)\end{array}$ & $\begin{array}{c}16.49^{44} \\
(2.75-67.47)\end{array}$ & $\begin{array}{c}13.63 \\
(3.56-57.93)\end{array}$ & $\begin{array}{c}11.26^{31} \\
(1.81-32.59)\end{array}$ & $\begin{array}{c}13.42^{39} \\
(4.74-139.39)\end{array}$ & $\begin{array}{c}6.22 \\
(1.30-11.08)\end{array}$ & $\begin{array}{c}7.32^{7} \\
(4.68-10.05)\end{array}$ \\
\hline $\begin{array}{r}\text { TN:TP } \\
\text { (molar ratio) }\end{array}$ & $\begin{array}{c}98.47 \\
(48.79-195.54)\end{array}$ & $\begin{array}{c}113.66 \\
(69.15-169.22)\end{array}$ & $\begin{array}{c}54.39 \\
(30.34-109.55)\end{array}$ & $\begin{array}{c}65.30 \\
(20.72-114.23)\end{array}$ & $\begin{array}{c}44.18 \\
(14.54-97.98)\end{array}$ & $\begin{array}{c}50.54 \\
(19.00-103.38)\end{array}$ & $\begin{array}{c}31.56 \\
(23.38-46.54)\end{array}$ & $\begin{array}{c}26.06^{7} \\
(10.21-40.40)\end{array}$ \\
\hline $\begin{array}{r}\text { POC:PP } \\
\text { (molar ratio) }\end{array}$ & $\begin{array}{c}823.81^{7} \\
(179.25-3003.98)\end{array}$ & $\begin{array}{c}370.49^{15} \\
(186.43-926.99)\end{array}$ & $\begin{array}{c}248.37^{44} \\
(48.78-1659.53)\end{array}$ & $\begin{array}{c}234.88 \\
(122.37-458.26)\end{array}$ & $\begin{array}{c}172.68^{31} \\
(63.71-474.79)\end{array}$ & $\begin{array}{c}174.53^{39} \\
(83.93-286.41)\end{array}$ & $\begin{array}{c}121.54 \\
(11.18-184.72)\end{array}$ & $\begin{array}{c}178.46^{7} \\
(140.64-216.36)\end{array}$ \\
\hline $\begin{array}{r}\mathrm{PN}: \mathrm{PP} \\
\text { (molar ratio) }\end{array}$ & $\begin{array}{c}82.35^{7} \\
(27.8-281.44)\end{array}$ & $\begin{array}{c}43.21^{15} \\
(19.68-87.08)\end{array}$ & $\begin{array}{c}29.98^{43} \\
(6.67-132.24)\end{array}$ & $\begin{array}{c}27.75^{37} \\
(18.39-51.94)\end{array}$ & $\begin{array}{c}22.30^{31} \\
(7.84-59.92)\end{array}$ & $\begin{array}{c}24.48^{39} \\
(13.22-58.28)\end{array}$ & $\begin{array}{c}18.14 \\
(1.93-26.22)\end{array}$ & $\begin{array}{c}25.03^{7} \\
(17.01-32.34)\end{array}$ \\
\hline $\begin{array}{r}\text { POC:PN } \\
\text { (molar ratio) }\end{array}$ & $\begin{array}{c}9.09^{7} \\
(6.45-15.1)\end{array}$ & $\begin{array}{c}8.43^{15} \\
(6.60-10.64)\end{array}$ & $\begin{array}{c}8.42^{43} \\
(1.92-14.42)\end{array}$ & $\begin{array}{c}8.42^{37} \\
(5.41-12.02)\end{array}$ & $\begin{array}{c}7.77^{31} \\
(6.28-11.72)\end{array}$ & $\begin{array}{c}7.23^{39} \\
(3.97-10.23)\end{array}$ & $\begin{array}{c}6.58 \\
(5.79-8.65)\end{array}$ & $\begin{array}{c}7.30^{7} \\
(5.62-8.75)\end{array}$ \\
\hline $\begin{array}{r}\mathrm{P} \text { debt } \\
\left(\mu m o l P \mu g \operatorname{chla}^{-1}\right)\end{array}$ & -- & $\begin{array}{c}0.23^{15} \\
(0.03-0.55)\end{array}$ & -- & $\begin{array}{c}0.15^{37} \\
(0.00-0.40)\end{array}$ & -- & $\begin{array}{c}0.08^{36} \\
(0.01-0.27)\end{array}$ & -- & $\begin{array}{c}0.03^{6} \\
(0.02-0.07)\end{array}$ \\
\hline $\begin{array}{r}\mathrm{NH}_{4}{ }^{+}-\mathrm{N} \text { debt } \\
\left(\mu m o l N \mu g \text { chla }^{-l}\right)\end{array}$ & -- & $\begin{array}{c}0.14^{12} \\
(0.00-0.58)\end{array}$ & -- & $\begin{array}{c}0.04^{36} \\
(0.00-0.23)\end{array}$ & -- & $\begin{array}{c}0.05^{37} \\
(0.00-0.25)\end{array}$ & -- & $\begin{array}{c}0.03^{6} \\
(0.00-0.07)\end{array}$ \\
\hline $\begin{array}{r}\mathrm{NO}_{3}^{-}-\mathrm{N} \text { debt } \\
\left(\mu m o l N \mu g \text { chlal }^{-1}\right)\end{array}$ & -- & $\begin{array}{c}0.04^{15} \\
(0.00-0.10)\end{array}$ & -- & $\begin{array}{c}0.03^{37} \\
(0.00-0.23)\end{array}$ & -- & $\begin{array}{c}0.03^{38} \\
(0.00-0.11)\end{array}$ & -- & $\begin{array}{c}0.03^{7} \\
(0.00-0.12)\end{array}$ \\
\hline $\begin{array}{l}+\mathrm{P} \text { 申PSII } \\
\text { (unitless) }\end{array}$ & -- & $\begin{array}{c}0.38^{11} \\
(0.16-0.64)\end{array}$ & -- & $\begin{array}{c}0.38^{34} \\
(0.16-0.58)\end{array}$ & -- & $\begin{array}{c}0.37^{38} \\
(0.20-0.89)\end{array}$ & -- & $\begin{array}{c}0.35^{6} \\
(0.27-0.47)\end{array}$ \\
\hline $\begin{array}{r}+\mathrm{NH}_{4}{ }^{+} \phi_{\text {PSII }} \\
\text { (unitless) }\end{array}$ & -- & $\begin{array}{c}0.36^{11} \\
(0.21-0.55)\end{array}$ & -- & $\begin{array}{c}0.38^{34} \\
(0.20-0.58)\end{array}$ & -- & $\begin{array}{c}0.36^{38} \\
(0.20-0.63)\end{array}$ & -- & $\begin{array}{c}0.34^{7} \\
(0.28-0.45)\end{array}$ \\
\hline $\begin{array}{r}+\mathrm{NO}_{3}{ }^{-} \phi_{\mathrm{PSII}} \\
\text { (unitless) }\end{array}$ & -- & $\begin{array}{c}0.36^{11} \\
(0.20-0.56)\end{array}$ & -- & $\begin{array}{c}0.39^{34} \\
(0.17-0.60)\end{array}$ & -- & $\begin{array}{c}0.37^{38} \\
(0.21-0.57)\end{array}$ & -- & $\begin{array}{c}0.34^{7} \\
(0.22-0.47)\end{array}$ \\
\hline
\end{tabular}




\begin{tabular}{|c|c|c|c|c|c|c|c|c|}
\hline \multicolumn{9}{|l|}{$\underline{P-E}$ Parameters } \\
\hline $\begin{array}{r}\phi_{\mathrm{PSII}} \\
(\text { unitless })\end{array}$ & -- & $\begin{array}{c}0.48^{11} \\
(0.33-0.56)\end{array}$ & -- & $\begin{array}{c}0.50^{35} \\
(0.34-0.66)\end{array}$ & -- & $\begin{array}{c}0.48^{38} \\
(0.38-0.63)\end{array}$ & -- & $\begin{array}{c}0.44^{7} \\
(0.38-0.53)\end{array}$ \\
\hline $\begin{array}{r}\alpha \\
\text { (photons reemitted photons } \\
\text { absorbed } \\
\text { /umol photons } m^{-2} \\
s^{-1} \text { ) }\end{array}$ & -- & $\begin{array}{c}0.52^{12} \\
(0.38-0.62)\end{array}$ & -- & $\begin{array}{c}0.52^{35} \\
(0.39-0.66)\end{array}$ & -- & $\begin{array}{c}0.50^{38} \\
(0.35-0.88)\end{array}$ & -- & $\begin{array}{c}0.47^{7} \\
(0.40-0.53)\end{array}$ \\
\hline $\begin{array}{r}\alpha^{\mathrm{B}} \\
\text { (photons reemitted photons } \\
\text { absorbed }{ }^{-1} / \mu \mathrm{mol} \text { photons }(\mathrm{mg} \\
\left.\text { chla })^{-1} \mathrm{~ms}^{-1}\right)\end{array}$ & -- & $\begin{array}{c}0.32^{12} \\
(0.03-0.59)\end{array}$ & -- & $\begin{array}{c}0.12^{35} \\
(0.02-0.44)\end{array}$ & -- & $\begin{array}{c}0.06^{38} \\
(0.01-0.40)\end{array}$ & -- & $\begin{array}{c}0.01^{7} \\
(0.00-0.01)\end{array}$ \\
\hline $\begin{array}{r}\mathrm{E}_{\mathrm{k}} \\
\left(\text { umol photons } m^{-2} s^{-1}\right)\end{array}$ & -- & $\begin{array}{c}278.20^{12} \\
(171.92-405.89)\end{array}$ & -- & $\begin{array}{c}261.41^{35} \\
(92.68-422.17)\end{array}$ & -- & $\begin{array}{c}311.35^{38} \\
(97.65-491.34)\end{array}$ & -- & $\begin{array}{c}319.55^{7} \\
(183.93-395.53)\end{array}$ \\
\hline $\begin{array}{r}\mathrm{E}_{\mathrm{k}}^{\mathrm{B}} \\
\left.(\text { umol photons (mg chla })^{-1} \mathrm{~ms}^{-1}\right)\end{array}$ & -- & $\begin{array}{c}160.97^{12} \\
(32.62-273.39)\end{array}$ & -- & $\begin{array}{c}66.13^{35} \\
(6.84-305.46)\end{array}$ & -- & $\begin{array}{c}30.02^{38} \\
(6.28-173.84)\end{array}$ & -- & $\begin{array}{c}5.13^{7} \\
(1.85-7.12)\end{array}$ \\
\hline $\begin{array}{r}\mathrm{rETR}_{\max } \\
\text { (photons reemitted photons } \\
\text { absorbed }^{-1} \text { ) }\end{array}$ & -- & $\begin{array}{c}140.32^{12} \\
(73.91-216.69)\end{array}$ & -- & $\begin{array}{c}135.79^{35} \\
(54.96-279.71)\end{array}$ & -- & $\begin{array}{c}152.71^{38} \\
(66.58-265.65)\end{array}$ & -- & $\begin{array}{c}151.74^{7} \\
(72.63-201.13)\end{array}$ \\
\hline $\begin{array}{r}\overline{\mathrm{E}}_{24} / \mathrm{E}_{\mathrm{k}} \\
\text { (unitless) }\end{array}$ & -- & $\begin{array}{c}0.80^{12} \\
(0.33-1.40)\end{array}$ & -- & $\begin{array}{c}0.54^{34} \\
(0.19-1.17)\end{array}$ & -- & $\begin{array}{c}0.38^{37} \\
(0.11-2.49)\end{array}$ & -- & $\begin{array}{c}0.28^{6} \\
(0.19-0.40)\end{array}$ \\
\hline
\end{tabular}

Shown are arithmetic means and ranges (minimum-maximum) of $n$ samples grouped along the trophic gradient. Superscript numbers indicate $n$ values that differed from those reported in the column headers. An asterisk (*) is used when values are below detection limit. See Table 2.1 for parameter definitions, abbreviations, and units. See Table 2.9 for additional epilimnetic dissolved nutrient concentrations $\left(\mathrm{TDP}^{\mathrm{T}} \mathrm{TDN}_{\mathrm{N}} \mathrm{NO}_{3}^{-}, \mathrm{NH}_{4}^{+}, \mathrm{TDON}^{-}\right.$ 
Table 2.4. Established light and nutrient status indicator thresholds that were applied to assess deficiency among the reservoir phytoplankton communities.

\begin{tabular}{|c|c|c|c|c|}
\hline Limiting Factor & Indicator & Deficient & Moderately Deficient & Extremely Deficient \\
\hline \multirow{2}{*}{ Light } & $\overline{\mathrm{E}}_{24}$ & & $<69.4$ & $<41.7$ \\
\hline & $\overline{\mathrm{E}}_{24} / \mathrm{E}_{\mathrm{k}}$ & $<1$ & & \\
\hline \multirow{4}{*}{$\begin{array}{r}\text { Phosphorus } \\
(P)\end{array}$} & $\mathrm{TN}: \mathrm{TP}$ & $>50$ & & \\
\hline & POC:PP & & $>129$ & $>258$ \\
\hline & $\mathrm{PN}: \mathrm{PP}$ & $>22$ & & \\
\hline & P debt & $>0.075$ & & \\
\hline \multirow{3}{*}{$\begin{array}{r}\text { Nitrogen } \\
(N)\end{array}$} & TN:TP & $<20$ & & \\
\hline & POC:PN & & $>8.3$ & $>14.6$ \\
\hline & $\mathrm{NH}_{4}{ }^{+}-\mathrm{N}$ debt & $>0.15$ & & \\
\hline \multirow{2}{*}{$N$ or $P$} & POC: $\operatorname{chl} a$ & & $>4.2$ & $>8.3$ \\
\hline & $\mathrm{TN}: \mathrm{TP}$ & $20-50$ & & \\
\hline
\end{tabular}

Most indicator values are from Guildford and Hecky (2000); $\bar{E}_{24}$ and $E_{k}$ are based on Hecky and Guildford (1984) and Knowlton and Jones (2000); P debt, POC:PP, $\mathrm{NH}_{4}{ }^{+}-\mathrm{N}$ debt, POC:PN, and POC:chla on Healey and Hendzel (1979). See Table 2.1 for parameter definitions, abbreviations, and units. 
Table 2.5. Linear mixed effect (LME) model output, grouped by physical, chemical, biological, nutrient status, and photosynthesis-irradiance (P-E) parameters. Data were tested for the effects of year, sampling event, trophic status, and watershed land-use. Each LME analysis was coupled with an ANOVA (F- and pvalues) and, when appropriate, followed with a Tukey's Honest Significant Difference test.

\begin{tabular}{|c|c|c|c|c|c|c|c|c|c|c|c|c|c|c|c|c|c|}
\hline & \multirow[b]{2}{*}{ Fixed effect } & \multirow[b]{2}{*}{$F$-value } & \multirow[b]{2}{*}{$p$-value } & \multicolumn{2}{|c|}{ Year } & \multicolumn{4}{|c|}{ Sampling event } & \multicolumn{4}{|c|}{ Trophic status } & \multicolumn{4}{|c|}{ Land-use } \\
\hline & & & & 2017 & 2018 & 1 & 2 & 3 & 4 & $\mathrm{O}$ & $\mathrm{M}$ & $E$ & $\mathrm{H}$ & $\mathrm{F}$ & Mix & Ag-P & Ag-C \\
\hline \multicolumn{18}{|l|}{ Physical } \\
\hline \multirow[t]{5}{*}{$\mathrm{Z}_{\text {mix }}^{\mathrm{a}}$} & Year & $F_{1,179}=1.088$ & 0.298 & & & & & & & & & & & & & & \\
\hline & Sampling Event & $F_{3,179}=1.131$ & 0.289 & & & & & & & & & & & & & & \\
\hline & Trophic Status & $F_{3,25}=3.580$ & 0.028 & & & & & & & $\mathrm{~b}$ & $\mathrm{ab}$ & $\mathrm{a}$ & $a b$ & & & & \\
\hline & Land-Use & $F_{3,25}=4.763$ & 0.009 & & & & & & & & & & & $\mathrm{~b}$ & $a b$ & $\mathrm{a}$ & $a b$ \\
\hline & Sampling Event:Year & $F_{3,179}=1.129$ & 0.289 & & & & & & & & & & & & & & \\
\hline \multirow[t]{5}{*}{ Secchi $^{\mathrm{a}}$} & Year & $F_{1,172}=8.287$ & 0.005 & $\mathrm{a}$ & $\mathrm{b}$ & & & & & & & & & & & & \\
\hline & Sampling Event & $F_{3,172}=1.892$ & 0.133 & & & & & & & & & & & & & & \\
\hline & Trophic Status & $F_{3,25}=22.117$ & $<0.001$ & & & & & & & $\mathrm{c}$ & $\mathrm{b}$ & $\mathrm{a}$ & $\mathrm{a}$ & & & & \\
\hline & Land-Use & $F_{3,25}=0.601$ & 0.621 & & & & & & & & & & & & & & \\
\hline & Sampling Event:Year & $F_{3,172}=2.069$ & 0.106 & & & & & & & & & & & & & & \\
\hline \multirow[t]{5}{*}{$\mathrm{K}_{\mathrm{d}}^{\mathrm{a}}$} & Year & $F_{1,175}=21.735$ & $<0.001$ & $\mathrm{~b}$ & $\mathrm{a}$ & & & & & & & & & & & & \\
\hline & Sampling Event & $F_{3,175}=1.731$ & 0.162 & & & & & & & & & & & & & & \\
\hline & Trophic Status & $F_{3,25}=13.527$ & $<0.001$ & & & & & & & $\mathrm{a}$ & $\mathrm{b}$ & $\mathrm{c}$ & $\mathrm{c}$ & & & & \\
\hline & Land-Use & $F_{3,25}=1.482$ & 0.244 & & & & & & & & & & & & & & \\
\hline & Sampling Event:Year & $F_{3,175}=1.855$ & 0.139 & & & & & & & & & & & & & & \\
\hline \multirow[t]{5}{*}{$\overline{\mathrm{E}}_{24}{ }^{\mathrm{a}}$} & Year & $F_{1,174}=0.582$ & 0.447 & & & & & & & & & & & & & & \\
\hline & Sampling Event & $F_{3,174}=3.133$ & 0.027 & & & $\mathrm{~b}$ & $a b$ & $a b$ & $\mathrm{a}$ & & & & & & & & \\
\hline & Trophic Status & $F_{3,25}=1.467$ & 0.248 & & & & & & & & & & & & & & \\
\hline & Land-Use & $F_{3,25}=5.838$ & 0.004 & & & & & & & & & & & $\mathrm{~b}$ & $a b$ & $\mathrm{a}$ & $a b$ \\
\hline & Sampling Event:Year & $F_{3,174}=0.365$ & 0.778 & & & & & & & & & & & & & & \\
\hline \multicolumn{18}{|l|}{ Chemical } \\
\hline \multirow[t]{5}{*}{$\mathrm{TP}^{\mathrm{a}}$} & Year & $F_{1,183}=14.270$ & $<0.001$ & $\mathrm{~b}$ & a & & & & & & & & & & & & \\
\hline & Sampling Event & $F_{3,183}=1.602$ & 0.191 & & & & & & & & & & & & & & \\
\hline & Trophic Status & $F_{3,25}=40.841$ & $<0.001$ & & & & & & & $\mathrm{a}$ & $\mathrm{b}$ & $\mathrm{c}$ & $\mathrm{d}$ & & & & \\
\hline & Land-Use & $F_{3,25}=1.835$ & 0.167 & & & & & & & & & & & & & & \\
\hline & Sampling Event:Year & $F_{3,174}=1.380$ & 0.251 & & & & & & & & & & & & & & \\
\hline \multirow[t]{3}{*}{$\mathrm{TDP}^{\mathrm{b}}$} & Sampling Event & $F_{3,67}=2.569$ & 0.062 & & & & & & & & & & & & & & \\
\hline & Trophic Status & $F_{3,20}=22.863$ & $<0.001$ & & & & & & & a & $\mathrm{b}$ & $\mathrm{c}$ & $\mathrm{d}$ & & & & \\
\hline & Land-Use & $F_{3,20}=1.044$ & 0.395 & & & & & & & & & & & & & & \\
\hline \multirow[t]{3}{*}{$\mathrm{DRP}^{\mathrm{b}}$} & Sampling Event & $F_{3,67}=1.465$ & 0.232 & & & & & & & & & & & & & & \\
\hline & Trophic Status & $F_{3,20}=5.799$ & 0.005 & & & & & & & $\mathrm{a}$ & $\mathrm{a}$ & $\mathrm{b}$ & $\mathrm{b}$ & & & & \\
\hline & Land-Use & $F_{3,20}=1.754$ & 0.188 & & & & & & & & & & & & & & \\
\hline $\mathrm{PP}^{\mathrm{a}}$ & Year & $F_{1,154}=11.651$ & $<0.001$ & $\mathrm{~b}$ & $\mathrm{a}$ & & & & & & & & & & & & \\
\hline
\end{tabular}




\begin{tabular}{|c|c|c|c|c|c|}
\hline & Sampling Event & $F_{3,154}=0.470$ & 0.704 & & \\
\hline & Trophic Status & $F_{3,25}=60.346$ & $<0.001$ & & \\
\hline & Land-Use & $F_{3,25}=3.128$ & 0.044 & & \\
\hline & Sampling Event:Year & $F_{3,154}=1.478$ & 0.223 & & \\
\hline \multirow[t]{5}{*}{$\mathrm{TN}^{\mathrm{a}}$} & Year & $F_{1,182}=1.234$ & 0.268 & & \\
\hline & Sampling Event & $F_{3,182}=2.245$ & 0.085 & & \\
\hline & Trophic Status & $F_{3,25}=11.605$ & $<0.001$ & & \\
\hline & Land-Use & $F_{3,25}=0.635$ & 0.599 & & \\
\hline & Sampling Event:Year & $F_{3,182}=0.623$ & 0.601 & & \\
\hline \multirow[t]{3}{*}{$\mathrm{TDN}^{\mathrm{b}}$} & Sampling Event & $F_{3,67}=2.193$ & 0.097 & & \\
\hline & Trophic Status & $F_{3,20}=6.939$ & 0.002 & & \\
\hline & Land-Use & $F_{3,20}=1.462$ & 0.255 & & \\
\hline \multirow[t]{3}{*}{$\mathrm{DON}^{\mathrm{b}}$} & Sampling Event & $F_{3,66}=0.918$ & 0.437 & & \\
\hline & Trophic Status & $F_{3,20}=3.381$ & 0.039 & & \\
\hline & Land-Use & $F_{3,20}=0.147$ & 0.930 & & \\
\hline \multirow[t]{5}{*}{$\mathrm{PN}^{\mathrm{a}}$} & Year & $F_{1,151}=5.658$ & 0.019 & $\mathrm{~b}$ & \\
\hline & Sampling Event & $F_{3,151}=0.155$ & 0.926 & & \\
\hline & Trophic Status & $F_{3,25}=27.069$ & $<0.001$ & & \\
\hline & Land-Use & $F_{3,25}=2.582$ & 0.076 & & \\
\hline & Sampling Event:Year & $F_{3,151}=0.825$ & 0.482 & & \\
\hline \multirow[t]{5}{*}{$\mathrm{DOC}^{\mathrm{a}}$} & Year & $F_{1,140}=7.363$ & 0.008 & $\mathrm{~b}$ & \\
\hline & Sampling Event & $F_{3,140}=19.803$ & $<0.001$ & & \\
\hline & Trophic Status & $F_{3,25}=2.689$ & 0.068 & & \\
\hline & Land-Use & $F_{3,25}=0.450$ & 0.720 & & \\
\hline & Sampling Event:Year & $F_{3,140}=6.250$ & $<0.001$ & & \\
\hline \multirow{5}{*}{$\mathrm{TSS}^{\mathrm{a}}$} & Year & $F_{1,178}=15.762$ & $<0.001$ & $\mathrm{a}$ & \\
\hline & Sampling Event & $F_{3,178}=0.567$ & 0.638 & & \\
\hline & Trophic Status & $F_{3,25}=23.365$ & $<0.001$ & & \\
\hline & Land-Use & $F_{3,25}=1.698$ & 0.193 & & \\
\hline & Sampling Event:Year & $F_{3,178}=1.241$ & 0.297 & & \\
\hline \multirow[t]{5}{*}{$\mathrm{POM}^{\mathrm{a}}$} & Year & $F_{1,178}=13.543$ & $<0.001$ & $\mathrm{a}$ & $\mathrm{b}$ \\
\hline & Sampling Event & $F_{3,178}=0.474$ & 0.701 & & \\
\hline & Trophic Status & $F_{3,25}=31.500$ & $<0.001$ & & \\
\hline & Land-Use & $F_{3,25}=4.562$ & 0.011 & & \\
\hline & Sampling Event:Year & $F_{3,178}=1.311$ & 0.272 & & \\
\hline \multirow[t]{4}{*}{ PIM $^{a}$} & Year & $F_{1,183}=10.712$ & 0.001 & $\mathrm{a}$ & $\mathrm{b}$ \\
\hline & Sampling Event & $F_{3,183}=2.219$ & 0.088 & & \\
\hline & Trophic Status & $F_{3,25}=5.672$ & 0.004 & & \\
\hline & Land-Use & $F_{3,25}=0.158$ & 0.923 & & \\
\hline
\end{tabular}

a b c d 


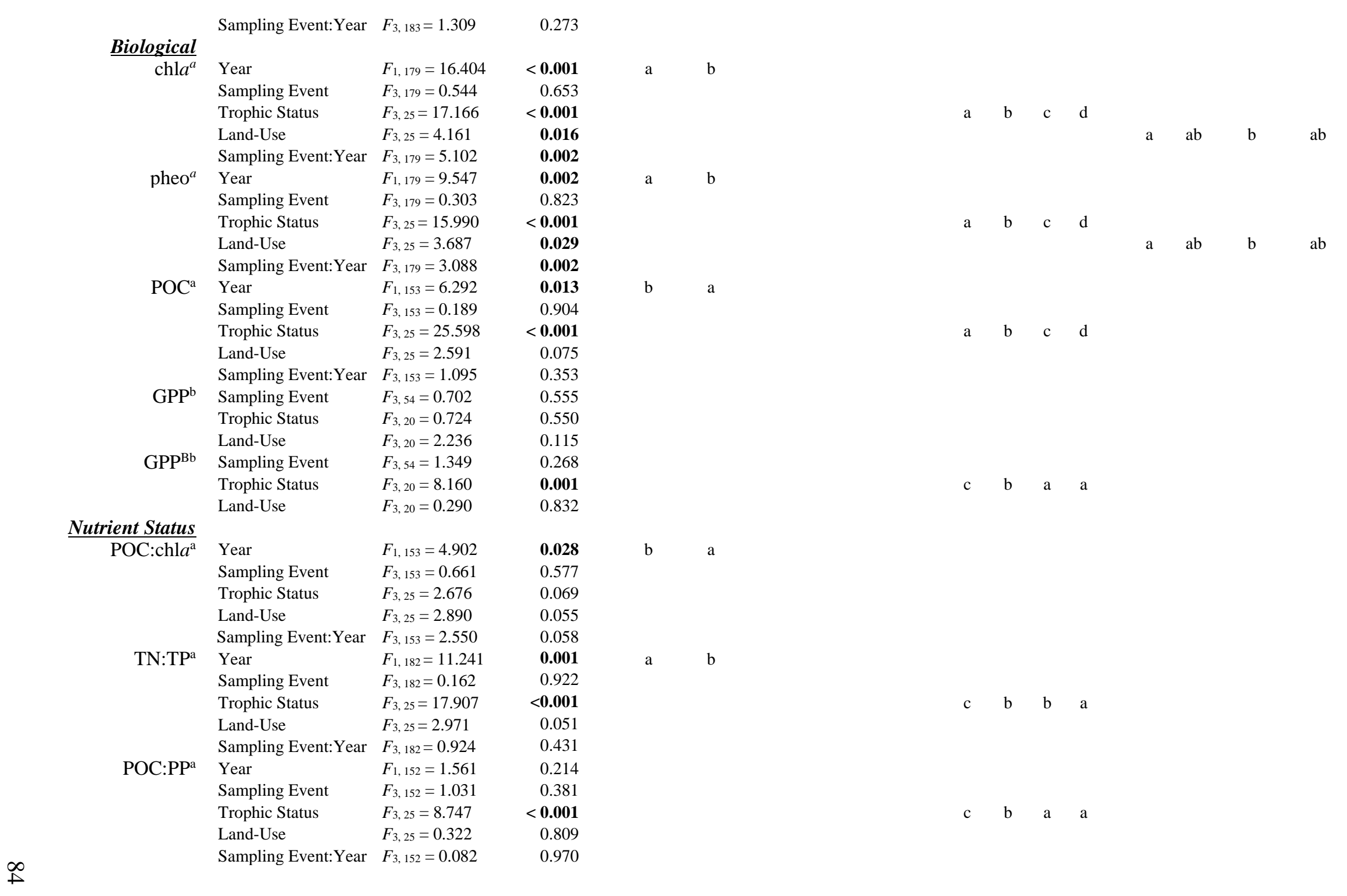




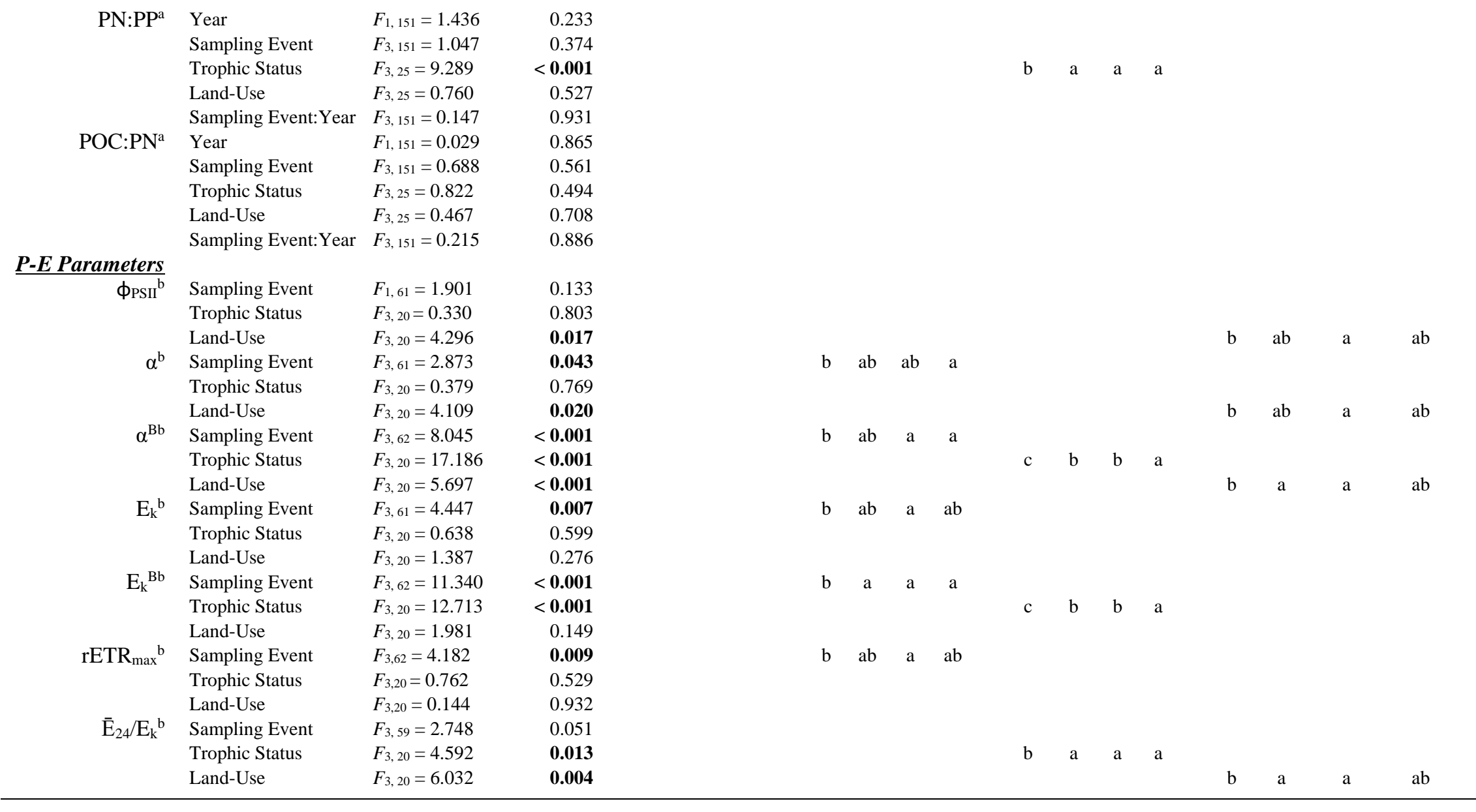

When factors were determined by the ANOVA to be significant (bolded, $p<0.05$ ), a Tukey's Honest Significant Difference test was conducted, as indicated by the lowercase letters. Different lowercase letters indicate significant differences between factor levels. Letters are ordered alphabetically to indicate trend direction where " $a$ " represents the lowest mean. Heading abbreviations are as follows: O, oligotrophic; M, mesotrophic; E, eutrophic; H, hypereutrophic; F, forested; Mix, mixed; Ag-P, pasture; Ag-C, cropland. Superscript ${ }^{a}$ indicates parameters collected in both 2017 and 2018, whereas superscript ${ }^{b}$ indicates parameters collected only in 2018. Interactions (Sampling Event:Year) were not included in the model for those parameters only collected in 2018. See Table 2.1 for parameter definitions, abbreviations, and units. 
Table 2.6. A Kruskal Wallis ANOVA was conducted on the 2018 nutrient debt parameters ( $\mathrm{P}$ debt, $\mathrm{NH}_{4}{ }^{+}-\mathrm{N}$ debt, $\mathrm{NO}_{3}{ }^{-} \mathrm{N}$ debt) to test for the effects of sampling event, trophic status, and watershed land-use. When appropriate, the Kruskal Wallis ANOVA was followed with a Dunn's Test of Multiple Comparisons.

\begin{tabular}{|c|c|c|c|c|c|c|c|c|c|c|c|c|c|}
\hline & \multirow[b]{2}{*}{ Factor } & \multirow[b]{2}{*}{ chi square } & \multirow[b]{2}{*}{$p$ value } & \multirow[b]{2}{*}{$n$} & \multirow[b]{2}{*}{$d f$} & \multicolumn{4}{|c|}{ Trophic status } & \multicolumn{4}{|c|}{ Land-use } \\
\hline & & & & & & $\mathrm{O}$ & $\mathrm{M}$ & $\mathrm{E}$ & $\mathrm{H}$ & $\mathrm{F}$ & Mix & Ag-P & $\mathrm{Ag}-\mathrm{C}$ \\
\hline \multirow[t]{3}{*}{ P debt } & Sampling Event & 3.084 & 0.380 & 94 & 3 & & & & & & & & \\
\hline & Trophic Status & 25.597 & $<0.001$ & & & $\mathrm{c}$ & $\mathrm{b}$ & $\mathrm{a}$ & $\mathrm{a}$ & & & & \\
\hline & Land-Use & 6.299 & 0.100 & & & & & & & & & & \\
\hline \multirow[t]{3}{*}{$\mathrm{NH}_{4}{ }^{+}-\mathrm{N}$ debt } & Sampling Event & 0.634 & 0.889 & 93 & 3 & & & & & & & & \\
\hline & Trophic Status & 3.461 & 0.326 & & & & & & & & & & \\
\hline & Land-Use & 9.552 & 0.023 & & & & & & & $\mathrm{a}$ & $a b$ & $\mathrm{~b}$ & $\mathrm{a}$ \\
\hline \multirow[t]{3}{*}{$\mathrm{NO}_{3}^{-}-\mathrm{N}$ debt } & Sampling Event & 7.434 & 0.059 & 97 & 3 & & & & & & & & \\
\hline & Trophic Status & 3.180 & 0.365 & & & & & & & & & & \\
\hline & Land-Use & 4.997 & 0.172 & & & & & & & & & & \\
\hline
\end{tabular}

When factors were determined by the Kruskal Wallis ANOVA to be significant (bolded, $p<0.05$ ), a Dunn's Test of Multiple Comparisons was conducted, as indicated by the lowercase letters. Different lowercase letters indicate significant differences between factor levels. Letters are ordered alphabetically to indicate trend direction where " $a$ " represents the lowest mean. Heading abbreviations are as follows: O, oligotrophic; M, mesotrophic; E, eutrophic; $H$, hypereutrophic; F, forested; Mix, mixed; Ag-P, pasture; Ag-C, cropland. 
Table 2.7. A one-way analysis of variance (ANOVA) was used to compare maximum quantum yields ( $\phi_{\text {PSII }}$ ) of phytoplankton in response to photosynthetic efficiency experiments. When experiment responses were significant (bolded, $\mathrm{p}<0.05$ ), a two-sided Dunnett-test (pairwise) post-hoc was conducted to test for significant differences between nutrient addition treatments $\left(+\mathrm{P},+\mathrm{NH}_{4}{ }^{+},+\mathrm{NO}_{3}{ }^{-},+\mathrm{P}_{+} \mathrm{NH}_{4}{ }^{+}\right)$and untreated controls

\begin{tabular}{|c|c|c|c|c|c|c|c|}
\hline & \multirow{2}{*}{ Sampling event } & \multirow{2}{*}{$F$-value } & \multirow{2}{*}{$p$-value } & \multicolumn{4}{|c|}{ Control vs. treatment comparison } \\
\hline & & & & $+\mathrm{P}$ & $+\mathrm{NH}_{4}^{+}$ & $+\mathrm{NO}_{3}^{-}$ & $+\mathrm{P}+\mathrm{NH}_{4}^{+}$ \\
\hline \multicolumn{8}{|l|}{ Oligotrophic } \\
\hline \multirow[t]{4}{*}{ Capri } & 1 & $F_{4,9}=3.169$ & 0.070 & & & & \\
\hline & 2 & N/A & N/A & & & & \\
\hline & 3 & $F_{4}, 10=4.943$ & 0.019 & & & & \\
\hline & 4 & $F_{4,10}=13.760$ & $<0.001$ & & & & \\
\hline \multirow[t]{4}{*}{ Council Bluff } & 1 & $F_{4,10}=1.966$ & 0.176 & & & & \\
\hline & 2 & N/A & N/A & & & & \\
\hline & 3 & $F_{4,8}=17.120$ & $<0.001$ & & & & $*$ \\
\hline & 4 & $F_{4,11}=4.163$ & 0.027 & & & & \\
\hline \multirow[t]{4}{*}{ Fellows } & 1 & $F_{4,9}=7.782$ & 0.005 & $*$ & & & \\
\hline & 2 & $F_{4,8}=6.370$ & 0.013 & $*$ & & $*$ & $*$ \\
\hline & 3 & $F_{4,9}=4.638$ & 0.026 & & & & \\
\hline & 4 & $F_{4}, 10=128.000$ & $<0.001$ & & & $*$ & \\
\hline \multirow[t]{4}{*}{ Shayne } & 1 & N/A & N/A & & & & \\
\hline & 2 & N/A & N/A & & & & \\
\hline & 3 & N/A & N/A & & & & \\
\hline & 4 & $F_{4}, 10=17.950$ & $<0.001$ & & & & \\
\hline \multicolumn{8}{|l|}{$\underline{\text { Mesotrophic }}$} \\
\hline \multirow[t]{4}{*}{ Bowling Green } & 1 & $F_{4,9}=3.672$ & 0.049 & & & & \\
\hline & 2 & $F_{4,11}=5.656$ & 0.010 & & & & \\
\hline & 3 & $F_{4,9}=10.220$ & 0.002 & & & $*$ & \\
\hline & 4 & $F_{4,13}=2.284$ & 0.116 & & & & \\
\hline \multirow[t]{3}{*}{ Lake Ozark } & 1 & $F_{4,10}=1.768$ & 0.212 & & & & \\
\hline & 2 & $F_{4,11}=9.370$ & 0.002 & $*$ & & & \\
\hline & 3 & $F_{4,9}=6.007$ & 0.012 & & $*$ & $*$ & \\
\hline \multirow[t]{4}{*}{ Lincoln } & 1 & $F_{4,7}=4.272$ & 0.046 & $*$ & $*$ & & \\
\hline & 2 & $F_{4}, 10=3.110$ & 0.008 & & & $*$ & $*$ \\
\hline & 3 & $F_{4,10}=5.767$ & 0.011 & & & & \\
\hline & 4 & $F_{4,14}=5.516$ & 0.007 & & & & \\
\hline \multirow[t]{4}{*}{ Little Prairie } & 1 & $F_{4,10}=15.120$ & $<0.001$ & & $*$ & & \\
\hline & 2 & N/A & N/A & & & & \\
\hline & 3 & $F_{4,13}=10.680$ & $<0.001$ & & & & \\
\hline & 4 & $F_{4,13}=1.407$ & 0.286 & & & & \\
\hline Pomme De Terre & 1 & $F_{4,11}=5.790$ & 0.009 & & & & \\
\hline
\end{tabular}


Prairie Home

N/A

$F_{4}, 10=27.510$

$F_{4,14}=166.900$

$F_{4,13}=6.303$

$F_{4}, 10=3.636$

$F_{4}, 8=10.320$

$F_{4},{ }_{16}=1.860$

$F_{4}, 11=4.737$

$F_{4,10}=7.305$

$F_{4}, 10=113.1$

$F_{4,9}=1.135$

N/A

$F_{4},{ }_{11}=1.863$

$F_{4}, 10=3.308$

$F_{4,6}=1.258$

$F_{4,9}=1.417$

$F_{4}, 10=1.155$

$F_{4,9}=0.532$

$F_{4},{ }_{10}=2.972$

N/A

$F_{4}, 10=2.298$

$F_{4,13}=12.860$

$<0.001$

$<0.001$

0.005

0.045

0.003

0.167

0.018

0.005

$<0.001$

0.399

N/A

0.187

0.057

0.381

0.304

0.386

0.716

0.074

N/A

0.130

< 0.001

$F_{4,11}=0.608$

$F_{4}, 10=10.560$

0.665

$F_{4,10}=14.540$

$F_{4,10}=16.930$

$F_{4}, 10=6.528$

$F_{4,10}=10.190$

$F_{4}, 11=0.710$

N/A

$F_{4},{ }_{10}=5.638$

N/A

$F_{4,10}=49.780$

$F_{4,9}=4.230$

$F_{4}, 10=0.507$

$F_{4,10}=120.700$

$F_{4},{ }_{10}=53.650$

$<0.001$

$<0.001$

0.008

0.001

0.602

N/A

N/A

0.012

N/A

$\mathbf{0 . 0 3 4}$

0.732
$<0.001$ 


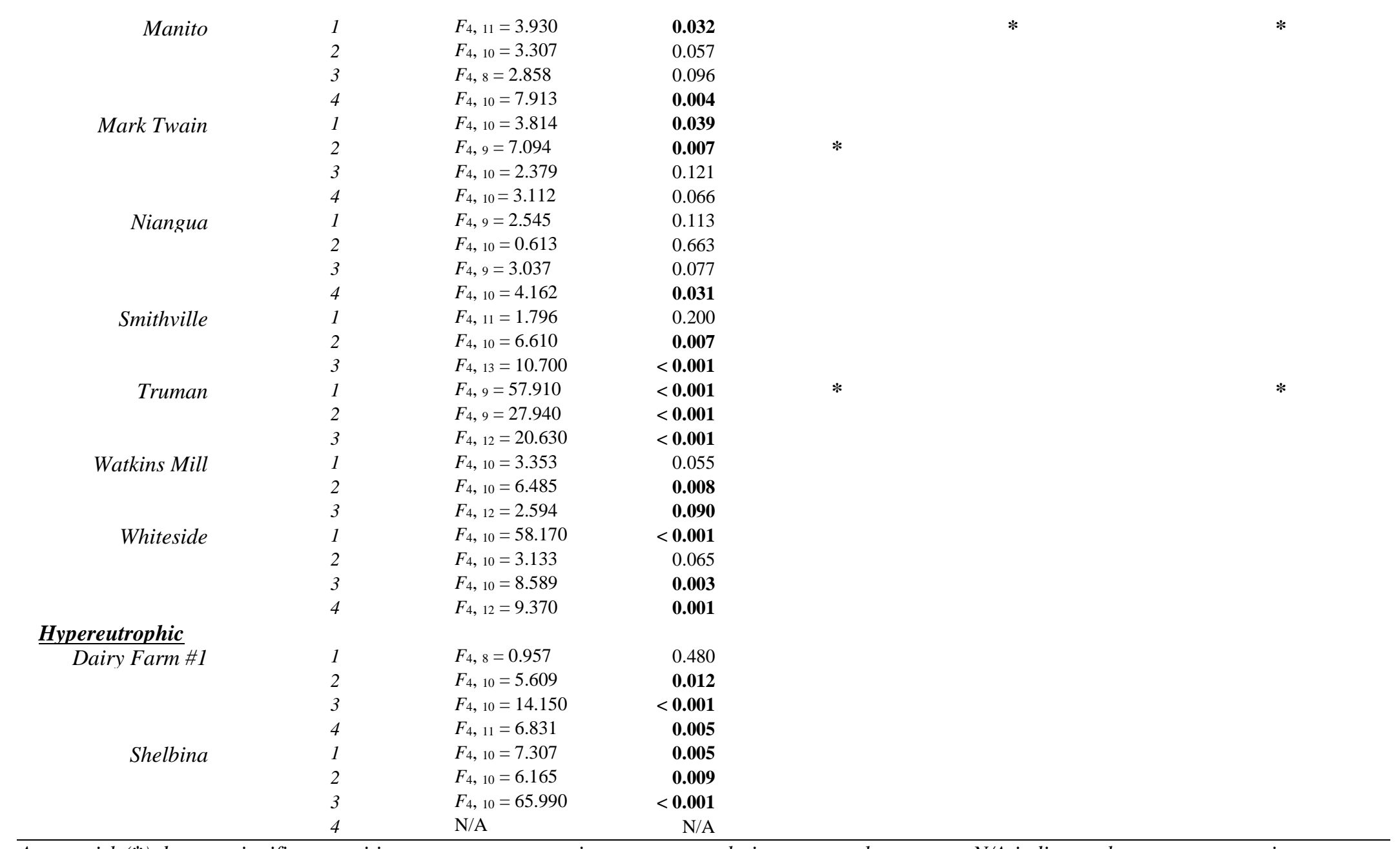

An asterisk (*) denotes significant positive responses to a nutrient treatment relative to control treatment. N/A indicates there was no experiment performed for a given sampling event. 
Table 2.8. Pearson correlation results for physical, chemical, biological, and physiological light (P-E) parameters that tested significant against daily gross primary productivity rates normalized to chlorophyll-a $\left(\mathrm{GPP}^{\mathrm{B}}\right)$. Parameters listed are only those that yielded significant correlations.

\begin{tabular}{|c|c|c|}
\hline & \multicolumn{2}{|c|}{ Pearson Correlation with GPPB } \\
\hline & Pearson coefficient $(r)$ & $p$-value \\
\hline \multicolumn{3}{|l|}{ Physical } \\
\hline $\mathrm{Z}_{\max }$ & 0.56 & $<0.001$ \\
\hline $\mathrm{Z}_{\text {mix }}$ & 0.36 & $<0.001$ \\
\hline Secchi & 0.69 & $<0.001$ \\
\hline $\mathrm{K}_{\mathrm{d}}$ & -0.70 & $<0.001$ \\
\hline$\overline{\mathrm{E}}_{24}$ & 0.37 & $<0.001$ \\
\hline \multicolumn{3}{|l|}{ Chemical } \\
\hline $\mathrm{TP}$ & -0.69 & $<0.001$ \\
\hline TDP & -0.56 & $<0.001$ \\
\hline DRP & -0.35 & 0.001 \\
\hline $\mathrm{TN}$ & -0.63 & $<0.001$ \\
\hline TDN & -0.43 & $<0.001$ \\
\hline DON & -0.43 & $<0.001$ \\
\hline DOC & -0.28 & 0.011 \\
\hline TSS & -0.62 & $<0.001$ \\
\hline POM & -0.69 & $<0.001$ \\
\hline PIM & -0.36 & $<0.001$ \\
\hline \multicolumn{3}{|l|}{ Biological } \\
\hline POC & -0.71 & $<0.001$ \\
\hline \multicolumn{3}{|l|}{ P-E Parameters } \\
\hline$\alpha^{\mathrm{B}}$ & 0.70 & $<0.001$ \\
\hline $\mathrm{E}_{\mathrm{k}}^{\mathrm{B}}$ & 0.75 & $<0.001$ \\
\hline
\end{tabular}


Table 2.9. Epilimnetic and hypolimnetic dissolved nutrient chemistry (generalized by trophic status) from the 27 reservoirs sampled while stratified in 2018.

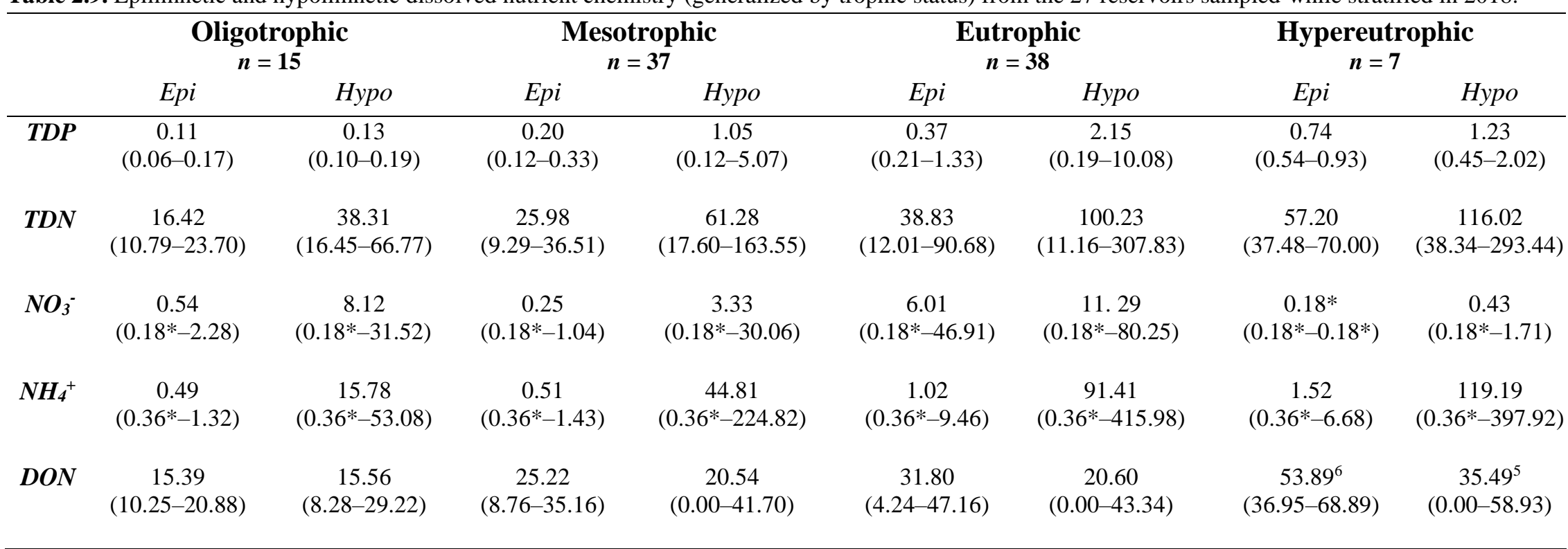

Shown are the seasonal arithmetic means and ranges (minimums-maximums) of $n$ samples grouped along the trophic gradient. Total dissolved phosphorus $(T D P)$, total dissolved nitrogen (TDN), nitrate $\left(\mathrm{NO}_{3}{ }^{-}\right)$, and ammonium $\left(\mathrm{NH}_{4}{ }^{+}\right)$were collected in the field. Dissolved organic nitrogen (DON) was calculated by difference. An asterisk (*) is used when values are below the detection limit; detection limits are $0.03 \mu \mathrm{mol} L^{-1}$ for TDP; for $2.50 \mu \mathrm{mol} L^{-1}$ TDN; $0.36 \mu \mathrm{mol} L^{-1}$ for $\mathrm{NO}_{3}^{-}$; and $0.71 \mu \mathrm{mol} \mathrm{L} \mathrm{L}^{-1}$ for $\mathrm{NH}_{4}^{+}$. Superscript numbers indicate $n$ values that differed from those reported in the column headers. See Table 2.1 for parameter definitions, abbreviations, and units. 
Table 2.10. Percentage of sampling events deemed deficient during the 2018 season based on individual nutrient status indicators. Percentages are shown for each trophic state and combined overall. Phosphorus (P) status indicators were molar ratios POC:PP and PN:PP, P debt, and photosynthetic efficiency response to $\mathrm{P}$ additions (+P $\left.\phi_{\text {PSII }}\right)$. Nitrogen $(\mathrm{N})$ status indicators were the molar ratio POC:PN, $\mathrm{NH}_{4}{ }^{+}-\mathrm{N}$ debt, photosynthetic efficiency response to $\mathrm{NH}_{4}{ }^{+}$additions $\left(+\mathrm{NH}_{4}{ }^{+}\right.$фPSII $), \mathrm{NO}_{3}{ }^{-}-\mathrm{N}$ debt, and photosynthetic efficiency response to $\mathrm{NO}_{3}{ }^{-}$additions $\left(+\mathrm{NO}_{3}{ }^{-} \phi_{\mathrm{PSII}}\right)$.

\begin{tabular}{|c|c|c|c|c|c|c|}
\hline & & $\begin{array}{c}\text { Oligotrophic } \\
n=15\end{array}$ & $\begin{array}{c}\text { Mesotrophic } \\
\quad n=\mathbf{3 7}\end{array}$ & $\begin{array}{c}\text { Eutrophic } \\
n=39\end{array}$ & $\begin{array}{c}\text { Hypereutrophic } \\
\qquad n=7\end{array}$ & $\begin{array}{c}\text { Overall } \\
n=98\end{array}$ \\
\hline \multirow{4}{*}{$\begin{array}{l}\text { Phosphorus } \\
\text { indicators }\end{array}$} & POC:PP & $100 \%$ & $95 \%{ }^{*}$ & $85 \%$ & $100 \%$ & $92 \%{ }^{*}$ \\
\hline & PN:PP & $93 \%$ & $81 \%$ & $62 \%$ & $71 \%$ & $74 \%$ \\
\hline & P debt & $93 \%$ & $70 \%$ & $44 \% *$ & $17 \% *$ & $61 \% *$ \\
\hline & $+\mathbf{P}$ фPSII & $13 \% *$ & $14 \% *$ & $8 \% *$ & $0 \%$ & $11 \% *$ \\
\hline \multirow{5}{*}{$\begin{array}{l}\text { Nitrogen } \\
\text { indicators }\end{array}$} & POC:PN & $53 \%$ & $54 \%$ & $10 \%$ & $14 \%$ & $34 \%$ \\
\hline & $\mathrm{NH}_{4}{ }^{+}-\mathrm{N}$ debt & $25 \%{ }^{*}$ & $6 \%^{*}$ & $5 \% *$ & $0 \% *$ & $8 \% *$ \\
\hline & $+\mathrm{NH}_{4}{ }^{+} \phi$ PSII & $0 \% *$ & $14 \% *$ & $3 \% *$ & $0 \%$ & $6 \% *$ \\
\hline & $\mathrm{NO}^{-}-\mathrm{N}$ debt & $15 \%$ & $3 \%$ & $0 \%^{*}$ & $0 \%$ & $1 \% *$ \\
\hline & +NO3- & $0 \% *$ & $14 \% *$ & $3 \% *$ & $0 \%$ & $9 \% *$ \\
\hline
\end{tabular}

An asterisk indicates $n$ values that differ from those reported in the column headers. See Table 2.1 for parameter definitions, abbreviations, and units; Table 2.3 for $n$ discrepancies; and Table 2.4 for nutrient deficiency thresholds. 
Table 2.11. Nutrient status indicator agreement for the 2018 sampling season. Results are shown for each sampling event, grouped by trophic status and reservoir. The nutrient status ruling according to each indicator is noted by a D or an S, where D means deficient and S means sufficient. If a cell contains neither a $\mathrm{D}$ nor an $\mathrm{S}$, then that indicator was not employed for that sampling event. $\mathrm{P}$ indicators are $\mathrm{POC}: \mathrm{PP}, \mathrm{PN}: \mathrm{PP}, \mathrm{P}$ debt, and $+\mathrm{P} \phi_{\mathrm{PSII}}$; $\mathrm{N}$ indicators are $+\mathrm{NH}_{4}{ }^{+} \phi_{\text {PSII }}, \mathrm{NH}_{4}{ }^{+}-\mathrm{N}$ debt, POC:PN, $+\mathrm{NO}_{3}{ }^{-} \phi_{\text {PSII }}$, and $\mathrm{NO}_{3}{ }^{-}-\mathrm{N}$ debt. Agreement is shown as a percent with the uppercase letter indicating majority agreement as either deficient (D) or sufficient (S).

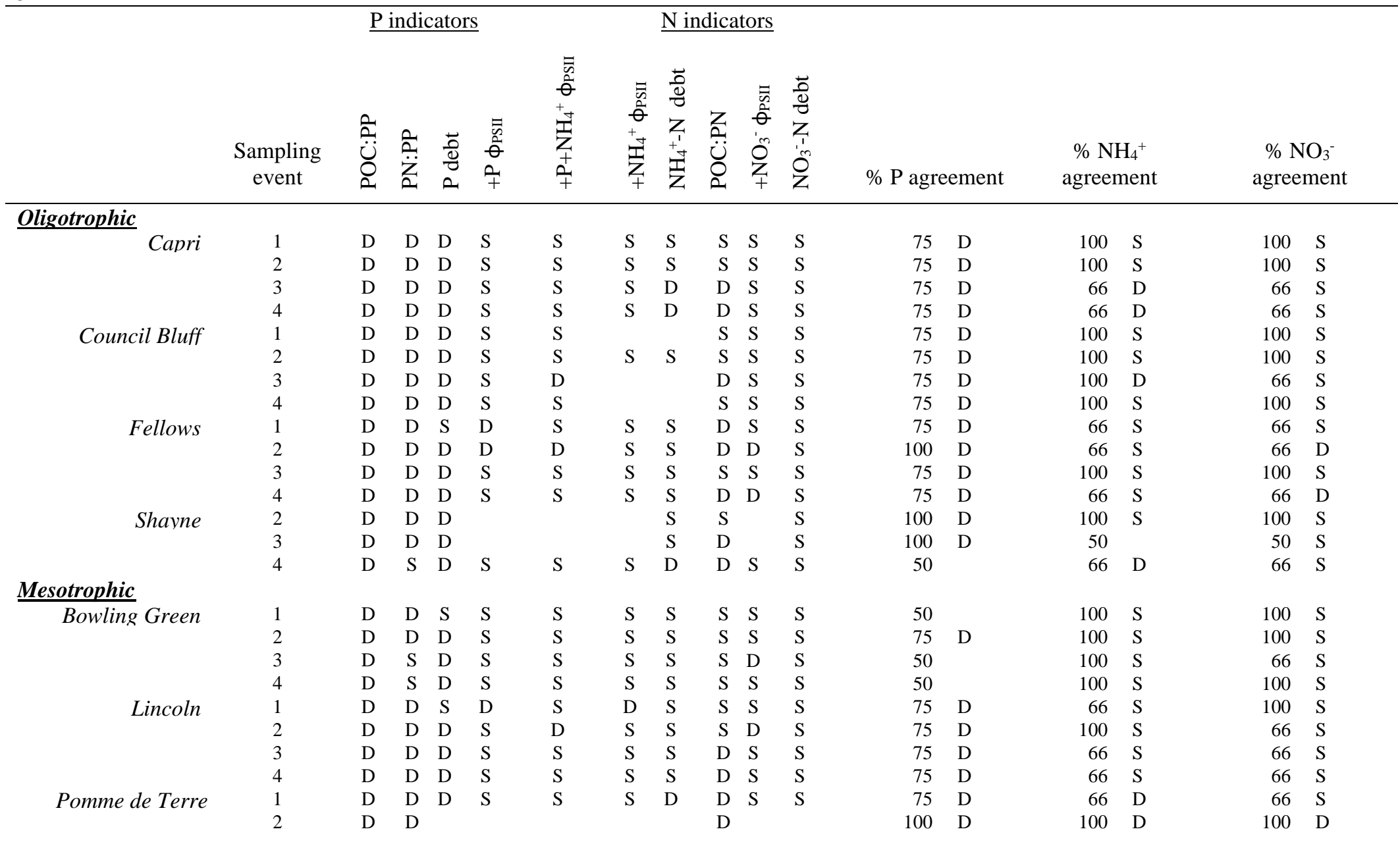




\begin{tabular}{|c|c|c|c|c|c|c|c|c|c|c|c|c|c|c|c|c|}
\hline & 3 & D & D & D & S & $S$ & $S$ & $S$ & D & $S$ & $S$ & 75 & D & 66 & $\mathrm{~S}$ & 66 \\
\hline & 4 & D & D & D & S & $S$ & D & S & D & D & S & 75 & $\mathrm{D}$ & 66 & $\mathrm{D}$ & 66 \\
\hline \multirow[t]{3}{*}{ Stockton } & 1 & D & D & D & S & S & S & S & $S$ & $S$ & S & 75 & $\mathrm{D}$ & 100 & $S$ & 100 \\
\hline & 2 & D & D & D & S & S & S & $S$ & D & $S$ & S & 75 & $\mathrm{D}$ & 66 & S & 66 \\
\hline & 3 & D & D & D & D & $S$ & S & S & D & S & S & 100 & $\mathrm{D}$ & 66 & S & 66 \\
\hline \multirow[t]{4}{*}{ Ziske } & 1 & D & S & D & S & S & S & $S$ & D & $S$ & S & 50 & & 66 & $S$ & 66 \\
\hline & 2 & D & D & S & S & $S$ & S & $S$ & D & $S$ & S & 50 & & 66 & $S$ & 66 \\
\hline & 3 & D & D & D & S & $S$ & S & $S$ & D & $S$ & S & 75 & $\mathrm{D}$ & 66 & S & 66 \\
\hline & 4 & D & D & D & D & S & S & D & D & S & S & 100 & D & 66 & $\mathrm{D}$ & 66 \\
\hline \multirow[t]{4}{*}{ Shawnee/Turner } & 1 & $\mathrm{D}$ & $\mathrm{D}$ & $\mathrm{D}$ & S & $S$ & $S$ & $S$ & S & $S$ & $S$ & 75 & $\mathrm{D}$ & 100 & S & 100 \\
\hline & 2 & $\mathrm{D}$ & $\mathrm{D}$ & S & S & $S$ & S & $S$ & $\mathrm{D}$ & $S$ & S & 50 & & 66 & S & 66 \\
\hline & 3 & $\mathrm{D}$ & $\mathrm{D}$ & S & S & $S$ & $S$ & $S$ & $\mathrm{D}$ & $S$ & $S$ & 50 & & 66 & S & 66 \\
\hline & 4 & $\mathrm{D}$ & $\mathrm{D}$ & $\mathrm{D}$ & S & $S$ & S & $S$ & $\mathrm{D}$ & $S$ & $S$ & 75 & $\mathrm{D}$ & 66 & $S$ & 66 \\
\hline \multirow[t]{4}{*}{ Little Prairie } & 1 & $\mathrm{D}$ & $\mathrm{D}$ & $\mathrm{D}$ & S & S & $\mathrm{D}$ & $S$ & $S$ & $S$ & $S$ & 75 & $\mathrm{D}$ & 66 & S & 100 \\
\hline & 2 & $S$ & $\mathrm{D}$ & S & S & $S$ & $S$ & $S$ & $S$ & $S$ & $S$ & 75 & S & 100 & S & 100 \\
\hline & 3 & $\mathrm{D}$ & $\mathrm{D}$ & $\mathrm{D}$ & S & $S$ & S & $S$ & $S$ & $S$ & S & 75 & $\mathrm{D}$ & 100 & S & 100 \\
\hline & 4 & $\mathrm{D}$ & $\mathrm{D}$ & $\mathrm{D}$ & S & $S$ & $S$ & $S$ & S & $S$ & $S$ & 75 & $\mathrm{D}$ & 100 & S & 100 \\
\hline \multirow[t]{3}{*}{ Lake Ozark } & 1 & $\mathrm{D}$ & S & $\mathrm{D}$ & S & $S$ & $S$ & & $\mathrm{D}$ & $S$ & $S$ & 50 & & 50 & & 66 \\
\hline & 2 & $\mathrm{D}$ & $\mathrm{D}$ & $\mathrm{D}$ & D & S & $S$ & $S$ & $S$ & $S$ & S & 100 & $\mathrm{D}$ & 100 & S & 100 \\
\hline & 3 & $\mathrm{D}$ & $\mathrm{D}$ & S & S & $S$ & $\mathrm{D}$ & $S$ & $S$ & $\mathrm{D}$ & $S$ & 50 & & 66 & S & 66 \\
\hline \multirow[t]{4}{*}{ Prairie Home 2} & 1 & $\mathrm{D}$ & & $\mathrm{D}$ & D & $S$ & S & $S$ & & $S$ & S & 100 & $\mathrm{D}$ & 100 & S & 100 \\
\hline & 2 & $\mathrm{D}$ & $\mathrm{D}$ & $\mathrm{D}$ & S & S & S & $S$ & D & S & S & 75 & $\mathrm{D}$ & 66 & $S$ & 66 \\
\hline & 3 & D & D & S & S & $S$ & D & S & S & D & S & 50 & & 66 & $S$ & 66 \\
\hline & 4 & $S$ & S & S & S & S & S & S & $S$ & $S$ & S & 100 & $S$ & 100 & S & 100 \\
\hline \multirow[t]{4}{*}{ Winegar } & 1 & D & D & D & S & S & S & $S$ & D & $S$ & S & 75 & $\mathrm{D}$ & 66 & $S$ & 66 \\
\hline & 2 & D & D & D & $S$ & S & S & S & D & S & D & 75 & $\mathrm{D}$ & 66 & $S$ & 66 \\
\hline & 3 & D & S & S & S & S & S & $S$ & D & S & S & 75 & S & 66 & S & 66 \\
\hline & 4 & D & S & S & S & $S$ & S & S & S & S & S & 75 & S & 100 & S & 100 \\
\hline \multicolumn{17}{|l|}{ Eutrophic } \\
\hline \multirow[t]{4}{*}{ Binder } & 1 & D & $\mathrm{S}$ & S & $S$ & S & $S$ & S & $S$ & $S$ & $S$ & 75 & S & 100 & S & 100 \\
\hline & 2 & D & D & S & $S$ & $S$ & $S$ & $S$ & $S$ & $S$ & $S$ & 50 & & 100 & S & 100 \\
\hline & 3 & D & D & S & S & S & S & S & S & S & S & 50 & & 100 & S & 100 \\
\hline & 4 & D & D & $\mathrm{S}$ & $S$ & $S$ & $S$ & $S$ & $S$ & $\mathrm{~S}$ & $S$ & 50 & & 100 & $S$ & 100 \\
\hline \multirow[t]{3}{*}{ Smithville } & 1 & D & D & D & S & S & S & S & S & S & S & 75 & D & 100 & S & 100 \\
\hline & 2 & D & D & D & $S$ & $S$ & $S$ & $S$ & $S$ & $S$ & $S$ & 75 & D & 100 & S & 100 \\
\hline & 3 & D & D & D & $S$ & $S$ & $S$ & D & S & S & S & 75 & $\mathrm{D}$ & 66 & S & 100 \\
\hline \multirow{3}{*}{ Watkins Mill } & 1 & D & $S$ & $S$ & $S$ & $S$ & $S$ & $S$ & $S$ & $S$ & $S$ & 75 & S & 100 & S & 100 \\
\hline & 2 & D & $\mathrm{D}$ & D & S & S & S & S & S & S & S & 75 & $\mathrm{D}$ & 100 & $S$ & 100 \\
\hline & 3 & D & D & D & $S$ & $S$ & $S$ & $S$ & $S$ & $S$ & $S$ & 75 & $\mathrm{D}$ & 100 & $S$ & 100 \\
\hline \multirow{3}{*}{ Truman } & 1 & D & $\mathrm{S}$ & D & D & $\mathrm{D}$ & S & & S & S & S & 75 & $\mathrm{D}$ & 100 & S & 100 \\
\hline & 2 & D & D & D & $S$ & $S$ & $S$ & $S$ & $S$ & $\mathrm{~S}$ & $S$ & 75 & D & 100 & S & 100 \\
\hline & 3 & D & D & D & $S$ & $S$ & $S$ & D & D & $S$ & $S$ & 75 & $\mathrm{D}$ & 66 & $\mathrm{D}$ & 66 \\
\hline
\end{tabular}




\begin{tabular}{|c|c|c|c|c|c|c|c|c|c|c|c|c|c|c|c|c|c|}
\hline \multirow{3}{*}{ Lamar } & 2 & $\mathrm{D}$ & $\mathrm{D}$ & $\mathrm{S}$ & $S$ & S & $S$ & S & $S$ & $S$ & $S$ & 50 & & 100 & $\mathrm{~S}$ & 100 & S \\
\hline & 3 & $\mathrm{D}$ & $\mathrm{S}$ & & & & & & $\mathrm{S}$ & & & 50 & & 100 & S & 100 & S \\
\hline & 4 & $\mathrm{D}$ & $\mathrm{D}$ & D & S & S & $\mathrm{S}$ & $\mathrm{S}$ & $\mathrm{S}$ & $S$ & $\mathrm{~S}$ & 75 & D & 100 & S & 100 & S \\
\hline \multirow[t]{3}{*}{ Hunnewell } & 1 & $\mathrm{D}$ & $\mathrm{D}$ & $\mathrm{D}$ & $\mathrm{D}$ & $\mathrm{D}$ & S & S & $\mathrm{S}$ & $\mathrm{D}$ & S & 100 & $\mathrm{D}$ & 100 & S & 66 & S \\
\hline & 2 & $\mathrm{D}$ & $\mathrm{S}$ & $\mathrm{D}$ & $\mathrm{S}$ & S & S & S & $\mathrm{S}$ & S & S & 50 & & 100 & S & 100 & S \\
\hline & 3 & $\mathrm{D}$ & $\mathrm{D}$ & $\mathrm{S}$ & S & S & S & S & $\mathrm{S}$ & S & S & 50 & & 100 & S & 100 & $\mathrm{~S}$ \\
\hline \multirow[t]{4}{*}{ Little Dixie } & 1 & $\mathrm{~S}$ & $\mathrm{~S}$ & $\mathrm{~S}$ & S & S & S & S & $\mathrm{S}$ & S & S & 100 & S & 100 & $S$ & 100 & $\mathrm{~S}$ \\
\hline & 2 & S & $\mathrm{S}$ & $\mathrm{S}$ & S & S & S & S & $\mathrm{S}$ & S & S & 100 & $\mathrm{~S}$ & 100 & $S$ & 100 & $\mathrm{~S}$ \\
\hline & 3 & $\mathrm{D}$ & $\mathrm{D}$ & $\mathrm{D}$ & S & S & S & S & $\mathrm{S}$ & S & S & 75 & $\mathrm{D}$ & 100 & S & 100 & $\mathrm{~S}$ \\
\hline & 4 & $\mathrm{D}$ & $\mathrm{D}$ & & & S & S & S & $\mathrm{S}$ & S & S & 100 & $\mathrm{D}$ & 100 & S & 100 & $\mathrm{~S}$ \\
\hline \multirow[t]{4}{*}{ Mark Twain } & 1 & $\mathrm{D}$ & $\mathrm{S}$ & $\mathrm{S}$ & S & S & S & S & $\mathrm{S}$ & S & S & 75 & $\mathrm{~S}$ & 100 & S & 100 & $\mathrm{~S}$ \\
\hline & 2 & $\mathrm{D}$ & $\mathrm{S}$ & $\mathrm{S}$ & $\mathrm{D}$ & S & S & S & $\mathrm{S}$ & S & S & 50 & & 100 & S & 100 & S \\
\hline & 3 & $\mathrm{D}$ & $\mathrm{D}$ & $\mathrm{D}$ & S & S & S & S & $\mathrm{D}$ & S & S & 75 & D & 66 & S & 66 & S \\
\hline & 4 & $\mathrm{D}$ & $\mathrm{D}$ & & & S & S & S & $\mathrm{S}$ & S & S & 100 & $\mathrm{D}$ & 100 & S & 100 & S \\
\hline \multirow[t]{4}{*}{ Manito } & 1 & $\mathrm{~S}$ & $\mathrm{~S}$ & $\mathrm{~S}$ & $S$ & $\mathrm{D}$ & $\mathrm{D}$ & S & $\mathrm{S}$ & S & S & 100 & $\mathrm{~S}$ & 66 & S & 100 & S \\
\hline & 2 & $\mathrm{D}$ & $\mathrm{D}$ & $\mathrm{S}$ & S & S & S & S & $\mathrm{S}$ & S & S & 50 & & 100 & S & 100 & S \\
\hline & 3 & $S$ & $\mathrm{~S}$ & $\mathrm{~S}$ & S & S & S & S & $\mathrm{S}$ & S & S & 100 & $\mathrm{~S}$ & 100 & S & 100 & S \\
\hline & 4 & $\mathrm{D}$ & $\mathrm{S}$ & $\mathrm{S}$ & S & S & S & S & $\mathrm{S}$ & S & S & 75 & S & 100 & S & 100 & $\mathrm{~S}$ \\
\hline \multirow[t]{4}{*}{ White Area } & 1 & $\mathrm{D}$ & $\mathrm{D}$ & $\mathrm{S}$ & S & S & S & S & $\mathrm{D}$ & S & S & 50 & & 66 & S & 66 & $\mathrm{~S}$ \\
\hline & 2 & $\mathrm{D}$ & $\mathrm{D}$ & $\mathrm{S}$ & S & S & S & S & $\mathrm{S}$ & S & S & 50 & & 100 & S & 100 & $\mathrm{~S}$ \\
\hline & 3 & $\mathrm{D}$ & $\mathrm{D}$ & $\mathrm{D}$ & S & S & S & S & $\mathrm{S}$ & S & S & 75 & $\mathrm{D}$ & 100 & $S$ & 100 & $\mathrm{~S}$ \\
\hline & 4 & $\mathrm{D}$ & $\mathrm{D}$ & $\mathrm{D}$ & S & S & S & S & $\mathrm{S}$ & S & S & 75 & $\mathrm{D}$ & 100 & S & 100 & S \\
\hline \multirow[t]{4}{*}{ Niangua } & 1 & $\mathrm{D}$ & $\mathrm{S}$ & $\mathrm{S}$ & S & S & S & S & $\mathrm{D}$ & S & S & 75 & $\mathrm{~S}$ & 66 & S & 66 & S \\
\hline & 2 & $\mathrm{~S}$ & $\mathrm{~S}$ & $\mathrm{~S}$ & S & S & S & S & $\mathrm{S}$ & S & S & 100 & $\mathrm{~S}$ & 100 & S & 100 & S \\
\hline & 3 & $\mathrm{D}$ & $\mathrm{D}$ & $\mathrm{D}$ & S & S & S & S & $\mathrm{S}$ & S & S & 75 & $\mathrm{D}$ & 100 & S & 100 & S \\
\hline & 4 & $\mathrm{~S}$ & $\mathrm{~S}$ & $\mathrm{~S}$ & S & S & S & S & S & S & S & 100 & $S$ & 100 & S & 100 & S \\
\hline \multicolumn{18}{|l|}{ Hypereutrophic } \\
\hline \multirow[t]{3}{*}{ Shelbina } & 1 & $\mathrm{D}$ & $\mathrm{D}$ & & & S & S & S & $\mathrm{S}$ & S & S & 100 & $\mathrm{D}$ & 100 & S & 100 & S \\
\hline & 2 & $\mathrm{D}$ & $\mathrm{S}$ & $\mathrm{S}$ & $S$ & $S$ & $S$ & S & $\mathrm{S}$ & S & $S$ & 75 & $\mathrm{~S}$ & 100 & $S$ & 100 & S \\
\hline & 3 & $\mathrm{D}$ & $\mathrm{S}$ & $\mathrm{S}$ & $S$ & $S$ & & & $\mathrm{D}$ & $S$ & $S$ & 75 & $\mathrm{~S}$ & 100 & $\mathrm{D}$ & 66 & S \\
\hline \multirow[t]{4}{*}{ Dairy Farm \#1 } & 1 & $\mathrm{D}$ & $\mathrm{D}$ & $\mathrm{S}$ & $S$ & $S$ & $S$ & $S$ & $\mathrm{~S}$ & $S$ & $S$ & 50 & & 100 & $S$ & 100 & S \\
\hline & 2 & $\mathrm{D}$ & $\mathrm{D}$ & $\mathrm{S}$ & $S$ & $S$ & $S$ & S & $\mathrm{S}$ & S & $S$ & 50 & & 100 & $S$ & 100 & S \\
\hline & 3 & $\mathrm{D}$ & $\mathrm{D}$ & $\mathrm{D}$ & $S$ & $S$ & $S$ & S & $\mathrm{S}$ & S & $S$ & 75 & $\mathrm{D}$ & 100 & S & 100 & S \\
\hline & 4 & $\mathrm{D}$ & $\mathrm{D}$ & $\mathrm{S}$ & $S$ & $S$ & $S$ & S & $\mathrm{S}$ & $S$ & $S$ & 50 & & 100 & S & 100 & S \\
\hline
\end{tabular}


Table 2.12. A selection of gross primary productivity (GPP) rates from relevant lake and reservoir studies in the literature. Mean areal rates were collected directly from the text or estimated via table values or by digitizing figures. Rates reported in units of carbon were converted to units of oxygen using the assumed photosynthetic quotient of 1.2. Where possible, volumetric rates were converted to areal rates using photic depth or 2x Secchi as a proxy for photic depth. GPP rates were also normalized to chlorophyll- $a\left(\mathrm{GPP}^{\mathrm{B}}\right)$ when possible. Shown are arithmetic means, unless noted otherwise, and ranges (min-max).

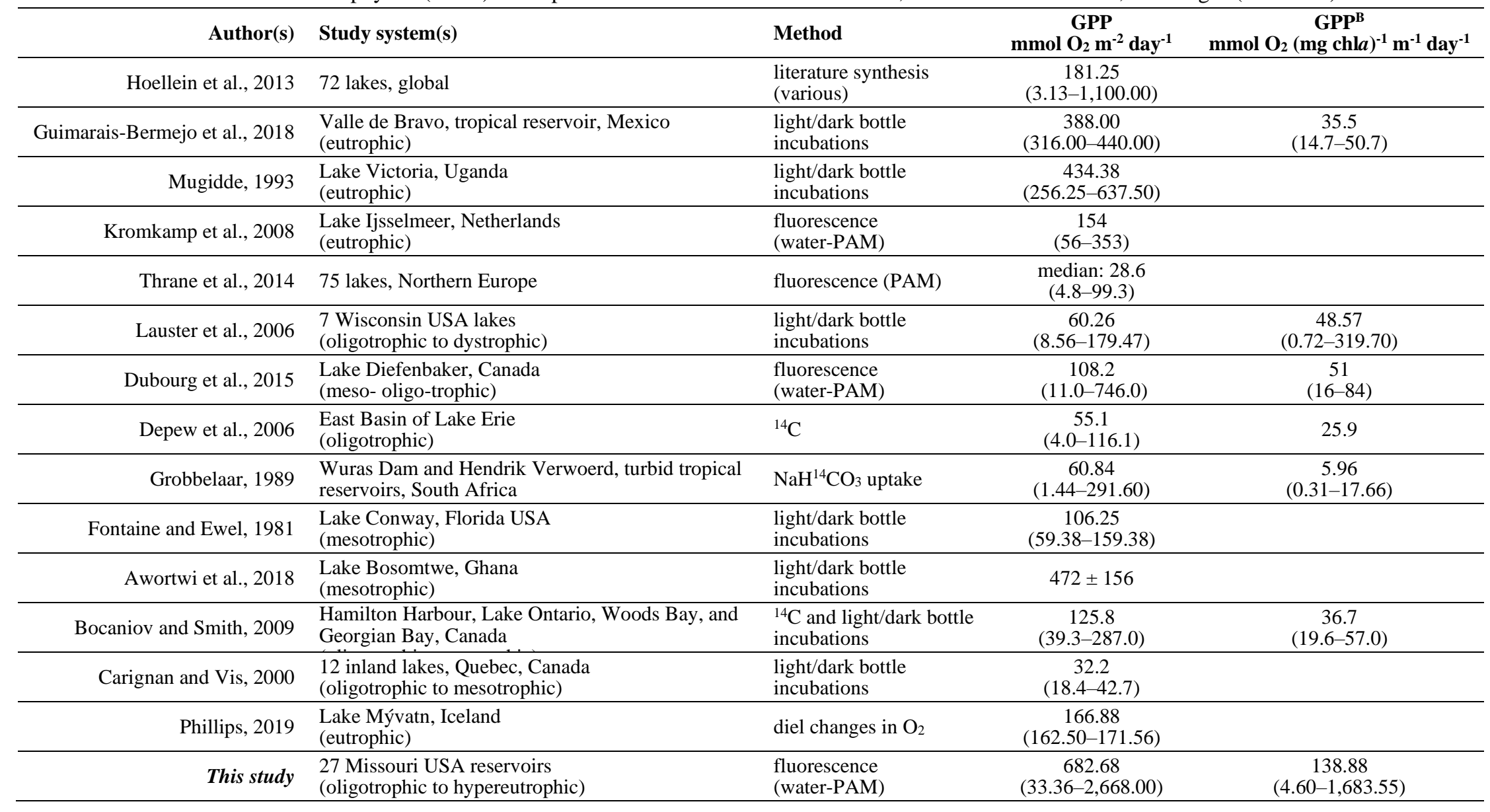




\section{Figures}

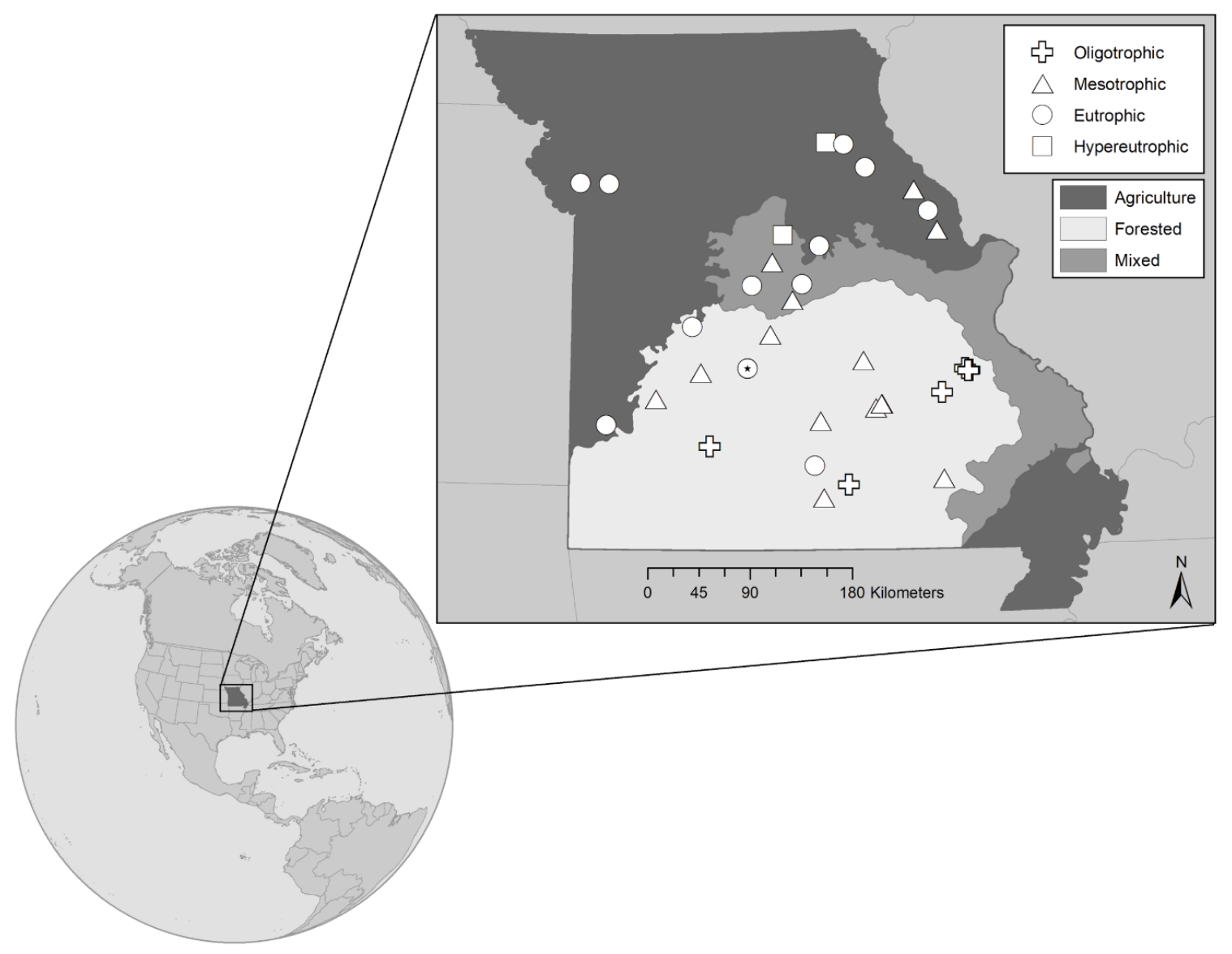

Figure 2.1. Locations of the 32 study reservoirs across the state of Missouri, USA. Sites represent the trophic gradient demonstrated by reservoirs throughout the state from very low $\left(\sim 0.10 \mu \mathrm{mol} \mathrm{L}^{-1}\right)$ to very high $\left(\sim 4.40 \mu \mathrm{mol} \mathrm{L}^{-1}\right)$ epilimnetic total phosphorus concentrations. Symbols distinguish trophic status, where $\uparrow, \Delta, O, \square$ represent oligotrophic, mesotrophic, eutrophic, and hypereutrophic, respectively. All reservoirs are warm monomictic, except for polymictic Lake Niangua which is denoted as a eutrophic circle with a filled $\operatorname{dot}(\bullet)$ in the center. Shading indicates the dominant land-use generalized for each of the state's major physiographic regions, with the north dominated by agriculture, the south largely forested, and mixed landcover in-between. Land-use specific to each reservoir's watershed has been classified separately. 


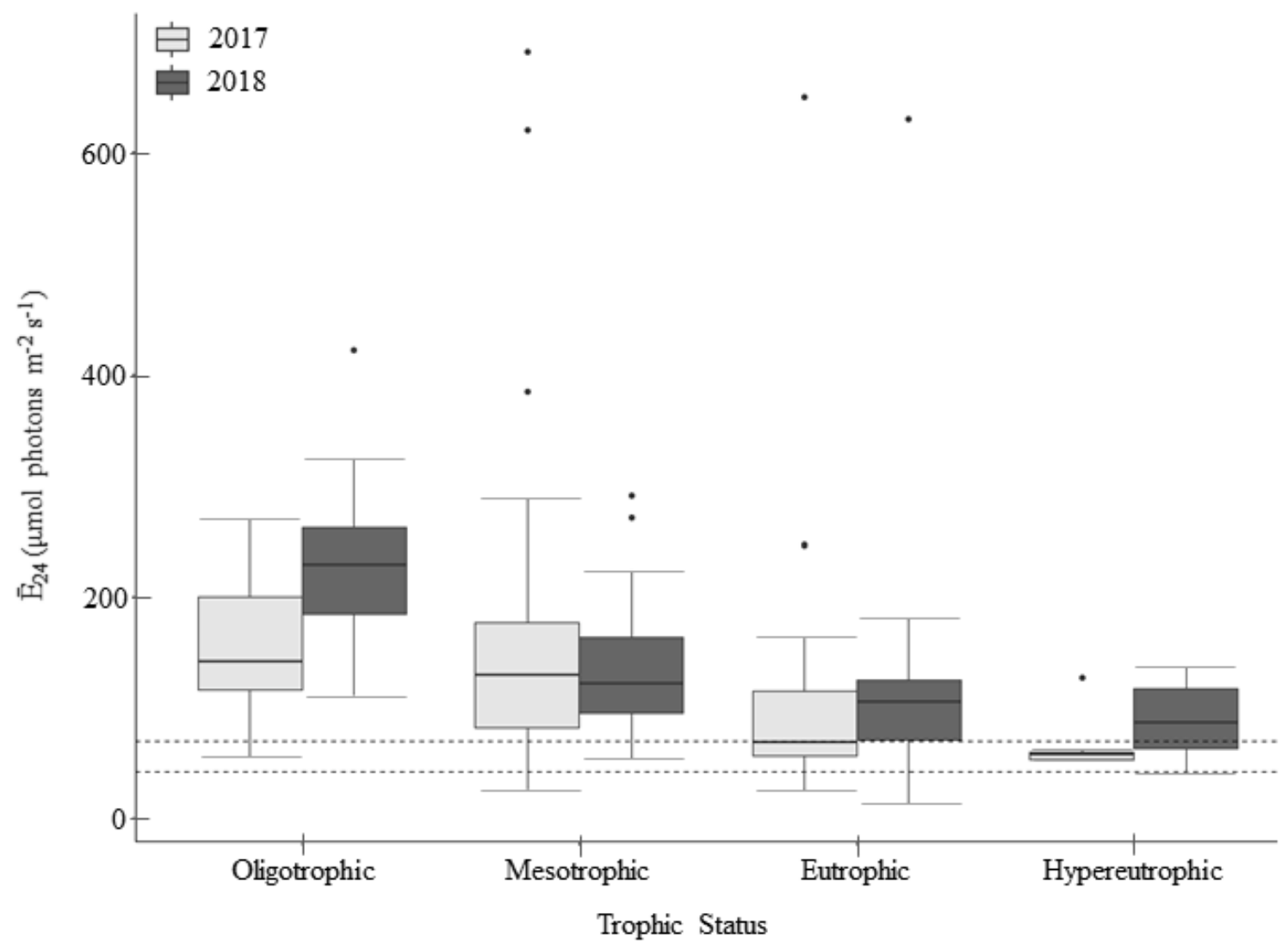

Figure 2.2. Mean daily mixed layer irradiance $\left(\overline{\mathrm{E}}_{24}\right)$ across the trophic gradient during the 2017 and 2018 sampling seasons $(n=213)$. The $50^{\text {th }}$ percentile (median) is visualized for each boxplot with a solid horizontal line. The $25^{\text {th }}$ and $75^{\text {th }}$ percentiles are represented by box hinges above and below the median line. Whiskers on either end of the box denote the smallest and largest values within $1.5 \mathrm{x}$ the interquartile range (IQR) and points indicate values beyond 1.5x the IQR. Dashed lines represent the light-deficiency thresholds. Values below which would suggest light-deficiency. There was no statistically significant difference between years, although generally, there was less light available during the wetter year (2017). Likewise, there was no statistically significant difference between trophic states, despite a general decline in $\overline{\mathrm{E}}_{24}$ as total phosphorus concentrations increased. 


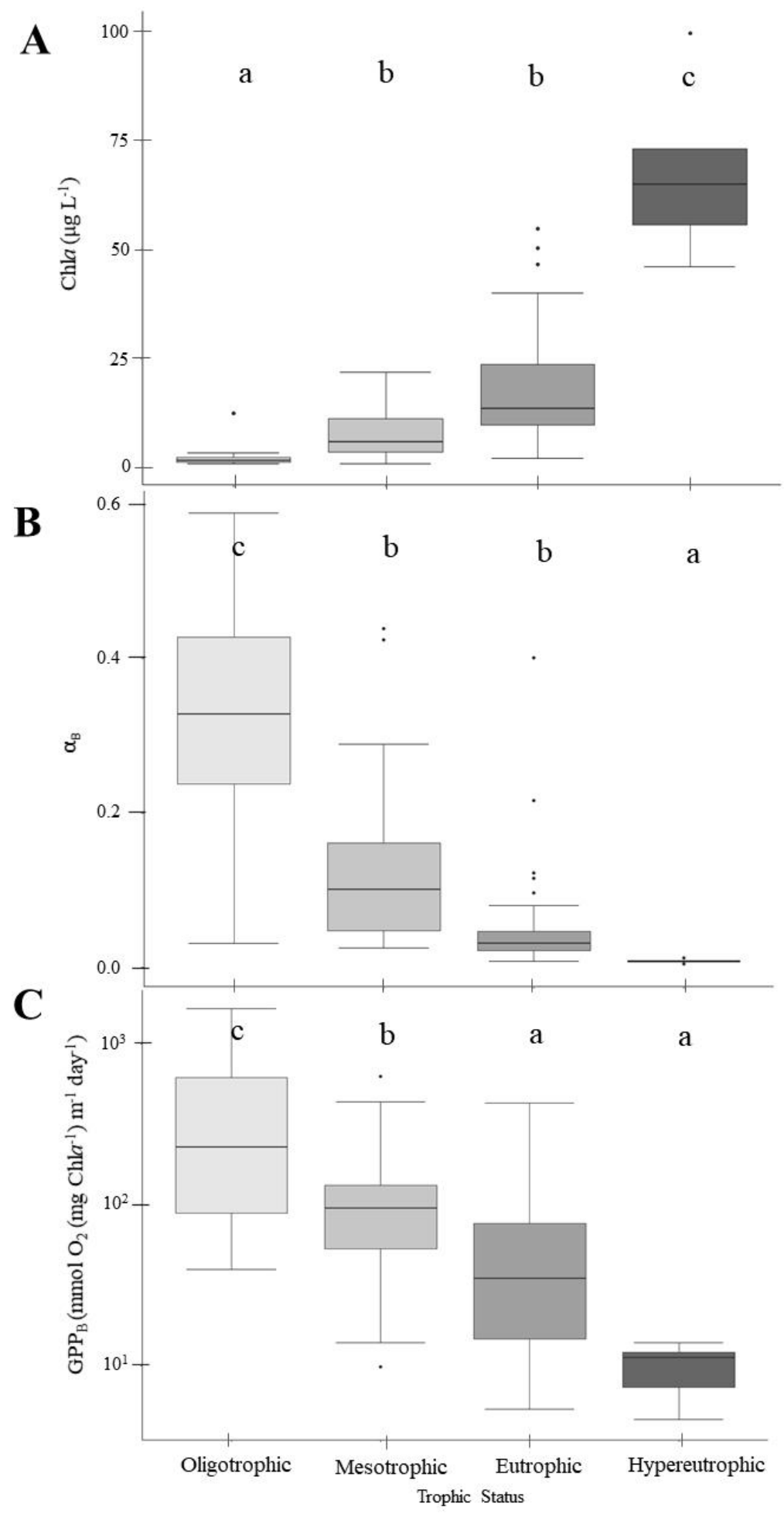

Figure 2.3. Chlorophyll-a (A), light utilization efficiency $\left(\alpha^{\mathrm{B}}\right)$ per unit of chlorophyll-a $(\mathrm{B})$, and gross primary production $\left(\mathrm{GPP}^{\mathrm{B}}\right)$ rates normalized to chlorophyll-a $(\mathrm{C})$ across the trophic gradient. The $50^{\text {th }}$ percentile (median) is visualized for each boxplot with a solid horizontal line. The $25^{\text {th }}$ and $75^{\text {th }}$ percentiles are represented by box hinges above and below the median line. Whiskers on either end of the box denote the smallest and largest values within 1.5x the interquartile range (IQR) and points indicate values beyond $1.5 x$ the IQR. Lowercase letters indicate results from multiple comparison posthoc tests, where similar letters denote no significant difference between trophic states. 


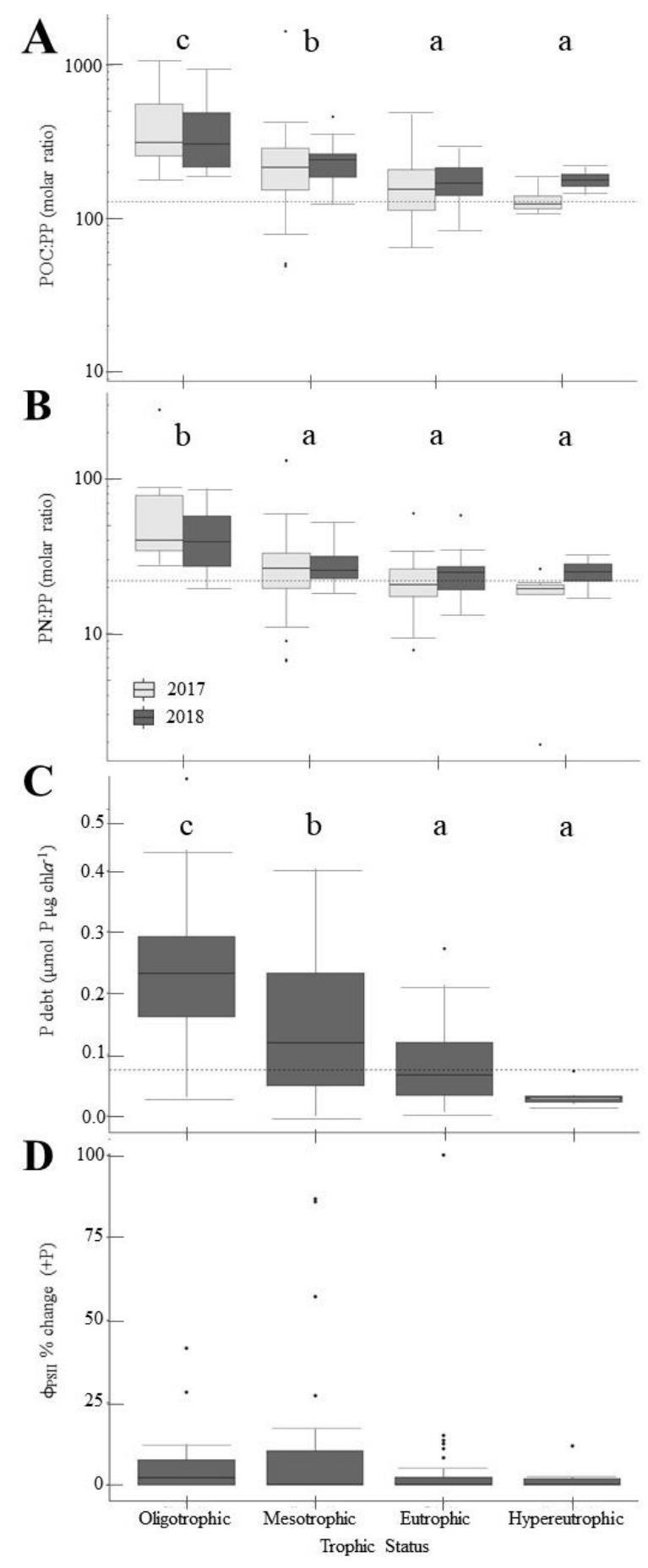

Figure 2.4. Patterns of phosphorus $(\mathrm{P})$ status across the trophic gradient, and, if applicable, the two-year sample period, based on P-deficiency indicators: particulate nitrogen to particulate phosphorus (PN:PP) ratios (A), particulate organic carbon to particulate phosphorus (POC:PP) ratios (B), phosphorus debts (P debt; C), and percent change in $\phi_{\text {PSII }}$ relative to the control treatment following P-additions (D). The $50^{\text {th }}$ percentile (median) is visualized for each boxplot with a solid horizontal line. The $25^{\text {th }}$ and $75^{\text {th }}$ percentiles are represented by box hinges above and below the median line. Whiskers on either end of the box denote the smallest and largest values within $1.5 \mathrm{x}$ the interquartile range (IQR) and points indicate values beyond $1.5 x$ the IQR. Dashed horizontal lines indicate P-deficiency thresholds, where applicable. Values above which suggest P-deficiency. Lowercase letters indicate results from multiple comparisons post-hoc tests, where similar letters denote no significant difference between trophic states. 


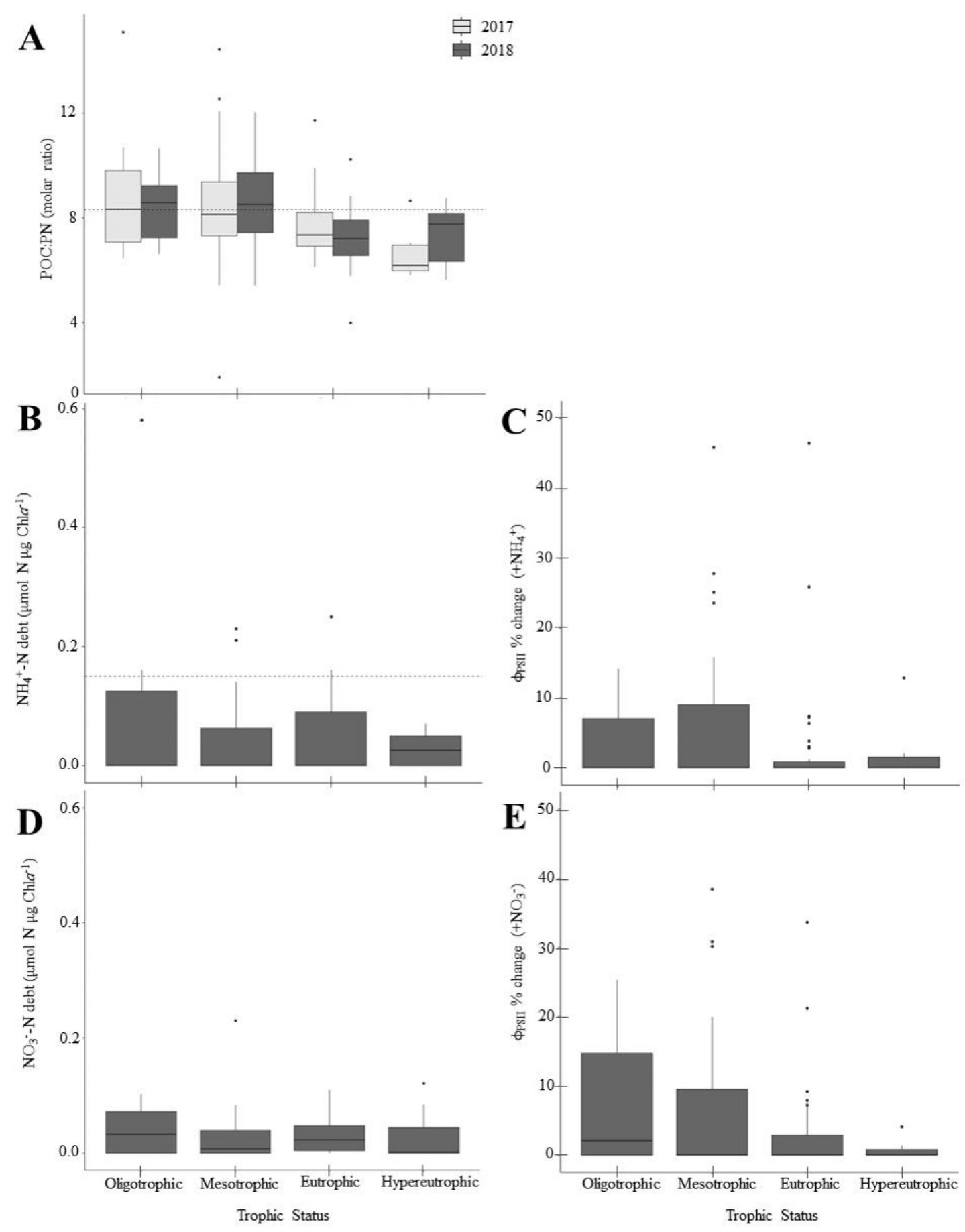

Figure 2.5. Patterns of nitrogen $(\mathrm{N})$ status across the trophic gradient, and, if applicable, the two-year sample period, based on $\mathrm{N}$-deficiency indicators: particulate organic carbon to particulate nitrogen (POC:PN) ratios (A), ammonium debts $\left(\mathrm{NH}_{4}{ }^{+}-\mathrm{N}\right.$ debt; $\left.\mathrm{B}\right)$, percent change in $\phi_{\mathrm{PSII}}$ relative to the control treatment after $\mathrm{NH}_{4}{ }^{+}$-additions (C), nitrate debts $\left(\mathrm{NO}_{3}{ }^{-} \mathrm{N}\right.$ debt; D), and percent change in $\phi_{\text {PSII }}$ relative to the control treatment after $\mathrm{NO}_{3}{ }^{-}$-additions (E). The $50^{\text {th }}$ percentile (median) is visualized for each boxplot with a solid horizontal line. The $25^{\text {th }}$ and $75^{\text {th }}$ percentiles are represented by box hinges above and below the median line. Whiskers on either end of the box denote the smallest and largest values within $1.5 \mathrm{x}$ the interquartile range (IQR) and points indicate values beyond 1.5x the IQR. Dashed horizontal lines indicate $\mathrm{N}$-deficiency thresholds, where applicable. Values above which suggest $\mathrm{N}$-deficiency. There were no significant differences between trophic states for any $\mathrm{N}$-indicator. 


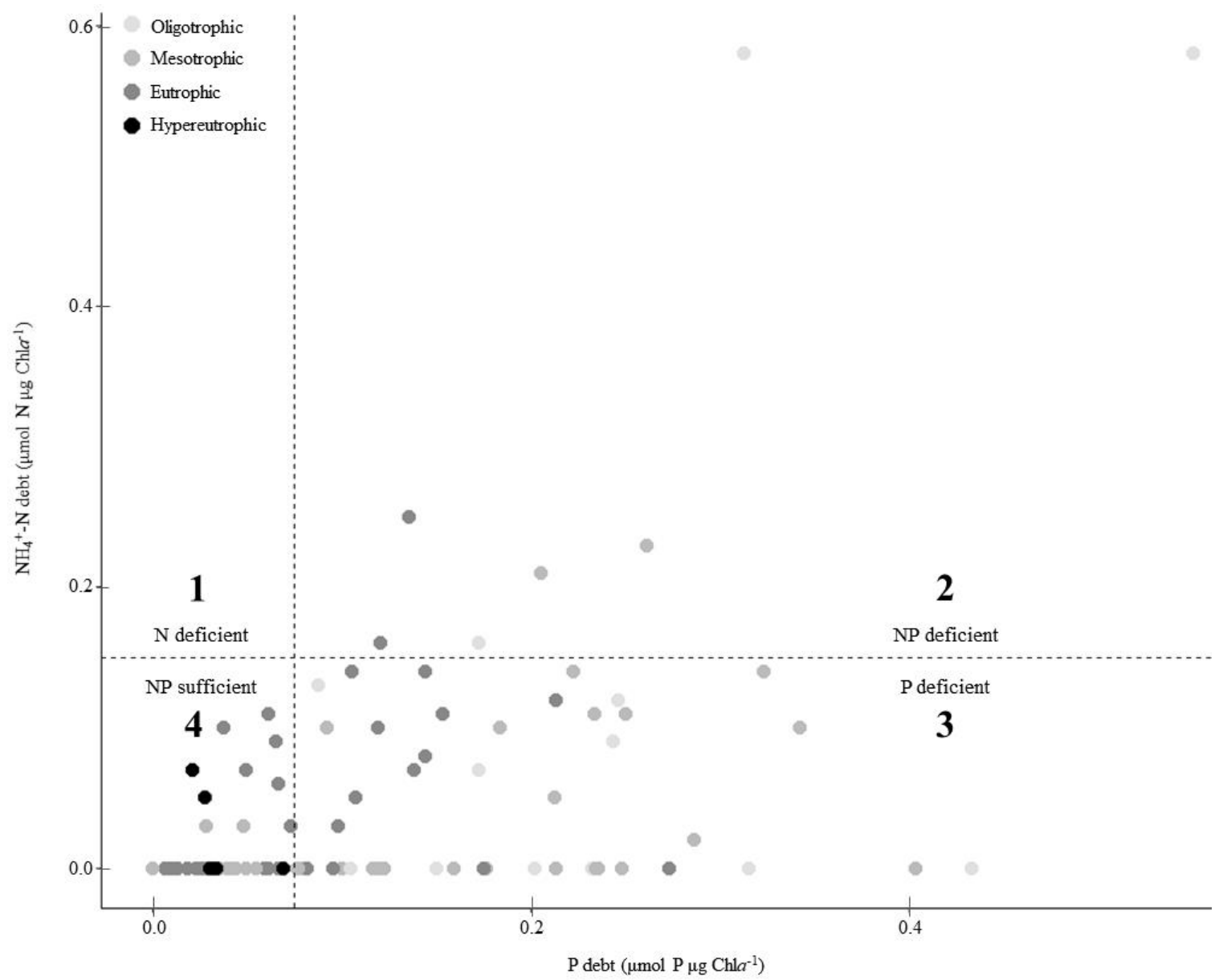

Figure 2.6. Summary of nutrient-deficiency across the trophic gradient according to phosphorus $(\mathrm{P})$ and ammonium-nitrogen $\left(\mathrm{NH}_{4}{ }^{+}-\mathrm{N}\right)$ debts. Dashed lines indicate deficiency thresholds for $\mathrm{P}$ and $\mathrm{NH}_{4}{ }^{+}-\mathrm{N}$ debts. Values greater than these lines suggest deficiency. Thus, quadrants 1, 3, and 2 represent $\mathrm{N}$-only deficiency, P-only deficiency, and NP co-deficiency, respectively. Quadrant 4 represents nutrient sufficiency in both $\mathrm{P}$ and $\mathrm{N}$. 


\section{Chapter 3: \\ Overall Conclusions and Projected Outcomes}

\section{Conclusions}

Phosphorus (P) and light availability play the most significant roles in constraining phytoplankton dynamics in Missouri reservoirs. Phytoplankton biomass was predominantly constrained by P-deficiency, with nitrogen- (N-) and light- deficiency playing much smaller roles than anticipated. Instead, light ended up being the central player to restrict primary productivity in Missouri's phytoplankton communities. Lownutrient oligotrophic systems were unable to support prolonged or abundant phytoplankton biomass; however, surprisingly, these high-light systems allowed for some of the most productive phytoplankton communities in the state, if not the region.

The data chapter within this thesis meaningfully contributes to the field of limnology and freshwater science in Missouri, the Midwest, and beyond, as there are lakes and reservoirs facing similar fates and circumstances all over the world. This is the culmination of my master's work, which encompass phytoplankton community dynamics and resource limitation in reservoirs as they relate to the impacts of regional nutrient loading and climate change. In addition to providing an underrepresented perspective on reservoirs to a field largely dominated by and effectively built upon natural lakes, I have examined relevant and timely real-world research questions that address surface water eutrophication and inform future management strategies to mitigate further degradation of such invaluable water resources. 


\section{Chapter 2 summary and significance}

Globally, climate change and anthropogenic eutrophication are anticipated to alter the light and nutrient regimes influencing phytoplankton dynamics across all surface waters. Present physical, chemical, and biological conditions in many Missouri reservoirs are much like those expected to occur in future waters under the stresses of intensified climatic and anthropogenic influences. For a field dominated largely by studies on natural lakes, this reservoir-centric study offers a less typical assessment of how the interactions between light and nutrients influence phytoplankton biomass and primary productivity across a wide gradient of trophic condition under the context of two climatically contrasting summers. If the predictions hold true, Missouri reservoirs indicate that both $\mathrm{P}$ and light availability will be important regulators of phytoplankton dynamics during summer stratification, with $\mathrm{P}$ constraining biomass and light constraining productivity.

My conclusions both support (e.g., biomass) and challenge (e.g., productivity) the traditional P-paradigms observed in and established for natural lakes. Like many lakes, P is the predominant regulator of biomass in Missouri reservoirs. This is especially important within the context of the nutrient management debate, where arguments for $\mathrm{P}$ management have mostly been based upon findings in geographically isolated, clearwater natural lakes located in the Experimental Lakes Area of the Canadian Shield (Schindler et al., 2008). Opposing viewpoints favoring N management have largely come from hypereutrophic Lake Taihu (China) and similar natural systems located on landscapes heavily influenced by human activity (Paerl et al., 2016). Here, however, is widespread evidence in the highly modified, agricultural Midwest that favors $\mathrm{P}$ management not only in low-nutrient reservoirs but also in high-nutrient reservoirs. These reservoirs have also provided evidence against the traditional P-paradigm for 
productivity, where light is instead the predominant regulator for productivity. My estimates of gross primary productivity (GPP), which offer data where reservoir-specific areal GPP rates are scarce, were much higher than many of those reported for natural lakes. Such differences could warrant separate consideration of the resources influencing phytoplankton dynamics and different prioritization of management, depending on the end-use of the waterbody.

Much of what is known about limnology comes from research gathered on natural lake systems. Reservoir-centric studies are rare in the field and most researchers assume that lakes and reservoirs should be treated synonymously, therefore, little effort is given to differentiate them in multisystem studies. While natural lakes and reservoirs are similar in many respects, the findings of this work suggest that greater attention should be given to revealing and understanding the actual differences between these inland systems. Unlike the natural glaciated lakes that define our understanding of limnology, these lower-latitude reservoirs experience a longer growing season and stratification period, and they receive greater inputs of nutrients and particulate inorganic matter from much larger, more heavily modified watersheds. This means that reservoirs often face greater biomass accrual with higher sedimentation rates (Kalff, 2002). I have shown that the phytoplankton in these reservoirs are more productive per unit of biomass, and more tolerant to low inorganic $\mathrm{N}$ concentrations and turbidity caused by particulate inorganic matter. The reservoirs appear to be more effective at $\mathrm{N}$ removal and habitually experience hypolimnetic anoxia, contributing to higher rates of internal loading. Valuable because it is a multisystem, reservoir-centric study, this work demonstrates that the light and nutrient regimes of reservoirs do not necessarily constrain phytoplankton in the same 
matter expected in natural lakes. It also contributes findings to understanding not only eutrophication, but also the implications of modified land-use and climatic variability on water quality in reservoir systems.

\section{Projected outcomes (meaningful application of research)}

This study has provided a robust, detailed assessment of the light and nutrient regimes constraining phytoplankton dynamics across a gradient of reservoir condition in Missouri. Such assessments have critical implications for developing regional management practices, particularly within watersheds where agricultural nutrient loading is high (Anderson et al., 2002; North et al., 2013). Ideally, managers will use the resulting resource limitation information to employ more effective strategies for controlling phytoplankton biomass and curbing cyanobacterial harmful algal bloom (CyanoHAB) development (North et al., 2013; Dubourg et al., 2015).

Eutrophic water bodies are projected to become increasingly prevalent across the landscape, therefore, there is a growing need for society to mitigate nutrient loading and reverse anthropogenic eutrophication (Tilman et al., 2001). Taking steps to reverse anthropogenic eutrophication has important financial implications, however, as there are costs associated with any nutrient reduction strategy (Schindler, 2012). Results from this study will be useful in determining whether strategies should be implemented to target $\mathrm{P}$ or $\mathrm{N}, \mathrm{P}$ and $\mathrm{N}$, or neither $\mathrm{P}$ nor $\mathrm{N}$ (i.e., light control). As state and federal agencies are working to develop or strengthen water quality standards related to lake nutrient criteria and considering the possibility of $\mathrm{P}$ credit trading, this work can be used to directly inform such policies. It will also further demonstrate, as previously suggested by 
Knowlton and Jones (2006), that environmental regulations should be framed appropriately to account for the naturally variable conditions seen in and across systems.

Widespread P-deficiency in these reservoirs implies that additional P inputs could contribute to increased algal blooms. To prevent excessive phytoplankton biomass that would negatively impact the light environment and inhibit phytoplankton primary productivity, improved P management is advised. Given that these systems are effective at $\mathrm{N}$-removal, as evidenced by low inorganic $\mathrm{N}$ concentrations and a lack of $\mathrm{N}$ deficiency, additional $\mathrm{N}$ management is unnecessary at this time. Reservoirs are intrinsically linked to their watersheds; therefore, I stress the importance of managing those watersheds in order to effectively manage reservoir water quality. Reservoirs are constructed to meet human needs by damming rivers and streams; therefore, they themselves exist as modified water bodies on an increasingly modified landscape. As a result, they have unnaturally large watersheds relative to their surface areas and are more likely to be within proximity to anthropogenic activity. Larger watersheds with more human disturbance contribute larger inputs of nutrients, organic matter, and sediment to reservoirs via streams and overland flow. This makes reservoirs with erosional topographies especially sensitive to high flushing and flow events. As such, Missouri reservoirs are characteristically more turbid, having faster flushing rates, shorter water retention times faster sedimentation rates than natural lakes (Jones et al., 2008b).

For Missouri reservoirs, watershed-based beneficial management practices (BMPs) designed to reduce $\mathrm{P}$ are practical options for eutrophication abatement. BMPs typically recommended to control P inputs in natural lakes, however, may not yield the same results if applied in a reservoir setting. Many are designed to reduce $\mathrm{P}$ inputs by 
limiting losses associated with sediment transport. Despite the phytoplankton in these inherently turbid reservoir systems demonstrating little to no light-deficiency under present conditions, reductions to the sediment load could improve the depth of light penetration, inadvertently increasing phytoplankton biomass (Jones et al., 2020c). BMPs implemented in the watersheds of reservoirs, therefore, should focus on reducing losses of bioavailable $\mathrm{P}$ in overland flow and stream discharge. While there is much uncertainty surrounding the effectiveness of specific watershed BMPs on improving reservoir water quality, I would advocate for efforts that increase the retention of applied nutrients on the landscape, such as targeted timing and precise incorporation of fertilizer, and maintaining healthy vegetative buffers. I would also advocate for improvements to waste management for poultry and livestock operations to reduce unintentional nutrient losses. Although high rates of internal nutrient loading may initially mask the improvements in water quality associated with positive changes in watershed management, overall external input reductions are paramount in seeing long-term recovery (Jones et al., 2008a).

Data collected as a part of this study contributed two additional years of water quality data to an invaluable, long-term monitoring dataset that spans $40+$ years on Missouri reservoirs (Jones et al., 2020a). In the field of limnology, long-term monitoring datasets on reservoirs are rare; however, long-term monitoring records are essential in understanding how complex and highly variable systems behave over time, revealing typical patterns and cycles as well as significant or abnormal shifts in conditions (Burt et al., 2014). Data reported in this dataset may be used in a number of applications, including scientific research, regulatory assessment and rulemaking, as well as resource management, by interested parties, such as academics, scientists, non-profit 
environmental groups, and local, state, and federal agencies. While many parameters collected in this study were traditionally collected by University of Missouri Limnology Laboratory's Statewide Lake Assessment Program (e.g., epilimnetic total nutrients, suspended solids, and chlorophyll- $a$, as well as field measurements of dissolved oxygen, $\mathrm{pH}$, conductivity, and Secchi depth), this study introduced new parameters to the monitoring dataset, such as mixing depth, mixed daily mean irradiance, as well as hypolimnetic nutrients and dissolved nutrients from both the epilimnion and hypolimnion. Findings from this study have also given reason to continue monitoring some of the introduced parameters for further characterization of the reservoirs and for use in future limnological research projects.

\section{Future considerations for further research}

To further build upon the findings of this study, the next researcher(s) might consider a closer examination of the phytoplankton community members, the actual rates of internal loading and denitrification, or the constituents of dissolved organic nitrogen (DON). While it is a valid approach to examine the nutrient status and physiological response of the general phytoplankton community, next steps could include a survey of the phytoplankton community wherein members are identified and counted. An improved understanding of the phytoplankton community structure and abundance would help inform the observed physiological responses of the phytoplankton community, as these responses are known to vary among species. Much of the basis for this work was that Missouri reservoirs are susceptible to cyanoHABs. Decade-old research offers evidence that cyanobacteria are present and often dominate in these waters, but more recent evidence is needed. Shifts in the nutrient status of inland systems may make conditions 
more favorable for cyanobacterial dominance (i.e., light- and N- deficiency). We can use other parameters as indicators of cyanobacterial presence, such as ${ }^{15} \mathrm{~N}$ stable isotope signatures and phycocyanin sensor measurements, but until an actual survey of the community is conducted, we will not know for sure.

Data presented here offer evidence that internal loading is occurring in nearly every study reservoir. Disparages between epilimnetic and hypolimnetic nutrient concentrations suggest that internal loading is likely a significant contributor of nutrients in these systems. Little is known about the rates by which nutrients are being resuspended in the water column via internal loading. With the hypolimnions of nearly all reservoirs going anoxic during summer stratification, these systems offer a quintessential opportunity for further investigation. Legacy nutrients are a growing and challenging concern for lake and reservoir management around the world. While watershed management can help mediate external loading to water bodies, more research is needed to understand how we might manage internal loading.

One of the most surprising findings of this research was that DON dominated the $\mathrm{N}$ supply in many reservoirs. Previously, ammonia and nitrate/nitrite were assumed the dominant sources of $\mathrm{N}$; however, concentrations of both species were negligible in most samples. Despite near depletion of these two primary sources of N, phytoplankton rarely indicated N-deficiency. Furthermore, preliminary examination of the ${ }^{15} \mathrm{~N}$ stable isotope to source $\mathrm{N}$ in these systems provided limited evidence of $\mathrm{N}$ fixation via cyanobacteria (this study, data not shown). This suggests that the phytoplankton communities are getting their $\mathrm{N}$ supply from other sources in the environment. While I was able to estimate DON concentrations by difference between total $\mathrm{N}$ and total inorganic $\mathrm{N}$ concentrations, work 
is still needed to more precisely measure concentrations of DON and its constituent, urea. The lack of inorganic $\mathrm{N}$ in these waters also suggests that Missouri reservoirs are effective at N-removal, presumably via denitrification. Little is known about denitrification rates in reservoirs, and research to date propounds that reservoirs may play a critical role in $\mathrm{N}$-management as $\mathrm{N}$-sinks.

\section{Lessons learned}

Scientific research revolves around trial and error. Having never done anything quite like this project before, mistakes were made and lessons were learned. If I were to conduct this research over again, I would like to rethink how I implemented the photosynthetic efficiency experiment component of this project; results of which offered the least in terms of interpretive value and indicator agreement. For the photosynthetic efficiency experiments, as well as the nutrient debts, I made the decision to prioritize having a larger volume for representativeness over having replicates for statistical soundness. Logistically, due to time and resource constraints, I could not have both. Knowing how the experiments turned out, I would now prioritize statistical soundness and robustness, and go with a smaller volume with duplicate samples. This would provide statistical rigor that I felt the experiments lacked. Experimental design could have also been improved for the photosynthetic efficiency and nutrient debt experiments. A more detailed record of times (e.g., first spike, last spike, beginning of dark incubation) and placement of each experimental unit during incubation could have helped explain anomalies in the experiments. For example, experimental units were randomized in their incubation placements, but there was no record of where each unit was placed. With a peripheral light source as opposed to an overhead light source, it could have been 
informative to know which samples were closest to the light and which were furthest away to evaluate shading of samples and diffusion of light intensity.

\section{Final Thoughts}

Nutrient pollution and cyanoHABs are contemporary hot button issues in the fields of limnology, water quality, and natural resource management. With anthropogenic activity and a changing climate exacerbating these troublesome environmental issues, action needs to be taken to mitigate the impairment of invaluable water resources worldwide. According to the Missouri Department of Natural Resources, most Missouri reservoirs either do not have point source nutrient inputs in their watersheds or have permitted inputs, such as treated wastewater. This means the most significant threat to these water bodies is nonpoint sources of nutrient pollution, for which there are no permits to protect waters in the United States. Scientific findings, such as those presented in this thesis, are crucial for effectively managing lakes and reservoirs, alike, so that they can continue to be used and enjoyed for generations to come. With Missouri's reservoirs predominantly P-deficient, nutrient reduction and retention strategies that focus on $\mathrm{P}$ will be among the most beneficial management strategies to limit phytoplankton biomass, maintain effective primary productivity, and preserve water quality in these systems. Continued monitoring and research will be needed to further our understanding of light, nutrients, and phytoplankton dynamics in Missouri reservoirs into the future so that we continue making better management decisions in this ever-changing world. 


\section{References}

Abell, J. M., Özkundakci, D., and Hamilton, D. P. (2010). Nitrogen and phosphorus limitation of phytoplankton growth in New Zealand lakes: implications for eutrophication control. Ecosystems 13, 966-977.

Abell, J. M., Özkundakci, D., Hamilton, D. P., and Jones, J. R. (2012). Latitudinal variation in nutrient stoichiometry and chlorophyll-nutrient relationships in lakes: A global study. Fundam Appl Limnol 181, 1-14.

Alexander, R. B., Smith, R. A., Schwarz, G. E., Boyer, E. W., Nolan, J. V, and Brakebill, J. W. (2008). Differences in phosphorus and nitrogen delivery to the Gulf of Mexico from the Mississippi River Basin. Environ Sci Technol 42, 822-830.

Anderson, D. M., Glibert, P. M., and Burkholder, J. M. (2002). Harmful algal blooms and eutrophication: Nutrient sources, composition, and consequences. Estuaries 25, 704-726.

APHA (2017). Standard methods for the examination of water and wastewater. 23rd ed. , eds. E. W. Rice, R. B. Baird, and A. D. Eaton Washington, DC: American Public Health Association.

Arrigo, K. R. (2005). Marine microorganisms and global nutrient cycles. Nature 437, 349-355.

Awortwi, F. E., Frempong, E., Aikins, S., Hecky, R. E., Hall, R., and Puchniak, M. (2018). Seasonality of primary productivity of phytoplankton of Lake Bosomtwe, Ghana - West Africa. West African J Appl Ecol 26, 105-119.

Beardall, J., Young, E., and Roberts, S. (2001). Approaches for determining phytoplankton nutrient limitation. Aquat Sci 63, 44-69.

Belisle, B. S., Steffen, M. M., Pound, H. L., Watson, S. B., DeBruyn, J. M., Bourbonniere, R. A., et al. (2016). Urea in Lake Erie: organic nutrient sources as potentially important drivers of phytoplankton biomass. J Great Lakes Res 42, 599-607.

Bennett, E. M., Carpenter, S. R., and Caraco, N. F. (2001). Human impact on erodable phosphorus and eutrophication: a global perspective. Bioscience 51, 227-234.

Benson, A., Raikow, D., Larson, J., Fusaro, A., and Bogdanoff, A. (2021). Zebra mussel sightings distribution. United States Geol Surv Nonindigenous Aquat Species Database. Available at: http://nas.er.usgs.gov/.

Bjorkman, K. M., and Karl, D. M. (2003). Bioavailability of dissolved organic phosphorus in the euphotic zone at Station ALOHA, North Pacific Subtropical Gyre. Limnol Ocean 48, 1049-1057.

Blackman, F. F. (1905). Optima and limiting factors. Ann Bot 19, 281-296.

Bocaniov, S. A., and Smith, R. E. H. (2009). Plankton metabolic balance at the margins of very large lakes: temporal variability and evidence for dominance of autochthonous processes. Freshw Biol 54, 345-362. 
Brady, N. C., and Weil, R. R. (2008). The nature and properties of soil. 14th ed. Boston: Pearson.

Brauer, V. S., Stomp, M., and Huisman, J. (2012). The Nutrient-Load Hypothesis: patterns of resource limitation and community structure driven by competition for nutrients and light. Am Nat 179, 721-740.

Brodie, C. R., Leng, M. J., Casford, J. S. L., Kendrick, C. P., Lloyd, J. M., Yongqiang, Z., et al. (2011). Evidence for bias in $\mathrm{C}$ and $\mathrm{N}$ concentrations and $\delta 13 \mathrm{C}$ composition of terrestrial and aquatic organic materials due to pre-analysis acid preparation methods. Chem Geol 282, 67-83.

Bronk, D. A., See, J. H., Bradley, P., and Killberg, L. (2006). DON as a source of bioavailable nitrogen for phytoplankton. Biogeosciences Discuss 3, 1247-1277.

Burt, T. P., Howden, N. J. K., and Worrall, F. (2014). On the importance of very longterm water quality records. Wiley Interdiscip Rev Water 1, 41-48.

Campbell, D., Hurry, V., Clarke, A. K., Gustafsson, P., and Oquist, G. (1998). Chlorophyll fluorescence analysis of cyanobacterial photosynthesis and acclimation. Microbiol Mol Biol Rev 62, 667-83.

Canfield, D. E., Kristensen, E., and Thamdrup, B. (2005). The phosphorus cycle. $A d v$ Mar Biol 48, 419-440.

Canfield, T., and Jones, J. (1996). Zooplankton abundance, biomass, and size-distribution in selected Midwestern waterbodies and relation with trophic state. J Freshw Ecol $11,171-181$.

Carignan, R., Planas, D., and Vis, C. (2000). Planktonic production and respiration in oligotrophic shield lakes. Limnol Oceanogr 45, 189-199.

Carpenter, S. R. (1996). Microcosm experiments have limited relevance for community and ecosystem ecology. Ecology 77, 677-680.

Carpenter, S. R., Stanley, E. H., and Vander Zanden, M. J. (2011). State of the world's freshwater ecosystems: physical, chemical, and biological changes. Annu Rev Environ Resour 36, 75-99.

Conley, D. J., Paerl, H. W., Howarth, R. W., Boesch, D. F., Seitzinger, S. P., Havens, K. E., et al. (2009). Controlling eutrophication: nitrogen and phosphorus. Science 323, 1014-1015.

Crumpton, W. G., Isenhart, T. M., and Mitchell, P. D. (1992). Nitrate and organic N analyses with second-derivative spectroscopy. Limnol Oceanogr 37, 907-913.

Daniel, T. C., Sharpley, A. N., and Lemunyon, J. L. (1998). Agricultural phosphorus and eutrophication: a symposium overview. J Environ Qual 27, 251-257.

de Mazancourt, C., and Schwartz, M. W. (2012). Starve a competitor: evolution of luxury consumption as a competitive strategy. Theor Ecol 5, 37-49.

del Giorgio, P. A., and Peters, R. H. (1993). Balance between phytoplankton production 
and respiration in lakes. Can J Fish Aquat Sci 50, 282-289.

Depew, D., Smith, R., and Guildford, S. (2006). Production and respiration in Lake Erie plankton communities. J Great Lakes Res 32, 817-831.

Downing, J. A., Prairie, Y. T., Cole, J. J., Duarte, C. M., Tranvik, L. J., Striegl, R. G., et al. (2006). The global abundance and size distribution of lakes, ponds, and impoundments. Limnol Oceanogr 51, 2388-2397.

Downing, J. A., Watson, S. B., and McCauley, E. (2001). Predicting cyanobacteria dominance in lakes. Can J Fish Aquat Sci 58, 1905-1908.

Dubourg, P., North, R. L., Hunter, K., Vandergucht, D. M., Abirhire, O., Silsbe, G. M., et al. (2015). Light and nutrient co-limitation of phytoplankton communities in a large reservoir: Lake Diefenbaker, Saskatchewan, Canada. J Great Lakes Res 41, 129-143.

Dzialowski, A. R., Wang, S. H., Lim, N. C., Spotts, W. W., and Huggins, D. G. (2005). Nutrient limitation of phytoplankton growth in central plains reservoirs, USA. $J$ Plankton Res 27, 587-595.

Elser, J. J., Bracken, M. E. S. M. E. S., Cleland, E. E., Gruner, D. S., Harpole, W. Stanley Hillebrand, H., Ngai, J. T., et al. (2007). Global analysis of nitrogen and phosphorus limitation of primary producers in freshwater, marine and terrestrial ecosystems. Ecol Lett 10, 1135-1142.

Elser, J. J., Marzolf, E. R., and Goldman, C. R. (1990). Phosphorus and nitrogen limitation of phytoplankton growth in the freshwaters of North America: a review and critique of experimental enrichments. Can J Fish Aquat Sci 47, 1468-1477.

Erikson, R. (1999). Algal respiration and the regulation of phytoplankton biomass in a polymictic tropical lake (Lake Xolotlán, Nicaragua). Hydrobiologia 382, 17-25.

Falkowski, P. G., and Raven, J. A. (2007). Aquatic photosynthesis. 2nd ed. Princeton, New Jersey: Princeton University Press.

Faust, D. R., Kröger, R., Moore, M. T., and Rush, S. A. (2018). Management practices used in agricultural drainage ditches to reduce Gulf of Mexico Hypoxia. Bull Environ Contam Toxicol 100, 32-40.

Fee, E. J. (1990). Computer programs for calculating in situ phytoplankton photosynthesis. Can Tech Rep Fish Aquat Sci 1740, 1-27.

Filstrup, C. T., and Downing, J. A. (2017). Relationship of chlorophyll to phosphorus and nitrogen in nutrient-rich lakes. Inl Waters 7, 385-400.

Fontaine, T. D., and Ewel, K. C. (1981). Metabolism of a Florida lake ecosystem. Limnol Oceanogr 26, 754-763.

Fuchs, E., Zimmerman, R. C., and Jaffe, J. S. (2002). The effect of elevated levels of phaeophytin in natural water on variable fluorescence measured from phytoplankton. J Plankton Res 24, 1221-1229.

Galloway, J. N. (1998). The global nitrogen cycle: changes and consequences. Environ 
Pollut 102, 15-24.

Galloway, J. N., Townsend, A. R., Erisman, J. W., Bekunda, M., Cai, Z., Freney, J. R., et al. (2008). Transformation of the nitrogen cycle: recent trends, questions, and potential solutions. Science 320, 889-892.

Gaskill, J. A. (2021). How changes in light impact phytoplankton in midwest reservoirs. [Unpublished doctoral dissertation]. University of Missouri.

Glibert, P. M., Harrison, J., Heil, C., and Seitzinger, S. (2006). Escalating worldwide use of urea: a global change contributing to coastal eutrophication. Biogeochemistry 77, 441-463.

Glibert, P. M., Wilkerson, F. P., Dugdale, R. C., Raven, J. A., Dupont, C. L., Leavitt, P. R., et al. (2016). Pluses and minuses of ammonium and nitrate uptake and assimilation by phytoplankton and implications for productivity and community composition, with emphasis on nitrogen-enriched conditions. Limnol Ocean 61, 165-197.

Gooding, R. M., and Baulch, H. M. (2017). Small reservoirs as a beneficial management practice for nitrogen removal. J Environ Qual 46, 96-104.

Gosselin, M., Legendre, L., Demers, S., and Ingram, R. G. (1985). Responses of sea-ice microalgae to climatic and fortnightly tidal energy inputs (Manitounuk Sound, Hudson Bay). Can J Fish Aquat Sci 42, 999-1006.

Graham, J. L., Jones, J. R., Jones, S. B., Downing, J. A., and Clevenger, T. E. (2004). Environmental factors influencing microcystin distribution and concentration in the midwestern United States. Water Res 38, 4395-4404.

Grobbelaar, J. U. (1989). The contribution of phytoplankton productivity in turbid freshwaters to their trophic status. Hydrobiologia 173, 127-133.

Grover, J. P. (2000). Resource competition and community structure in aquatic microorganisms: experimental studies of algae and bacteria along a gradient of organic carbon to inorganic phosphorus supply. J Plankton Res 22, 1591-1610.

Guildford, S. J., Bootsma, H. A., Fee, E. J., Hecky, R. E., and Patterson, G. (2000). Phytoplankton nutrient status and mean water column irradiance in lakes Malawi and Superior. Aquat Ecosyst Heal Manag 3, 35-45.

Guildford, S. J., and Hecky, R. E. (2000). Total nitrogen, total phosphorus, and nutrient limitation in lakes and oceans: is there a common relationship? Limnol Oceanogr 45, 1213-1223.

Guimarais-Bermejo, M. O., Merino-Ibarra, M., Valdespino-Castillo, P. M., CastilloSandoval, F. S., and Ramírez-Zierold, J. A. (2018). Metabolism in a deep hypertrophic aquatic ecosystem with high water-level fluctuations: a decade of records confirms sustained net heterotrophy. PeerJ 2018, 1-27.

Hammer, R. D. (1997). Missouri Ozark forest soils: perspectives and realities. MOFEP Proc, 106-121. 
Hanson, P. C., Bade, D. L., Carpenter, S. R., Kratz, T. K., and Long, W. (2003). Lake metabolism: relationships with dissolved organic carbon and phosphorus. Limnol Ocean 48, 1112-1119.

Hayes, N. M., Deemer, B. R., Corman, J. R., Razavi, N. R., and Strock, K. E. (2017). Key differences between lakes and reservoirs modify climate signals: a case for a new conceptual model. Limnol Oceanogr Lett 2, 47-62.

Hayes, N. M., Vanni, M. J., Horgan, M. J., and Renwick, W. H. (2015). Climate and land use interactively affect lake phytoplankton nutrient limitation status. Ecology 96, 392-402.

Hayhoe, K., Wuebbles, D. J., Easterling, D. R., Fahey, D. W., Doherty, S., Kossin, J., et al. (2018). "Our changing climate," in Impacts, risks, and adaptation in the United States: fourth national climate assessment, eds. D. R. Reidmiller, C. W. Avery, D. R. Easterling, K. E. Kunke, K. L. M. Lewis, T. K. Maycock, et al. (Washington, DC), 72-144.

Healey, F. P. (1977). Ammonium and urea uptake by some freshwater algae. Can J Bot $55,61-69$.

Healey, F. P., and Hendzel, L. L. (1979a). Fluorometric measurement of alkaline phosphatase activity in algae. Freshw Biol 9, 429-439.

Healey, F. P., and Hendzel, L. L. (1979b). Indicators of phosphorus and nitrogen deficiency in five algae in culture. J Fish Res Board Canada 36, 1364-1369.

Healey, P. F. (1985). Interacting effects of light and nutrient limitation on the growth rate of Synechococcus linearis (Cyanophyceae). J Phycol 21, 134-146.

Hecky, R. E., Campbell, P., and Hendzel, L. L. (1993). The stoichiometry of carbon, nitrogen, and phosphorus in particulate matter of lakes and oceans. Limnol Oceanogr 38, 709-724.

Hecky, R. E., and Guildford, S. J. (1984). Primary productivity of Southern Indian Lake before, during, and after impoundment and Churchill River diversion. Can J Fish Aquat Sci 41, 591-604.

Hecky, R. E., and Kilham, P. (1988). Nutrient limitation of phytoplankton in freshwater and marine environments: a review of recent evidence on the effects of enrichment. Limnol Oceanogr 33, 796-822.

Higgins, S. N., Paterson, M. J., Hecky, R. E., Schindler, D. W., Venkiteswaran, J. J., and Findlay, D. L. (2018). Biological nitrogen fixation prevents the response of a eutrophic lake to reduced loading of nitrogen: evidence from a 46-year whole-lake experiment. Ecosystems 21, 1088-1100.

Higgins, S. N., and Vander Zanden, M. J. (2010). What a difference a species makes: a meta-analysis of dreissenid mussel impacts on freshwater ecosystems. Ecol Monogr 80, 179-196.

Hoellein, T. J., Bruesewitz, D. A., and Richardson, D. C. (2013). Revisiting Odum (1956): 
a synthesis of aquatic ecosystem metabolism. Limnol Oceanogr 58, 2089-2100.

Howarth, R., Swaney, D., Billen, G., Garnier, J., Hong, B., Humborg, C., et al. (2012). Nitrogen fluxes from the landscape are controlled by net anthropogenic nitrogen inputs and by climate. Front Ecol Environ 10, 37-43.

Howarth, R. W., and Marino, R. (2006). Nitrogen as the limiting nutrient for eutrophication in coastal marine ecosystems: evolving views over three decades. in Limnology and Oceanography, 364-376.

Howarth, R. W., Marino, R., Lane, J., and Cole, J. J. (1988). Nitrogen fixation in freshwater, estuarine, and marine ecosystems. Limnol Oceanogr 33, 669-687.

Hoyer, M. V., and Jones, J. R. (1983). Factors affecting the relation between phosphorus and chlorophyll a in midwestern reservoirs. Can J Fish Aquat Sci 40, 192-199.

Huston, M. A., Drenner, R. W., and Mazumder, A. (1999). Microcosm experiments have limited relevance for community and ecosystem ecology: synthesis of comments. Ecology 80, 1081-1085.

Hutchinson, G. E. (1957). A treatise on limnology. New York: John Wiley \& Sons, Inc.

Iestyn Woolway, R., and Merchant, C. J. (2017). Amplified surface temperature response of cold, deep lakes to inter-annual air temperature variability. Sci Rep 7, 1-8.

Jane, S. F., Hansen, G. J. A., Kraemer, B. M., Leavitt, P. R., Mincer, J. L., North, R. L., et al. (2021). Widespread deoxygenation of temperate lakes. Nature 594, 66-70.

Jeppesen, E., Moss, B., Bennion, H., Carvalho, L., Demeester, L., Feuchtmayr, H., et al. (2010). "Interaction of Climate Change and Eutrophication," in Climate Change Impacts on Freshwater Ecosystems, eds. M. Kernan, R. W. Battarbee, and B. Moss (Blackwell Publishing Ltd), 119-151.

Jones, J. R., Argerich, A., Obrecht, D. V., Thorpe, A. P., and North, R. L. (2020a). Missouri lakes and reservoirs long-term limnological dataset, version 1. EDI Data Portal. Available at: https://portal.edirepository.org/nis/mapbrowse?packageid=edi.520.1.

Jones, J. R., and Hubbart, J. A. (2011). Note: empirical estimation of non-chlorophyll light attenuation in Missouri reservoirs using deviation from the maximum observed value in the Secchi-chlorophyll relationship. Lake Reserv Manag 27, 1-5.

Jones, J. R., and Knowlton, M. F. (1993). Limnology of missouri reservoirs: an analysis of regional patterns. Lake Reserv Manag 8, 17-30.

Jones, J. R., and Knowlton, M. F. (2005). Suspended solids in Missouri reservoirs in relation to catchment features and internal processes. Water Res 39, 3629-3635.

Jones, J. R., Knowlton, M. F., and Obrecht, D. V. (2008a). Role of land cover and hydrology in determining nutrients in mid-continent reservoirs: implications for nutrient criteria and management. Lake Reserv Manag 24, 1-9.

Jones, J. R., Knowlton, M. F., Obrecht, D. V., and Graham, J. L. (2011). Temperature 
and oxygen in Missouri reservoirs. Lake Reserv Manag 27, 173-182.

Jones, J. R., Obrecht, D. V., Perkins, B. D., Knowlton, M. F., Thorpe, A. P., Watanabe, S., et al. (2008b). Nutrients, seston, and transparency of missouri reservoirs and oxbow lakes: an analysis of regional limnology. Lake Reserv Manag 24, 155-180.

Jones, J.R., Pollard, C., and Obrecht, D. V. (2020c). Factors influencing phosphorus in midcontinent impoindments (USA) and challenges for detecting abatement. Inland Waters, 1-9.

Jones, J. R., Thorpe, A. P., and Obrecht, D. V. (2020b). Limnological characteristics of Missouri reservoirs: synthesis of a long-term assessment. Lake Reserv Manag 36, $412-422$.

Kalff, J. (2002). Limnology: Inland Water Ecosystems. Upper Saddle River, NJ: PrenticeHall.

Kimmel, B. L., and Groeger, A. W. (1984). Factors controlling primary production in lakes and reservoirs : a perspective. Lake Reserv Manag 1, 277-281.

King, K. W., Williams, M. R., and Fausey, N. R. (2015). Contributions of systematic tile drainage to watershed-scale phosphorus transport. J Environ Qual 44, 486-494.

Kirk, J. T. (1985). Effects of suspensoids (turbidity) on penetration of solar radiation in aquatic ecosystems. Hydrobiologia 125, 195-208.

Kirk, J. T. O. (2003). The vertical attenuation of irradiance as a function of the optical properties of the water. Limnol Oceanogr 48, 9-17.

Kirk, J. T. O. (2011). Light and photosynthesis in aquatic ecosystems. 3rd ed. New York: Cambridge University Press.

Kleinman, P., Buda, A. R., Saporito, L. S., Sharpley, A. N., and Bryant, R. B. (2009). Application of manure to no-till soils: phosphorus losses by sub-surface and surface pathways. Nutr Cycl Agroecosyst 84, 215-227.

Knoll, L. B., Vanni, M. J., and Renwick, W. H. (2003). Phytoplankton primary production and photosynthetic parameters in reservoirs along a gradient of watershed land use. Limnol Ocean 48, 608-617.

Knowlton, M. F. (1984). Flow-through micocuvette for fluorometric determination of chlorophyll. Water Resour Bull 20, 795-799.

Knowlton, M. F., and Jones, J. R. (1995). Temporal and spatial dynamics of suspended sediment, nutrients, and algal biomass in Mark Twain Lake, Missouri. Arch. Hydrobiol. 135, 145-178.

Knowlton, M. F., and Jones, J. R. (1996). Experimental evidence of light and nutrient limitation of algal growth in a turbid midwest reservoir. Arch für Hydrobiol 135, $321-335$.

Knowlton, M. F., and Jones, J. R. (2000). Non-algal seston, light, nutrients, and chlorophyll in Missouri reservoirs. J Lake Reserv Manag 16, 322-332. 
Knowlton, M. F., and Jones, J. R. (2006). Natural variability in lakes and reservoirs should be recognized in setting nutrient criteria. Lake Reserv Manag 22, 161-166.

Kolber, Z., and Falkowski, P. G. (1993). Use of active fluorescence to estimate phytoplankton photosynthesis in situ. Limnol Oceanogr 38, 1646-1665.

Kolzau, S., Wiedner, C., Rücker, J., Köhler, J., Köhler, A., and Dolman, A. M. (2014). Seasonal patterns of nitrogen and phosphorus limitation in four German lakes and the predictability of limitation status from ambient nutrient concentrations. PLoS One 9.

Kromkamp, J. C., Dijkman, N. A., Peene, J., Simis, S. G. H., and Gons, H. J. (2008). Estimating phytoplankton primary production in Lake IJsselmeer (the Netherlands) using variable fluorescence (PAM-FRRF) and C-uptake techniques. Eur J Phycol 43, 327-344.

Kromkamp, J. C., and Forster, R. M. (2003). The use of variable fluorescence measurements in aquatic ecosystems: differences between multiple and single turnover measuring protocols and suggested terminology. Eur J Phycol 38, 103-112.

Laas, A., Noges, P., Koiv, T., and Noges, T. (2012). High-frequency metabolism study in a large and shallow temperate lake reveals seasonal switching between net autotrophy and net heterotrophy. Hydrobiologia 694, 57-74.

Lauster, G. H., Hanson, P. C., and Kratz, T. K. (2006). Gross primary production and respiration differences among littoral and pelagic habitats in northern Wisconsin lakes. Can J Fish Aquat Sci 63, 1130-1141.

Levine, S. N., and Schindler, D. W. (1999). Influence of nitrogen to phosphorus supply ratios and physicochemical conditions on cyanobacteria and phytoplankton species composition in the Experimental Lakes Area, Canada. Can J Fish Aquat Sci 56, 451-466.

Lewis, W. M., and Wurtsbaugh, W. A. (2008). Control of lacustrine phytoplankton by nutrients: erosion of the phosphorus paradigm. Int Rev Hydrobiol 93, 446-465.

Lewis, W. M., Wurtsbaugh, W. A., and Paerl, H. W. (2011). Rationale for control of anthropogenic nitrogen and phosphorus to reduce eutrophication of inland waters. Environ Sci Technol 45, 10300-10305.

Maberly, S. C., King, L., Dent, M. M., Jones, R. I., and Gibson, C. E. (2002). Nutrient limitation of phytoplankton and periphyton growth in upland lakes. Freshw Biol 47, $2136-2152$.

MacIntyre, H. L., Kana, T. M., Anning, T., and Geider, R. J. (2002). Review photoacclimation of photosynthesis irradiance response curves and photosynthetic pigments in microalgae and cyanobacteria. $J$ Phycol 38, 17-38.

Mari, L., Bertuzzo, E., Casagrandi, R., Gatto, M., Levin, S. A., Rodriguez-Iturbe, I., et al. (2011). Hydrologic controls and anthropogenic drivers of the zebra mussel invasion of the Mississippi-Missouri river system. Water Resour Res 47, 1-16.

Marshak, S. (2013). Essentials of geology. 4th ed. New York: Norton \& Company. 
Mazumder, A. (1994). Phosphorus-chlorophyll relationships under contrasting herbivore and thermal stratification: predictions and patterns. Can J Fish Aquat Sci 51, 390-400.

Michalak, A. M., Anderson, E. J., Beletsky, D., Boland, S., Bosch, N. S., Bridgeman, T. B., et al. (2013). Record-setting algal bloom in Lake Erie caused by agricultural and meteorological trends consistent with expected future conditions. PNAS 110, 64486452.

Millard, E. S., Myles, D. D., Johannsson, O. E., and Ralph, K. M. (1996). Seasonal phosphorus deficiency of Lake Ontario phytoplankton at two index stations: light versus phosphorus limitation of growth. Can J Fish Aquat Sci 53, 1112-1124.

Missouri Department of Natural Resources (2019a). MO 2019 Dams. Missouri Spat Data Inf Serv. Available at: https://data-msdis.opendata.arcgis.com/datasets/mo-2019-dams/.

Missouri Department of Natural Resources (2019b). MO 2019 Lake Numeric Nutrient Criteria Watersheds. Missouri Spat Data Inf Serv. Available at: https://datamsdis.opendata.arcgis.com/datasets/mo-2019-lake-numeric-nutrient-criteriawatersheds/.

Mitsch, W. J., Day, J. W., Gilliam, J. W., Groffman, P. M., and Hey, D. L. (2001). Reducing nitrogen loading to the Gulf of Mexico from the Mississippi River Basin: strategies to counter a persistent ecological problem. Bioscience 51, 373-388.

Morales-Williams, A. M., Wanamaker, A. D., and Downing, J. A. (2017). Cyanobacterial carbon concentrating mechanisms facilitate sustained $\mathrm{CO} 2$ depletion in eutrophic lakes. Biogeosciences 14, 2865-2875.

Morris, D. P., and Lewis, W. M. (1988). Phytoplankton nutrient limitation in Colorado mountain lakes. Freshw Biol 20, 315-327.

Mugidde, R. (1993). The increase in phytoplankton primary productivity and biomass in Lake Victoria (Uganda). SIL Proceedings, 1922-2010 25, 846-849.

Napoléon, C., and Claquin, P. (2012). Multi-parametric relationships between PAM measurements and carbon incorporation, an in situ approach. PLoS One 7, 1-12.

Napoléon, C., Raimbault, V., and Claquin, P. (2013). Influence of nutrient stress on the relationships between PAM measurements and carbon incorporation in four phytoplankton species. PLoS One 8.

NLCD (2016). National Land Cover Database. Multi-Resolution L Charact Consort. Available at: https://www.mrlc.gov/data/nlcd-2016-land-cover-conus.

NOAA (2019). Historical Palmer Drought Indices. Natl Ocean Atmos Adm. Available at: https://www.ncdc.noaa.gov/temp-and-precip/drought/historical-palmers.

North, R. L., Guildford, S. J., Smith, R. E. H., Havens, S. M., and Twiss, M. R. (2007). Evidence for phosphorus, nitrogen, and iron colimitation of phytoplankton communities in Lake Erie. Limnol Oceanogr 52, 315-328.

North, R. L., Guildford, S. J., Smith, R. E. H., Twiss, M. R., and Kling, H. J. (2008). 
Nitrogen, phosphorus, and iron colimitation of phytoplankton communities in the nearshore and offshore regions of the African Great Lakes. Verh Intern Verein Limnol 30, 259-264.

North, R. L., Winter, J. G., and Dillon, P. J. (2013). Nutrient indicators of agricultural impacts in the tributaries of a large lake. Inl Waters 3, 221-234.

North, R. P., North, R. L., Livingstone, D. M., Köster, O., and Kipfer, R. (2014). Longterm changes in hypoxia and soluble reactive phosphorus in the hypolimnion of a large temperate lake: consequences of a climate regime shift. Glob Chang Biol 20, 811-823.

Nurnberg, G. K. (2009). Assessing internal phosphorus load - problems to be solved. Lake Reserv Manag 25, 419-432.

O’ Reilly, C. M., Rowley, R. J., Schneider, P., Lenters, J. D., Mcintyre, P. B., Kraemer, B. M., et al. (2015). Rapid and highly variable warming of lake surface waters around the globe. Geophys Res Lett 42, 10773-10781.

O’Beirne, M. D., Werne, J. P., Hecky, R. E., Johnson, T. C., Katsev, S., and Reavie, E. D. (2017). Anthropogenic climate change has altered primary productivity in Lake Superior. Nat Commun 8, 15713.

O’Reilly, C. M., Alin, S. R., Piisnier, P. D., Cohen, A. S., and McKee, B. A. (2003). Climate change decreases aquatic ecosystem productivity of Lake Tanganyika, Africa. Nature 424, 766-768.

Oliver, S. K., Collins, S. M., Soranno, P. A., Wagner, T., Stanley, E. H., Jones, J. R., et al. (2017). Unexpected stasis in a changing world: lake nutrient and chlorophyll trends since 1990. Glob Chang Biol 23, 5455-5467.

Ozersky, T., Barton, D. R., Hecky, R. E., and Guildford, S. J. (2013). Dreissenid mussels enhance nutrient efflux, periphyton quantity and production in the shallow littoral zone of a large lake. Biol Invasions 15, 2799-2810.

Ozersky, T., Evans, D. O., and Ginn, B. K. (2015). Invasive mussels modify the cycling, storage and distribution of nutrients and carbon in a large lake. Freshw Biol 60, 827843.

Paerl, H. W., Fulton, R. S., Moisander, P. H., and Dyble, J. (2001). Harmful freshwater algal blooms, with an emphasis on cyanobacteria. Sci World J 1, 76-113.

Paerl, H. W., and Scott, J. T. (2010). Throwing fuel on the fire: synergistic effects of excessive nitrogen inputs and global warming on harmful algal blooms. Environ Sci Technol 44, 7756-7758.

Paerl, H. W., Scott, J. T., McCarthy, M. J., Newell, S. E., Gardner, W. S., Havens, K. E., et al. (2016). It takes two to tango: when and where dual nutrient (N \& P) reductions are needed to protect lakes and downstream ecosystems. Environ Sci Technol 50, $10805-10813$.

Phillips, J. S. (2019). Time-varying responses of lake metabolism to light and 
temperature. Limnol Oceanogr, 1-15.

Pinheiro, J., Bates, D., DebRoy, S., Sarkar, D., and Team, R. C. (2018). nlme: Linear and Nonlinear Mixed Effects Models. Available at: https://cran.rproject.org/package $=$ nlme.

Power, M. E. (1992). Top-down and bottom-up forces in food webs: do plants have primacy? Ecology 73, 733-746.

Rabalais, N. N., Turner, R. E., Dortch, Q., Justic, D., Bierman, V. J., and Wiseman, W. J. (2002). Nutrient-enhanced productivity in the northern Gulf of Mexico: past, present and future. Hydrobiologia 475-476, 39-63.

Reynolds, C. S. (1984). The ecology of freshwater phytoplankton. Cambridge, UK: Cambridge University Press.

Reynolds, C. S. (2006). The ecology of phytoplankton. New York: Cambridge University Press.

Rohatgi, A. (2019). WebPlotDigitizer. Available at: https://automeris.io/WebPlotDigitizer.

Rose, K. C., Hamilton, D. P., Williamson, C. E., Mcbride, C. G., Fischer, J. M., Olson, M. H., et al. (2014). Light attenuation characteristics of glacially-fed lakes. $J$ Geophys Res Biogeosciences 119, 1446-1457.

Rowland, F. E., North, R. L., McEachern, P., Obrecht, D. V., Gurung, T. B., Jones, S. B., et al. (2019). Phytoplankton nutrient deficiencies vary with season in sub-tropical lakes of Nepal. Hydrobiologia 833, 157-172.

Saito, M. A., Goepfert, T. J., and Ritt, J. T. (2008). Some thoughts on the concept of colimitation: three definitions and the importance of bioavailability. Limnol Ocean $53,1-16$.

Sartory, D. P., and Grobbelaar, J. U. (1984). Extraction of chlorophyll a from freshwater phytoplankton for spectrophotometric analysis. Hydrobiologia 114, 177-187.

Schallenberg, M., and Burns, C. W. (2004). Effects of sediment resuspension on phytoplankton production: teasing apart the influences of light, nutrients and algal entrainment. Freshw Biol 49, 143-159.

Schindler, D. W. (1974). Eutrophication and recovery in experimental lakes: implications for lake management. Science 184, 897-899.

Schindler, D. W. (1977). Evolution of phosphorus limitation in lakes. Science 195, 260-262.

Schindler, D. W. (1998). Replication versus realism: the need for ecosystem-scale experiments. Ecosystems 1, 323-334.

Schindler, D. W. (2012). The dilemma of controlling cultural eutrophication of lakes. Proc R Soc B Biol Sci 279, 4322-4333.

Schindler, D. W., Hecky, R. E., Findlay, D. L., Stainton, M. P., Parker, B. R., Paterson, M. 
J., et al. (2008). Eutrophication of lakes cannot be controlled by reducing nitrogen input: results of a 37-year whole-ecosystem experiment. PNAS 105, 11254-11258.

Schmid, M., Hunziker, S., and Wüest, A. (2014). Lake surface temperatures in a changing climate: a global sensitivity analysis. Clim Chang 124, 301-315.

Scott, J. T., and Grantz, E. M. (2013). N2 fixation exceeds internal nitrogen loading as a phytoplankton nutrient source in perpetually nitrogen-limited reservoirs. Freshw Sci $32,849-861$.

Sharpley, A., Jarvie, H. P., Buda, A., May, L., Spears, B., and Kleinman, P. (2013). Phosphorus legacy: overcoming the effects of past management practices to mitigate future water quality impairment. J Environ Qual 42, 1308-1326.

Silsbe, G. M., Hecky, R. E., and Smith, R. E. H. (2012). Improved estimation of carbon fixation rates from active flourometry using spectral fluorescence in light-limited environments. Limnol Oceanogr Methods 10, 736-751.

Silsbe, G. M., and Malkin, S. Y. (2015). phytotools: Phytoplankton Production Tools. Available at: https://cran.r-project.org/package=phytotools.

Smith, D. R., King, K. W., Johnson, L., Francesconi, W., Richards, P., Baker, D., et al. (2015). Surface runoff and tile drainage transport of phosphorus in the midwestern United States. J Environ Qual 44, 495-502.

Søballe, D. M., and Kimmel, B. L. (1987). A large-scale comparison of factors influencing phytoplankton abundance in rivers, lakes, and impoundments. Ecology 68, 1943-1954.

Solomon, C. T., Bruesewitz, D. A., Richardson, D. C., Rose, K. C., Van de Bogert, M. C., Hanson, P. C., et al. (2013). Ecosystem respiration: drivers of daily variability and background respiration in lakes around the globe. Limnol Oceanogr 58, 849-866.

Søndergaard, M., Jensen, J. P., and Jeppesen, E. (2003). Role of sediment and internal loading of phosphorus in shallow lakes. Hydrobiologia 506-509, 135-145.

Søndergaard, M., Lauridsen, T. L., Johansson, L. S., and Jeppesen, E. (2017). Nitrogen or phosphorus limitation in lakes and its impact on phytoplankton biomass and submerged macrophyte cover. Hydrobiologia 795, 35-48.

Spivak, A. C., Vanni, M. J., and Mette, E. M. (2011). Moving on up: can results from simple aquatic mesocosm experiments be applied across broad spatial scales? Freshw Biol 56, 279-291.

Staehr, P. A., and Sand-Jensen, K. (2007). Temporal dynamics and regulation of lake metabolism. Limnol Oceanogr 52, 108-120.

Staehr, P., Sand-Jensen, K., Raun, A., Nielsson, B., and Kidmose, J. (2010). Drivers of metabolism and net heterotrophy in contrasting lakes. Limnol Ocean 55, 817-830.

Sterner, R. W. (2008). On the phosphorus limitation paradigm for lakes. Int Rev Hydrobiol 93, 433-445. 
Strayer, D. L., Beighley, R. E., Thompson, L. C., Brooks, S., Nilsson, C., Pinay, G., et al. (2003). Effects of land cover on stream ecosystems: roles of empirical models and scaling issues. Ecosystems 6, 407-423.

Su, X., Steinman, A. D., Tang, X., Xue, Q., Zhao, Y., and Xie, L. (2017). Response of bacterial communities to cyanobacterial harmful algal blooms in Lake Taihu, China. Harmful Algae 68, 168-177.

Tassan, S., and Ferrari, G. M. (1995). An alternative approach to absorption measurements of retained on filters aquatic particles. Limnol Ocean 40, 1358-1368.

Thom, R. H., and Wilson, J. H. (1980). The natural divisions of Missouri. Trans Mo Acad Sci 4, 9-23.

Thornton, K. W. (1990). "Perspectives on reservoir limnology," in Reservoir limnology: ecological perspectives, eds. K. W. Thornton, B. L. Kimmel, and F. E. Payne (New York: John Wiley \& Sons, Inc.), 1-14.

Thorpe, A. P., and Jones, J. R. (2005). Bacterial abundance in Missouri (USA) reservoirs in relation to trophic state and global patterns. Verh Intern Verein Limnol 29, 239-245.

Thrane, J.-E., Hessen, D. O., and Andersen, T. (2014). The absorption of light in lakes: negative impact of dissolved organic carbon on primary productivity. Ecosystems $17,1040-1052$.

Tidball, R. R. (1984). Geochemical survey of Missouri: geography of soil geochemistry and classification by factor analysis of Missouri agricultural soils. US Geol Surv Prof Pap 954, 1-73.

Tilman, D., Fargione, J., Wolff, B., Antonio, C. D., Dobson, A., Howarth, R., et al. (2001). Forecasting agriculturally driven global environmental change. Science 292, 281-284.

Titman, D. (1976). Ecological competition between algae: experimental confirmation of resource-based competition theory. Science 192, 463-465.

Torremorell, A., Llames, M., Perez, G., Escaray, R., Bustingorry, J., and Zagarese, H. (2009). Annual patterns of phytoplankton density and primary production in a large, shallow lake: the central role of light. Freshw Biol 54, 437-449.

Toseland, A., Daines, S. J., Clark, J. R., Kirkham, A., Strauss, J., Uhlig, C., et al. (2013). The impact of temperature on marine phytoplankton resource allocation and metabolism. Nat Clim Chang 3, 979-984.

Tyrrell, T. (1999). The relative influences of nitrogen and phosphorus on oceanic primary production. Nature 400, 525-531.

Unklesbay, A. G., and Vineyard, J. D. (1992). Missouri geology: three billion years of volcanoes, seas, sediment, and erosion. Columbia, MO: University of Missouri Press.

USDA (2019). 2017 census of agriculture: United States summary and state data. National Agricultural Statistics Service, US Department of Agriculture.

Verburg, P., and Hecky, R. E. (2009). The physics of the warming of Lake Tanganyika 
by climate change. Limnol Oceanogr 54, 2418-2430.

Vitousek, P. M., Mooney, H. A., Lubchenco, J., and Melillo, J. M. (1997). Human domination of Earth's ecosystems. Science 277, 494-499.

Vollenweider, R. A. (1976). Advances in defining critical loading levels for phosphorus in lake eutrophication. Mem Ist Ital Idrobiol 33, 53-83.

Von Liebig, J. (1840). Die organische Chemie in ihrer Anwendung auf Agrikultur und Physiologie. Braunschweig: Friedrich Vieweg.

Wagner, C., and Adrian, R. (2009). Exploring lake ecosystems: hierarchy responses to long-term change? Glob Chang Biol 15, 1104-1115.

Watanabe, S., Knowlton, M. F., Vincent, W. F., and Jones, J. R. (2009). Variability in the optical properties of colored dissolved organic matter in Missouri reservoirs. Verh Intern Verein Limnol 30, 1117-1120.

Webb, W. L., Newton, M., and Starr, D. (1974). Carbon dioxide exchange of Alnus rubra. Oecologia 17, 281-291.

Wetzel, R. G. (2001). Limnology: Lake and River Ecosystems. 3rd ed. San Diego, CA: Academic Press.

Williamson, C. E., Dodds, W., Kratz, T. K., and Palmer, M. A. (2008). Lakes and streams as sentinels of environmental change in terrestrial and atmospheric processes. Front Ecol Environ 6, 247-254.

Williamson, C. E., Saros, J. E., and Schindler, D. W. (2009a). Sentinels of change. Science 323, 887-888.

Williamson, C. E., Saros, J. E., Vincent, W. F., and Smol, J. P. (2009b). Lakes and reservoirs as sentinels, integrators, and regulators of climate change. Limnol Oceanogr 54, 2273-2282.

Winslow, L., Read, J., Woolway, R., Brentrup, J., Leach, T., Zward, J., et al. (2017). rLakeAnalyzer: Lake Physics Tools. Available at: https://cran.rproject.org/package $=$ rLakeAnalyzer.

Woolway, R. I., and Merchant, C. J. (2019). Worldwide alteration of lake mixing regimes in response to climate change. Nat Geosci 12, 271-276.

Woolway, R. I., Verburg, P., Lenters, J. D., Merchant, C. J., Hamilton, D. P., Brookes, J., et al. (2018). Geographic and temporal variations in turbulent heat loss from lakes: a global analysis across 45 lakes. Limnol Oceanogr 63, 2436-2449.

Zarfl, C., Lumsdon, A. E., Berlekamp, J., Tydecks, L., and Tockner, K. (2014). A global boom in hydropower dam construction. Aquat Sci 77, 161-170. 